

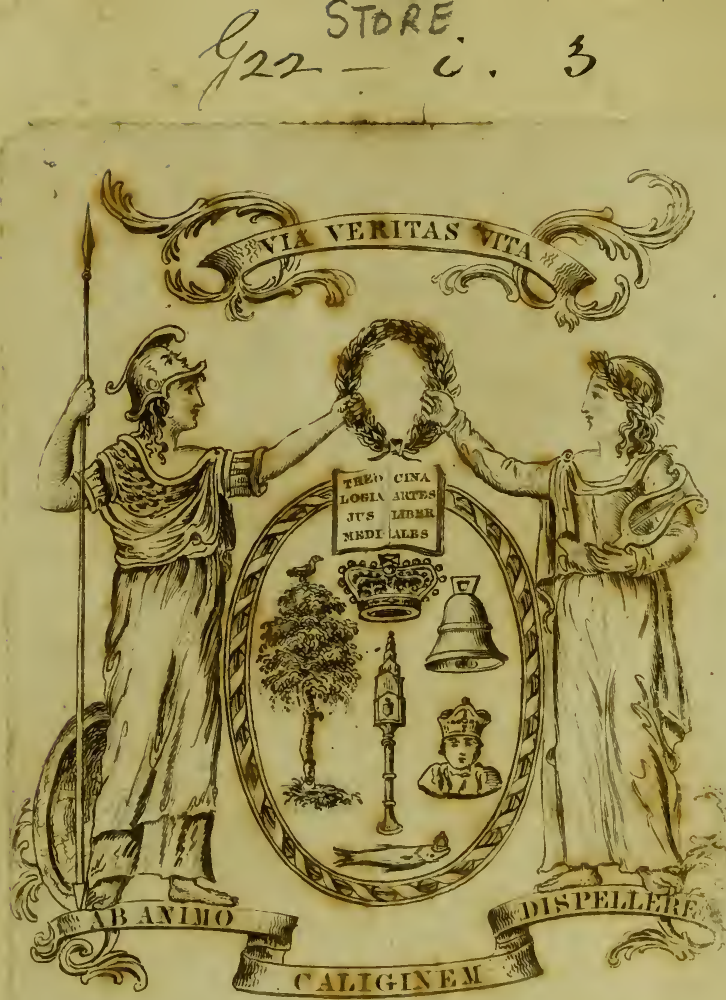

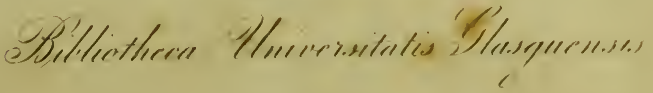
D. 111.13 


Digitized by the Internet Archive in 2015 



\section{COMPENDIOUS POCKET-MANUAL}

OF TIIF

\section{VETERINARY A RT;}

BEING A

PRACTICAL DESCRIPTION OF THE TRUE SYMPTOHS AND MOST RATIONAL TREATMENT OF

\section{ALL DISEASES INCIDENT TO THE HORSE;}

ADAPTED TO TIE READY COMPREHENSION OF

EVERY CLASS OF HORSEMEN, viz.

OWNERS, FARRIERS, FARMERS, OSTLERS, GROOMS AND LADS.

Comprising all that has been usefully said by various Authors;

REVISED AND CORRECTED,

WITII CONSIDERABLE IMPORTANT MODERN IMPROVEMFNTS,

By JOHN HINDS, V.S. and OTHers.

\section{ONDON :}

SHERWOOD, GILBERT, \& PIPER, PATERNOSTER ROW ;

AND WHITTAKER, TREACHFR, AND CO. AVE-MAIIA-LANF. 


\section{ON DON :}

GIIBERT AND RIVINGTON, PRINTERS, ST. JOHN'S SQUARE. 


\section{CONTENTS.}

PAGE

Description of the Figures represented ............ v

Preface, containing the Author's views $\ldots \ldots \ldots \ldots \ldots \ldots$ vii

Chapter I. Disorders arising from excessive heat of the animal system -inflammatory complaints ......... Signs, by which one may judge when any inward sickness

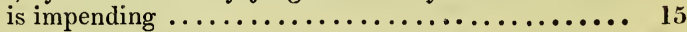

The Distemper of $\mathrm{J} 832 \ldots \ldots \ldots \ldots \ldots \ldots \ldots \ldots \ldots \ldots \ldots$

Inflammation, general principles of............ 25

Chapter II. Fever-and first of Simple fever .......... 32

Symptomatic fevers .................... 38

Chapter III. Inflammation of the Lungs........... 42

Catarrh or Cold; Cough, and its effects...........47

-Epidemic fever, or the distemper ............ 52

-Low Fever ......................... 55

The Cough-chronic cough ................ 57

Broken wind ........................ 61

Chapter IV. Affections of the Stomach-inflammation .... 65

Poisons, effects of, and antidotes .............. 67

Worms-Botts, \&c. ...................... 68

A poplexy, Staggers, Epilepsy ................. 74

Chapter V. Diseases of the Bowels .............. 78

Inflammation :- scouring, molten grease $\ldots \ldots \ldots \ldots \ldots \ldots 79$

Colic, gripes, or fret ...................... 85

Chapter VI. Liver complaints .................. 89

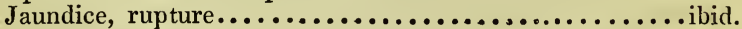

Ulceration-adhesion $\ldots \ldots \ldots \ldots \ldots \ldots \ldots \ldots \ldots \ldots \ldots$. 1

Chapter VII. Inflammation of the Kidneys............ 95

Chapter VIII. Affections of the Bladder-diabetes ...... 98

Suppression of Urine $\ldots \ldots \ldots \ldots \ldots \ldots \ldots \ldots \ldots \ldots \ldots \ldots . . \ldots 9$

Incontinence of Urine $\ldots \ldots \ldots \ldots \ldots \ldots \ldots \ldots \ldots \ldots \ldots \ldots$ 
Chapter IX. Diseases of the Eyes-Inflammation of..... 102

Moon blindness, accidents ................... 103

Projecting haw, Warts, Eruptions .............. 107

Chapter X. Vices : Crịb-biting, Wind-sucking, \&c. ..... 109

Chapter XI. Tumours, general principles of ......... 115

Strangles, 116; Surfeit or Mange..$\ldots \ldots \ldots \ldots \ldots \ldots 118$

Farcy, 122; Glanders $\ldots \ldots \ldots \ldots \ldots \ldots \ldots \ldots \ldots \ldots \ldots 127$

Fistula in the Withers, 131; Poll Evil ............. 134

Saddle galls, Warbles, Sitfasts................. 136

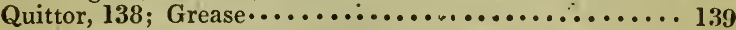

Water farcy, Wens, 142 ; Anbury $\ldots \ldots \ldots \ldots \ldots \ldots \ldots$. 144

Chapter XII. Wounds and Bruises, external .......... 145

Incised Wounds, punctured and contused wounds $\ldots \ldots .146$

Foot wounds, 148 ; punctured Tendon............ 149

Bruises, blows ......................... 150

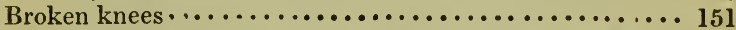

Inflictions : Cutting ..................... 154

Strains, of shoulder, hip, stifle $\ldots \ldots \ldots \ldots \ldots \ldots \ldots \ldots \ldots . \ldots \ldots$

Strain of the back sinews $\ldots \ldots \ldots \ldots \ldots \ldots \ldots \ldots \ldots \ldots$

Chapter XIII. Anatomical description of the Horse's foot -its internal structure, \&c................. 162

Chapter XIV. The Art of Shoeing-sound feet........ 172 -unsound feet ........................ 176 -one-side nailing, 177; Pointing the toe $\ldots \ldots \ldots \ldots \ldots 178$

Chapter XV. Lameness : 1. Diseases of the Legs ....... 179

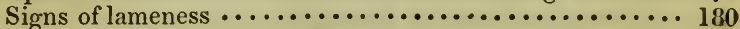
-Spavin, 181 ; Splents $\ldots \ldots \ldots \ldots \ldots \ldots \ldots \ldots \ldots \ldots \ldots 182$

-Ring-bone-Curb ...................... 183

-Windgalls. Thoroughpin. Mallenders and Sallenders.. 184

2. Disorders of the feet $\ldots \ldots \ldots \ldots \ldots \ldots \ldots \ldots \ldots \ldots \ldots 185$

Founder, 188; of Nerving................. 191

Thrush or frush, 192, Canker................. 194

Corns, 195; Sand-crack $\ldots \ldots \ldots \ldots \ldots \ldots \ldots \ldots \ldots \ldots$

Chapter XV1. Some account of the prescriptions, remedies, and applications, recommended in the course of the work. .......................... 198

Authorities and persons quoted. . . . . . . . . . . . 204

INDEX. . . . . . . . . . . . . . . . . . . . 205

Hinds's Veterinary Works-opinions of the judges conceruing their merits, utility, and fitness......... 212 


\title{
DESCRIPTION OF THE FIGURES
}

\author{
INTENDED TO ILLUSTRATE
}

\section{WHAT IS SAID IN THE COURSE OF THE WORK.}

The FOOT OR HOOF, its contents and disorders.

N.B. fig. 5. is inserted at page 165 .

Back sinew (the) is shown at $(m)$ fig. 5 , descending into the foot to form its attachment to the bottom of the coffin bone $(c)$.

In the old dilapidated foot, represented in fig. 6, this sinew is - decayed and distorted.

Bars (the) are two ridges $(n)$ fig. 4 , on each side the frog $(m)$; they form the connecting link between the wall $(g)$ and the sole $c, d$.

Coffin (the) wall, or hoof proper, - a side view is given at $g \mathrm{~g}$, fig. 2; a bottom view at $g$, fig. 4 ; and it is again seen, in section, at $g$, fig. 5 , and $g$, fig. 6 .

Coffin bone (the) is represented, with its blood vessels and lamellated substance covering it, at (c) fig. 1, front view, and a back view of the bone at $(c)$ fig. 3 ; it appears again in section, at (c) fig. 5 and at $(c)$ fig. 6 . Its under surface lies beneath the sole $(c)(e)$ and $(p)$ in fig. 4. Its cartilage is shown at $g$, fig. 3.

Coffin joint (the) is shown in full vigour, with all its nourriture flowing, in fig. 5 , bêtween the small pastern bone $(b)$ and the coffin bone $(c)$; both bones being kept in play by the navicular bone $(d)$, here depicted in its actual healthy state. But, in fig. 6, this nourriture is dried up, and the navicular bone $(d)$ no longer moveable, as in healtl, at every step the horse takes, is here seen growing to and incommoding the action of the coffin bone: this is " Coffin joint lameness."

Coronet (the) is bared of hair at (b) fig. 1 , and it is laid open at $(b b)$ fig. 2, showing the circulation of the material which supplies the loss by wear and tear of horn. From its making the entire circle of the upper part, or crown of the foot, it obtains the name of coronary ring; it reaches as high up as $(n)$ fig. 5 , and $(n)$ fig. 6 ; and firmly embraces the coronary bone, otherwise small pastern, at $b$, fig. 3 . 
Frog (the), as seen externally upon turning up the foot, is shown at ( $n$ ) fig. 4 ; but the horny parts being removed, we see the sensible frog at $(q)$ : Its cleft-formerly denominated its frush-the seat of "Thrush," is seen at (a). Its point $(e)$ shows the situation of the largest veins of the sole-to which the knife must nearly extend when bleeding at the foot is required to be copious.

Heels (the) are shown in all the figures at (o).

Lamella, lamina, or lamellated substance, is that which forms the fibrous connexion between the horny hoof, or coffin, and the coffin bone. It is seen covering that bone entirely in fig. 1 , and again at $f f$, fig. 5 , though dried up, and contracted in fig. 6 .

Navicula, or shuttle bone. Its action is mentioned above, under coffin joint. It is seen, bare, at $(d)$ fig. 3 ; in section at $(d)$ fig. 5 , and again at $(d)$ diseased and anchylosed in fig. 6.

Pastern (the) bone is marked (a) in fig. $\mathbf{1}$, also (a) in fig. $\mathbf{3}, \mathbf{5}, \mathbf{6}$, but is now termed large pastern, by reason of the coronet bone, ( $b$, fig. 3) having been new named " small pastern," on account of its articulating with the large pastern at $f f$, fig. 3 .

Sole (the). The bottom of the foot, upon being turned up, as seen by fig. 4 , though technically the hollow part only, at $b, c, d, e, p$, in that figure ; $c d$ being the horny or insensible, $b, p$, the sensible sole, full of blond-vessels and nerves, the sufferer under all inflictions and diseases of the foot, and the seat of founder of every denomination.

Toe. To preserve uniformity, the toe in every figure is marked with $(l)$.

Wounds, pricks, stubs, bruises and strains, are incurred in hunting, as delineated on page 101 ; whilst it is the pace that destroys the legs, as shown at page 108.

Yare's Crib-biting apparatus; the principle is described at page 113; where is shown one of the iron rods, which being placed to each side of the head-from the lips to the eyes, they are joined together by cross bars of the same material, and fastened to the cheek-stall and ear-band, immoveably, by many well-contrived straps. 


\section{PREFA CE.}

That " a great book is a great evil," is an old saying, as true as it is trite, and applies without exception to Treatises on the modern science of Veterinary Medicine - which are all great ones; because, in almost every new proposition, or recent improvement, the writers sought to adduce, they had some ancient prejudice to encounter, or deep-rooted blunder to grub up, ere they could obtain the requisite credence with their readers. Hence the unavoidable bulk of all former works which laid any claim to originality, or were derived from experience. At any rate, such was the case with our own production, and such with White's celebrated Compendium. In the latter, full 150 pages of diffuse controversy, doubts, correspondence, and repetition, stood constantly in the way of a perfect comprehension as to what might be the author's more mature conviction. This deformity was long felt, and many years ago pointed out (by letter) for correction-but to little purpose; on the contrary, one crude pile of addenda was heaped upon another in each successive reprint, errors were not disposed of, valuable alterations in practice went unnoticed, and, what is more strange, Mr. White's inertia did not allow him to record even his own changes of opinion-some of which are noticed here. 
In the present volume-by the rejection of such exuberances, by the economy of printing, and employing a terse style, all that is truly practical in the works of White, in Osmer, and our own volume, as well as others-is here compressed into a Pocket Manual fit for daily use, one-sixth of their size, and one quarter of their quantity, i.e. $40 s$. worth for $5 s$. This includes an addition to our former stock of the practice of three busy years; which were also replete with able investigation and patient research, elsewhere, aided by veterinary facts and observations derived from various sources. In fact, the recent times have been prolific of improvements in the Art Veterinary, as in almost every other branch of art and science throughout this mighty empire. Of these the reader should keep in mind that we have availed ourselves to the fullest extent of utility, as in duty bound, after applying the test of experience to each : so that the purchaser of this Manual-small and thin as it may seem, is here put in possession of every new and valuable improvement up to the end of April, 1832, as well in France and England as in America. And for this step we find a perfect justification : having furnished to the common stock, we now demand our quota. From the last mentioned country, indeed, the contribution is very trifling - a particle; whilst they have there reprinted the "Veterinary Surgery" and the "Groom's Oracle," we understand, word for word. In France, the same two works, nearly, have been condensed into one Manual d'Equitation. At home, the celebrated writer who has chosen "Nimrod" for his cognomen, acknowledged "Hinds" for his authority in above twenty instances, a tribute of respect we are disposed by no means to cavil at; whilst the "Society for the Diffi- 
sion of Useful Knowledge," in a treatise on The Horse, sent forth from that prolific source, did not fail to open, and keep open, the same volume of "Veterinary Surgery ;" as appears by the extraction of many peculiarities, and the adoption of certain idiotropic phrases, to say nothing of coincidence in matters of pure research, and the results of practice. "I am at a loss, however, (says the critic) to know in what way the ordinary and middle classes of mankind can be benefited by reading a scientific treatise couched in language, and incommoded with terms of art, much beyond their comprehension."

Of the volume, entitled "Veterinary Surgery and Practice of Physic," we say no more here: doubtless the publishers will accumulate and present the reader with the characters given of that work, and the opinions expressed concerning it, by the critics. We find it has operated with the desired effect on that large portion of the community where it was intended to act, most beneficially-viz. outside the schools. Nor is the present little compendium less teachable than its predecessor, it is presumed, whilst its usefulness in another respect is likely to be still more extended; for, it may be said to embrace a condensation of all the existing knowledge on the subject of the Horse's ailments, at an easy price. With a view to plainness of manner, we have called things by their vulgar or generally received names, so as to meet the notions of the mere stable men and juniors, notwithstanding we had in several instances pointed out a more accurate nomenclature, and that these have been adopted by the learned. We make no apology for the apparent deviation.

As to the novelties, or modern improvements, here first introduced to public notice, we have found occasion to turn round, while at press, to cast anew some 
passages upon which new lights were found to have been reflected in the interval; for we never shall want the candour to review our own opinions and first rough impressions; and indeed we can see no other mode of arriving at the truth, or approaching towards perfection in any art, much less so in the treatment of disease - uncertain, conjectural, and surrounded with difficulties, as it most assuredly is. In this respect, we are proud to say that the supply is to a considerable amount, and of the most valuable kind. Upon all those accounts, therefore, we do not arrogate too much in insisting upon this edition being an improvement upon all the former works, as set forth in the preceding pages.

Would the Reader refer to any given point for verification hereof, he will, perhaps, turn per INDEX toCrib-biting-Debility-Distemper-Eyes-Fever - Inflammation - Knock-up - Liver complaints Surfeit-Signs for discovering the true nature of all ailments-Tumours and Tuberculous affections.

25 The PRESCRIPTIONs and REMEDIES recommended in the course of the work are not repeated in detail each time, but are referred to, by the page, or generally, in order to economise the space, and are to be found recapitulated in Chapter XVI. A saving of many pages has thus been effected, besides occasioning less distraction in the maling up a multitude of medicines apparently varying, but which differ from each other only in some aromatic scent or essential oil-mere adjuventia of the laboratory, that afforded no real aid to the action of the main ingredients. 


\section{MANUAL}

OF THE

\section{VETERINARY ART.}

\section{CHAPTER I.}

Disorders arising From excessive Heat of the

Animal System:-Inflammatory complaints.

Section 1. Introductory. There is scarcely any disorder known to attack the horse that will not be found, upon strict examination, either to consist in, or to be a consequence of, inflammation, that is always aggravated, and sometimes brought on, by the excessive exertions he is compelled to make. When the inflammation fixes itself upon any of his internal organs (as enumerated below, page 13), it gives rise to the most dangerous diseases, and even when subdued, leaves behind it some baleful effects that admit of no permanent cure. Thus, inflammation of the lungs, the bowels, or any other internal part, will produce that kind of derangement of the whole animal system which we term fever, the violence whereof will be proportioned to the degree and extent of the inflammation, and the importance of the inflamed organ in carrying on the economy of animal life. Even when the fever is abated and pronounced $a$ cure, a ten- 
dency to slight illness remains a long time after : debility, or weakness, and a disposition to knock up, profuse sweating, unaccountable lameness, vertigo, form scarcely a tithe-part of the evils that are so engendered and left behind; and which are to be ascribed as much to injudicious haste, or violence, in applying even the best remedies, as to the disorder itself. But, when the medicine employed is inappropriate, as too often happens, or the patient is overdosed, as is customary, the ruinous effects of such a mistaken practice are lamentably obvious, when too late to admit of adequate remedy.

2. Whenever a horse is taken ill, therefore, our first study should be directed to this point-namely, to ascertaining the existence and degree of fever, and what particular organ is then inflamed, that the adverse symptoms may be combated and alleviated in their earliest stages; for, by procrastination and neglect, and continuance of work, with increased severity when the afflicted horse is least able to bear it, we altogether confirm the disease, or hasten a fatal termination. This point the attentive reader will be enabled to accomplish by watching the symptoms as described under the various heads in this TREATISE, by meeting each indication of derangement with its appropriate remedy, and thereby assisting nature to recover the lost function after the most rational and approved methods, as here set down. The general principles upon which this knowledge is founded, and due discrimination to be employed, is undoubtedly acquired most perfectly by the after-death examination of horses which have died of previously well-marked, and (to the examiner) of well-known disorders ; for these are the means whereby the most expert and successful horse-surgeons of the present day attain celebrity by their skill, and are enabled to speak with decision as to the actual seat and progress of every ailment, of its nature, degree, and virulence: the cause of each kind of attack (which distinctly mark out the remerly), is acquired by practice, by the comparison or 
analogy of cases, and the information that is to be obtained from books, from lectures, and conversations with intelligent persons about the sick stable.

3 . In this manner did the best veterinary instructors formerly teach their pupils the Art of Farriery, as they humbly termed this species of knowledge; and thus did Mr. White introduce to his readers his first simple treatise on curing the disorders of the horse: Gibson had done so an age before him, but more elaborately. Both those excellent men were confessedly much too technical for the general reader, and White too brief for the learned one; we have therefore passed over his too short and too erudite anatomical essay as unnecessary to such a Pocket Manual as the present little volume pretends to be. Should the more ardent inquirer, however, incline to seek for knowledge as to the 'formation of the horse, the structure and functions of his organs of life, the causes of their derangement, and the principles upon which the cure is to be undertaken,' these will be found detailed to his complete satisfaction in the first chapters of Hinds' book of 'Veterinary Surgery,' which has been written expressly for the use, and the language brought intelligibly within the comprehension, of such general readers as have leisure and inclination for the task. To this recommendation we may add, without blushing, that it will profitably repay the labour and assiduity which may be bestowed upon the perusal, though the subject may not, perhaps, be studied so intensely as it deserves.

4. Of the disorders here spoken of, as arising from the great natural heat of the horse's blood, augmented by strong work, and furthermore rendered excessive by the stimulation of dry food, and still more stimulating cordials, we shall proceed to treat under the following heads, as those which may fairly be attributed to an over-excited system; - a state of perilous existence, that we have the consolation of premising, may be mainly averted by cool- 
ing regimen, green food, moderate exercise, refreshing air, and frequent watering:-

1. Inflammation generally, pertaining to all the organs of life.

2. Simple fever; and symptomatic fevers.

3. Inflammation of the lungs: cold and catarrh. Epidemy; cough, chronic cough, broken-wind.

4. Affections of the stomach : inflammation, poisons, worms; apoplexy, staggers, epilepsy, vertigo.

5. Diseases of the bowels : inflammation, spasmodic colic or gripes; scouring, costiveness, molten grease, adhesion.

6. Liver complaints : inflammation, jaundice, rupture, ulceration, choler or bilious obstructions.

7. Inflammation of the kidneys.

8. Affections of the bladder, and of its neck: diabetes, incontinence and suppression of urine; rupture, concretions, \&c.

5. In the midst of so many and conflicting disorders, most of them of dangerous import, and all militating against the future usefulness of the afflicted animal, who is to pronounce, at a first view, which among the whole it is that at any time 'takes him off his work?' This being the interested hinge upon which the inquiry then turns, the next question of the more sordid proprietors, as to ' how long the cure will take?' depends entirely on the saneness of the conclusion that is come to on the first point-namely, "What is the matter with the horse?' ' Tell us the name of the disorder (say they), that we may turn to the books for the prescribed remedies,' and here begins that ruinous series of mismanagement of the disease before spoken of (stetion 1): then it is that some busy fool, or forward stableman, steps in with his 'receipt for this thing, that has cured hundreds,' or ' receipt for that, which never fails,' and the mischief is complete, the event disastrous. 'Thus, it will be seen, much more depends upon a name than is at first sight assigned to it: so true is this, that the wrong naming of 
some one of the disorders set down in the preceding page, would inevitably cost a horse its life, or reduce it in the scale of beings; for many more are ruined by wrong medicines and injudicious treatment, than by all the diseases that are comprised in the too-long catalogue of ailments to be found in our modern veterinary works. In order to avert such lamentable mistakes in what is called symptomatology, and to obviate this difficulty in deciding on the properest treatment in every case, the reader is here furnished with the previous tokens and corresponding symptoms that denote each malady, in the following-

SigNS, by which one may judge when any inward sickness is impending over THE HoRse.

As hath been said, the principal constitutional disorders of horses may be traced to the excessive heats they are put to; with the like view we find many that are attributable to cold, or check upon the perspiration while this may be at its highest state: all these shew their effects upon the skin or coat. Another series of disorders arise from over feeding, or bad food, or a defective supply, generally termed surfeits : these are known by a change in the horse's appetite; and the whole occasion a change of some sort or other in his manner of behaviour; that is to say, his liveliness, his mode of going, of standing in his stall, of taking notice of persons and things, and others of the like nature : to which add his general appearance, countenance, \&c.

6 . "Off his feed"-although the first perceptible defection in the health of the horse is not always a proof of constitutional illness, but may arise from a disorder in the mouth that is easily removed-as lampas, paps, \&c.; and we should look for and remove all such temporary causes, as well as inquire respecting the existence of other symptoms of illness. Nevertheless, this very striking symptom, refusal of hay and leaving his corn, always accompanies disorders of the stomach, which is 
itself extremely susceptible of all other internal affections whatever, by reason of the influence that is exercised over it by all the other organs of life [See Chapter IV.], particularly by the liver, as shewn in Chapter VI. Also, consult the Index for 'Sympathy,' 'Stomach.' By the way, lampas should not be fired, but scarified or pricked with the lancet, as should the paps; accompanied by physick and the fever powders, as the horse so affected is always of full habit. The stomach is likewise liable to be gorged with too much corn, given alone without hay, which is absolutely necessary to enable the corn to pass off: if it do not pass, rupture sometimes ensues, or at least the horse loses his appetite.

7. The coat. As the appetite often goes off, and very soon after returns again with horses in full flesh, in consequence of ill usage or harl work, and its relaxation, this may be pleaded in excuse by some sort of persons for neglecting its admonition in the more decided cases; and they would do well to attend to the corresponding symptoms of constitutional derangement, as exhibited by the eyes and the coat. Firstly, then, the eyes exhibit a sure sign of the evil influence of a disordered stomach [see Chapter IX.]; but it is painful to remark, that these luminous instructors of our art do not undergo that frequent inspection which such an important indication proves they deserve and require. Secondly, the coat presents itself as the most obvious and teachable indication of health and disease. If this be rough, staring, and apparently dusty, though these extend to a part only, we may conclude that 'something is amiss' internally, and must then examine further; when we shall find, 1st. that he is slower at his work, or uncertain in his paces; 2nd. hot and dry in the mouth and between the ear's, probably the ears and legs cold at the same time. The liver is then the original seat of the disorder, and the reader should turn to Chapter VI. to ascertain in what degree, in order to employ the reme- 
dies in time, upon which mainly depends the cure. 3rd. the dung is found to be hard and slimy; when the anxious inquirer will consult Chapters IV. and V. 4th. on the other hand, if a scouring comes on, with abasement of the animal's powers, he will find his difficulties solved at Chapter VI. sections 3 and 4 吱. Should the dung give out no odour, the horse has then a cold, inactive liver, incapable of secreting bile (alias choler) sufficiently, and he will require the stimulation that good oats and beans impart, with malt mashes, and a cordial drench; but the direct contrary, when the dung smells uncommonly bad-the secretion is then superabundant, and the liver, or its spleen, enlarged, as may be ascertained by the means directed in the same 4 th section.

8 . In all those cases, the roughness is first perceivable about the flanks. If the great gut is affected by stoppage or chill, the hair on the lower part of the belly first shows the sympathy of the skin, by the hair hanging down shaggy, as if it had grown longer : hereupon, consult Chapter V. In like manner, when cold of the lungs has been incurred, this is indicated by staring coat on the chest, ribs, or breast, and the reader must turn to see what is said of this disorder in Chapter III. After several days' continuance of any or either such attack, however, the entire coat puts on the same rough unhealthy appearance, and hide bound commences upon the ribs.

Hide bound, however, is not an original disorder, but an effect, or symptom of other disorders, the which being removed, the effect ceases; we have not therefore consented to treat of it separately, though the custom or the fashion has been followed by us in most other instances. Neither is the coat always to be relied upon as a perfect indication of general health, or the monitor of approaching disorders, since it may be affected temporarily, or adversely, by other circumstances, whereby the stable people are thrown off their guard: 1. Drinking very cold water while the horse is hot, or standing in a draft of air, each B 3 
produces a staring coat for a short time, which frequently goes off again; though at other times producing a surfeit, \&c. \&c. See Chapter XI. for that subject. 2. Old blind horses do not change their coats as other horses do, but seem to be governed by the rule of contraries.

9. Perspiration. If, after very strong work, the horse's coat gets dry in a short time, this must be taken as a proof that the secretions and excretions, upon which health (and restoration to health) wholly depends, are going on correctly; if not so, then the contrary ; and we must infer that disorder is creeping in ; and so it is when a sweating comes on without adequate work to cause it, as also when it lasts an uncommonly long while for the season. Sometimes profuse perspiration is caused by restlessness and nervous anxiety of the craving, gorging horse; whence it is that those which have gone blind through diseased stomach, [see Chapter IX. Section 9 of ], as mostly happens, fret to get out in summer, and thereby incur the staring coat; whilst it becomes smooth in winter, not only from the absence of any such desire, but from enjoying the comforts of indoor keep, and experiencing no inconvenience from the loss of the sun's influence. This influence of the sun (by the way), is of much superior consideration in horse-keeping than has been usually bestowed upon it; but this is not the place upon which we can afford to bestow more than this slight hint.

10. As the coat, then, is not always to be implicitly relied upon, we must, under any doubt, search deeper, and look at the skin itself as a more unerring guide. If this feels dry and husky, with hard lumps upon it [see Surfeit, Chapter XI.], and is of a dusky hue, with scurf rising upon the surface of it, we may depend on the horse being out of condition, and an affection of the lungs is first to be apprehencled. [See Chapter III.] But this is not to be mistaken for the healthy rising of the yolk on the skin, which is then moist to the touch, though not so in reality, 
and the root of each individual hair rises clear out of its root: the horse is then in an improving state. If the hairs of the coat, mane, or tail, be tweaked smartly, and come away readily, it is a sign that he has been constitutionally unwell a long time, and will not recover: the lymphatic function has surceased; the excretions will be found in a deranged state.

11. In manner of behaviour, and in appearance altogether, especially of the face, the observant groom or owner will detect the existence of any inward illness as soon as by auy other means, and principally of horses with some sort of breeding in them: your dull cart horse is not so readily moved by his griefs, nor excited by emulation. The staring of the coat has been described-if this do not happen, but the hairs lie in numerous distinct series, what is called "pen-feathered," something is then amiss, as in the preceding case. If the bright bay, or grey, or shining black, becomes dull or dusky, it is a sign of disease; as is every other charge therein, or losing the mottled buttocks, or feeling flabby at the mane, when upon shaking it rudely, we feel that the muscle there wants firmness. Also, when the hair at the flanks and underneath the arm becomes of a tawny hue, we may be assured of some lurking sickness. By the same rule, as every horse hath his gaieties and manners upon being fed, or saddled, or going in his exercises, which he exhibits in the carriage of his head, neck, ears, and tail, whereby he is wont to show himself off in his pride; whenever these are discontinued, and he becomes heavy and lumpy, stepping short in his paces, and perspiring freely upon little occasions, then take heed of his dunging, for he is assuredly shut up in his body, and requires laxatives or diuretics, if not much more particular treatment. Examine some minute details regarding those obstructions in Chapters IV., V., VI., VII.; also, pay attention to the principles upon which the cure is to be conducted, as set forth in Chaper II., "Symptomatic 
Fevers." There is another disorder very prevalent at this time, which partakes in its natures of many others, and is known as

\section{Tile DistenPer of 1832.}

12. Neither are its symptoms always the same in any two individuals, nor is any one case of so decided a character as to enable us to prescribe the remedy with the usual confidence. Like all other Epidemic diseases, it is considered contagious, and is usually guarded against as such; which is the safest way of meeting the thing, though allowedly the most alarming - whether it regards man or beast; for both have submitted to its ravages, and 'tis thence ascribed to some latent atmospheric influence, which none can satisfactorily account for. However this be, we have ascertained by examination that the liver is invariably affected, the secretion of bile or choler being imperfect, or the function surceased in every case ; the consequence whereof has been, increased action of the pulmonary arteries, rupture, and congestion of blood at the heart-death. In some subjects, water has been found accumulated in the heart bag, to the amount of submersion and consequent extinction of life; in others (a few instances only) it pervaded the chest ; but we have reason for saying the disorder originated in imperfect secretion of bile-the liver having been subjected to too slight an examination by most of our neighbours. See Chapter VI. and consult Index, under the words Epidemic, Distemper, Sympathy. That horses in good health have been attacked by the distemper and died, we entertain no doubt; but those most exposed to incur the disorder under our own eyes, have been previously subject to a catarrhal complaint ; in fact, the disorder now prevailing is as much like that described by Osmer, that happened 70 years ago, as England now is like England thenmore moderate, better understood, and manageable by milder means. In fine, the discrimination and the treat- 
ment directed by that discerning old father of Veterinary Science, are strictly available at the present crisis. See some of his practical observations at Sections 7-14 of Catarrh.

13. At any rate the distemper is epidemic, and has visited various and distant parts of this country, not only in the London district, to which our practice is confined, and at Newmarket, but in Scotland, Yorkshire, and other counties, thence to the southernmost parts of our island. It appeared first upon the present occasion about October, 1831, and so continues up to March, 1832. Very little warning is given of its approach ; but when it does come, it is fearfully made known by the following symptoms :-1. General debility; 2. Pulse low, but a little accelerated, seldom beyond 50 , unless the patient be of full habit, with previous robustness; 3. Eyes dull, blearing, languid, the lining of the lid yellowish ; 4. Lungs affected with a small weak cough, or a rattling emission of breath, whilst each inspiration is free but feeble: this has been called the stomach cough; turn to Chapter IV. Sect. 6. 㑑; 5. Coat pen-feathered; 6. Legs and Ears cold; 7. Urine, a very little at the first attack, entire suppression afterwards; 8. Dunging scanty, hard, and dark, if not black for once, and then a scouring that is nearly colourless. 9. Mouth and nose-lining of a pale yellow. Seldom, however, does it happen that the whole of these symptoms present themselves in one individual case; though the debility and paucity of urine (as described) do attend every case. The distemper ball is here distinctly called for, as prescribed under that head. Administer calomel in $\frac{1}{2}$ drams, two or three times a day, and at night, the blue pill, 1 dram of the mass. A less decisive practice would but delude, but must be guided as to quantity and continuance by the state of the dunging, the colour whereof it materially corrects.

is By paying prompt attention to those several leading tokens of disease, and by using ordinary diligence at the commencement, the careful horse-keeper, owner, or 
groom, detects disorder in its earliest stages, and prevents those dangerous attacks which have been referred to from gaining ground upon him unawares. He will find his keenest observation of the progress of THE DISTEMPER called into action ; inasmuch as this appears to be an accumulation of symptoms, varying in every patient, and in every particular, as to virulence, changeableness, continuance, and manner of termination. If he have the care of a valuable stud, he will find the young and the vigorous horses, which have been subjected to very strong work, such as incur the prevalent distemper readiest; a fact that will teach him to take less work out of this description of cattle at any one time-to sweat less, and to avoid the cold half-hour before day-light in going upon the downs. He will also be pleased to consult "Symptomatic Fever" in the 2nd Chapter, and to pay some attention to a few further particulars-

14. The Eyes are spoken of upon every occasion [in the preceding pages, in Chapter IX. and elsewhere] as being the unfailing intelligencers of the pain or pleasure, the state of health or disease, a horse may experience at any time; as may be ascertained, profitably, upon every physicking we may think proper; for, as soon as the medicine begins to work, its operation affects the eyes with dulness. This proves the intimate connexion that exists between the organs of digestion and the head. See Chapter IV. Section 1., also "Staggers," and Chapter V. Again, whenever positive inflammation of any part, or fever afflicts the horse, the existence of either may be detected by turning down the eye-lid, when an uncommon redness will be found to pervade the inside lining thereof, which shall be exactly in proportion in intensity of colour to the virulence of the fever. Further, when the whites of the eyes turn up in an unusual manner, it is a sign the horse suffers much internal pain, as in the last paroxysms of locked jaw; when they impart a tear he suffers inflammation of the stomach, or has a cold in the bead, or in the lining of the nose, as in glanders. See 
Chapter IX. Yellowness of the membranous lining of the lid is spoken of in the preceding section.

15. Mouth. So is yellowness of the mouth mentioned in a preceding page (21) as one of the signs usually accompanying incipient distemper; but neither these monitory indications nor the accompanying yellowness of the nostrils, have been found sufficiently irstructive with contemporary Veterinary surgeons, to convince them that the liver is then subject to derangement, to inflammation, to enlargement, though demonstrated by us, and published many years since. See Chapter VI. In other respects, the mouth, by its increased heat and dryness, tells man as plainly as words can express, when a parching fever prevails; and the pulsation underneath the tongue, by its irregularity, its acceleration or its occasional weakness, informs him more particularly of the nature of that fever. For this see Chapter II, and Chapter III. Section 4. On such occasions the breath is hot, and if it stink, also, the lungs are mainly affected with disease. After long continuance this organ becomes rotten (one lobe, at least), and the horse will cast forth small lumps from the mouth upon any little exertion-vulgarly mistaken for portions of the liver, which does not so come forth.

16. The Nostrils are now attainted; when the tearful eye just adverted to discharges by this channel a watery humour : if it issue from the left nostril only, and this be white, we may suspect a touch of the glanders; if dark coloured, it proceeds from an ulcer, such as attends the second stage of confirmed glanders; if it be yellowish, the liver is the seat of the disease. But, referring to the age of the ailing animal, if we find he is about 3 or 4 years old and has a cough, with slavering, and a discharge from both nostrils, we conclude, without further hesitation, that this is neither glander's nor a cold in the head, but that the patient has the strangles.-See Chapter XI. a The symptoms of inflammation exhibited by the livid appearance of the membrane that lines the eye-lids has been spoken of above (Section 14.) as a true indica- 
tion of the actual state of the stomach, \&c.; no less so is the lining of the septum or division of the nostrils, the appearance of which is decidedly affected by the state of the lungs, as these are by that of the whole system. Thus, in health, we find the colour of this lining upon the division of the nostrils presents a pale pinkiness; flog the horse, run him, or otherwise excite his ardour, and the membrane immediately assumes a deeper red; but deeper still, florid and striated, when this has been excessive, or inflammation has begun; which symptoms increase, and the fine blood vessels thereof become distinct, when the fever runs high, and the pulse also. As fever recedes, and the inflammation is subdued, those indications are also found to decrease, instructively to the close observer. In low fever-termed debility, or weakness, the membrane loses nearly all its colour, except a slight patch or two of red, that tells of lingering fever still unsubdued; very often, this state of the system becomes typhous or putrid, whereupon the membrane assumes a pale livid colour, that is found deeper and interspersed with brown, as the danger increases.

17. The head, by its motions, adds an instructive series of symptoms to the foregoing. If a horse holds up his head in going much more than while he stands still, pointing his toes sharply forward, he is foundered-in the feet probably; or he is chest-foundered, if not both at the same time.-See Chapter XV., Foot lameness, section 3. If in going the horse wag his head from side to side, he is weak in the hind-quarters or legs; but if he nod it up and down, his weakness or disorder lies in the fore-quarters or feet. If before, he will sometimes go along tolerably well without showing his defects for a long trial; but bring him up sharply, shake a stick at his eyes, and he will discover the defect by grunting, or, as we say, roaring. In fact, this is a good method of finding out a concealed roarer. The head being hung down dolefully low, shows a sense of dull pain there; and if the horse exhibits 
proof of weakness in the loins at the same time, he is already struck with the worst stage of the distemper: it has reached the liver. See Chapter III. section 8, and Chapter VI. section 1. But, if he turn his head round to his side, looking either at-1st, the chest, or $2 \mathrm{~d}$, the belly, or 3rd, at the flank, - this denotes, either that the lungs, or $2 \mathrm{~d}$, the organs of digestion, or 3rd, the liver, suffers pain. For the remedies, consult Chapters III, IV, V, and VI, which respectively treat of the disorders of these parts. If, when the head and eyes droop, without any sensation of acute pain, an uncommon pulsation is felt at the temples, this denotes a determination of blood thither, and the staggers: grasp the pasterns, which are then found cold. Whenever the head is turned about suddenly, the pain is then acute, and the danger imminent; not so when the horse appears dull and slothful in that motion.-See page 39.

\section{IN FLAMMATION,}

1. Consists of an increased action of the heart and arteries, when general-whereby the blood circulates with uncommon velocity and uncertainty, but when local, or existing only in a particular part, the increased heat is then confined to the vessels of that part only, although the whole body feels its effects in some degree. - See Symptomatic Fever, page 38.

2. When a part is inflamed, there arises in it an unusual degree of heat, generally attended with considerable tension and swelling; the sensibility and irritability are always increased, and produced by it, even in parts where no such feeling before existed. In bones and tendons, for example, scarcely any sensibility can be perceived when they are in a state of health; but, when inflamed by a bruise or strain, it is roused to an alarming degree of irritation, and the most dangerous consequences may probably ensue. Inflammation has four modes of termi- 
nation; either of which may proceed naturally, or be accelerated by medicines. The first is effected by dispersion, termed resolution; that is to say, when the disease, after going a certain length, gradually disappears again : the second is, by suppuration; that is, when an abscess or tumour is formed, and matter produced: the third method is named effusion, which implies an extravasation (or issue from the vessels) either of blood, of lymph, or of serum. The fourth method of termination is by gangrene, or mortification of the inflamed part, and death. Of each of these four, let us enter into further particulars, premising that the first and second are both desirable to our views-each under its peculiar circumstances; the third and fourth are both undesirable, with only one exception, $i . e$. on occasion of extra bleeding. See page 51.

3. Inflammation of the external parts is generally occasioned by some mechanical injury; such as contused wounds, bruises, \&c.; sometimes, however, it arises in consequence of internal inflammation, or symptomatic fever, of which it is the crisis, and is then to be considered merely as an effort of nature to relieve itself of the internal disease. Thus, we sometimes find in fevers, an abscess or tumour taking place on the surface of the body, whereby the fever is considerably diminished, and generally terminates favourably in suppuration, with a critical discharge of the offensive matter. When shivering accompanies the first appearance of inflamed swelling, it belongs to the latter kind of attack ; if arising from external causes, no such shivering affection is perceivable - a distinction very proper to be noted in applying the remedies.

4. Inflammation is often produced by plethora, or redundancy of blood in the body, through gross feeding, when the arterial part of the system has its action increased, and the affection gencrally extends to the entire system. [See Fever.] Similarly to the preceding, this may be considered as an effort of nature to get rid of the superfluous blood, and points.out the propriety of assisting 
the effort by copious bleeding. Neglect hereof allows the blood to determine to some particular part, occasioning local inflammation. With horses in full work it usually falls upon the lungs; otherwise on some one other internal organ-never on two at the same time, until by long continuance a fellow feeling may be said to arise: hence we trace the most dangerous fevers of the horse; apoplexy, or sudden death, when it ascends to the brain; rupture of the liver or the heart, when it accunulates in either organ. To the same cause - plethora - we have ascertained almost every disorder of the eyes is indebted; redness of these delicate organs, at the inner lining of the eye-lid, with projection of the haws, being the earliest and most apparent symptom of this fulness of the blood.

5. In the treatment of external inflammation of the solids, we should endeavour to bring it to the most favourable termination, that is, resolution; excepting always when we can ascertain that it arises from an effort of nature to relieve itself of some internal disease ; as just before remarked, it is then most desirable to bring it speedily to suppuration. The remedies to be employed for so resolving inflammation, are local or general bleeding (vide bleeding, p. 50), purgatives, with cooling fomentations and poultices, or the saturnine lotion made warm; sometimes, indeed, we find the cold applications used with complete success, when great heat and tension can be felt at the part affected-these are sal ammoniac dissolved in vinegar, Goulard's extract diluted, \&c.

6. When inflammation takes place in tendinous parts, or on joints, the saturnine poultice has been found an useful remedy; and in the latter case (the joints), blisters are ever exceedingly efficacious. As in these latter cases the inflammation becomes more troublesome, and as the pain it occasions is often so considerable as to produce symptomatic fever, it becomes necessary to employ, without loss of time, the most prompt and efficacious means for its reduction. With this view, we excite c 2 
artificial inflammation in the contiguous skin and membrane underneath it, which are parts of far less importance in the animal economy than either joints or tendons, and are moreover capable of bearing a considerable degree of inflammation without inconvenience to the animal: this is effected by means of rowels and blistering, and the inflammation thus excited by art will tend to diminish in a considerable degree that which is going on in the more important part. This portion of the subject is resumed in Chapter XII.

7. Should we fail in our endeavours to resolve inflammation of the solids-which sometimes happens in spite of all our efforts, seeming to upbraid us for the attempt, and proving at the same time that resolution in similar forward cases ought never to be undertakenthen must it terminate in suppuration. When this desirable process proceeds but slowly, an assiduous application of herb fomentations, and bread poultice, will expedite the suppurative process, and afford immediate relief from pain; the horse evinces a desire to feed, and should be indulged, as it contributes to the cure. When the inflammation, or rather the swelling which it occasions, arrives at this state, and a fluctuation may be felt upon its being pressed by two fingers alternately, the abscess is ripe (as we say), and contains laudable matter that requires to be evacuated. If this occurs not spontaneously, an opening is to be made with a knife or lancet, at its lowest or most dependent part, upwards, to such an extent that the matter may completely escape; and future accumulation is prevented by keeping its orifice open by pledgets a, day or two, to drain. Dress the ulcer with any digestive ointment; but should the wound appear indisposed to heal when this treatment has been pursued a short time, discharging a thin, offensive matter, and wanting that healthy red appearance by which the healing process is indicated, a detergent lotion will soon remove those unfavourable appearances; the discharge thereupon becomes whiter and thicker, and 
red granulations of new flesh will sprout forth, displacing the old diseased flesh. Should these granulations, however, sprout too luxuriantly, constituting what is commonly termed "proud flesh," they are to be reduced by caustic powder strewed on the plaister, or the lunar caustic in very bad cases. This portion of the subject is more particularly treated of as Critical Abscess, Page 26, and Tumours, Chapter XI.

8. Effusion of the fluids, as hath been said, is the third manner of inflammation of the solids terminating; and consists in the withdrawal of the secretion that is necessary to the life of the part, and, of course, to its cure; induration then ensues, and leaves a tumour that has neither feeling nor blood-vessels belonging to it. If inconvenient or unsightly, remove the indurated tumour by stimulating embrocations, blisters or caustics, by fire or the knife. See Tumours, Chapter XI., article Sitfasts.

9. Lastly, when the inflammation runs very high, as sometimes happens in cases of violent bruises, or deep and extensive wounds of the lacerated kind, it may terminate in gangrene or mortification, which is always attended with great danger. In this case, the matter discharged, instead of being white and thick, consists of a dark-coloured fluid, of a peculiarly offensive smell; the patient's constitution is generally debilitated, the pulse becoming quick, weak and irregular; the appetite goes off, whereby a fearful lasting debility is induced, and it dies if not relieved in time. With those symptoms, if arising from a wound, let it be dressed with digestive liniment, oil of turpentine, or camphorated spirits of wine; the parts should be scarified, and fomentations applied almost incessantly until the mortified parts appear to separate, and the matter discharged loses in great measure its offensive smell, appearing whiter and more thick. When the horse is much weakened by the disease, with loss of appetite, particularly if there is $a$ copious discharge from the wound, give one or two of the following cordial balls:- 
Yellow Peruvian bark ....... 4 drams. Powdered snake-root $\ldots \ldots .2$ drams. Cassia, powdered ......... $1 \frac{1}{2}$ drams. Oil of cloves ............20 drops.

with syrup enough to form one ball. If the disease be accompanied by purging, add to the above, opium 1 dram. If the four materials could be given in gruel, without alarming the patient, by means of the stomach tube, the medicine would be found much more effectual.

10. Internal inflammation, arising from a change of form, has been recently proved to exist in the horse, and is of two kinds, having different causes, somewhat different seats, and affecting animals under very different circumstances : though having one symptom in common, namely, great and evident internal pain, ending in death ; in the one case slowly, in the other suddenly: the first comes on gradually, is the effect of rapid action or hard work, insufficient water, and frequently of bad living; the second is the effect of idleness, and high and dry feeding; it comes on rapidly, and always terminates in death by mortification, in the course of one, two, or three days. This latter has been long considered vulgarly as ' twisting of the guts,' as well as ' the dry gripes,' the latter term being given with good reason; because no stool is to be procured, the means usually employed to obtain this evacuation only accelerating the sad catastrophe: indeed, total emptiness of the straight gut is the surest symptom of its baleful existence, and should tell us instructively of the utter uselessness of endeavouring to produce alleviation of the patient's miseries by this means. As this second species is thus sudden and immediately fatal, the first admits of alleviation, and life may be protracted several years, even so far as to raise a hope that a cure has been brought about-as indeed partially happens by the course of nature, unless injudicious treatment has been employed, under a mistake of the symptoms being those of colic.

11. A growing of some internal organ to the adjacent 
parts-generally of the lungs to the ribs, the midriff, \&c. is the disorder we term adhesion, by others cohesion -meaning the same misfortune we are now considering ; and which, when treated with cordial stimulants, as for colic, is hereby confirmed, or augmented in virulence, and death is surely accelerated. Adhesion of the bowels to the liver also takes place from the same causes as first mentioned, and is, in fact, a primary disease of ulcerated liver, remedying itself by a slow course of nature, as before observed. But we postpone further remark hereon to the pages appropriated to ' inflammation of the bowels,' which form of disease it more assuredly assumes, and that with a ruthless vengeance; whilst adhesion of the lungs comes to be treated of under inflammation thereof. See also Chapter VI. for Diseases of the Liver.

12. In every case of internal inflammation, the practice has been to bleed copiously, whereby either resolution or effusion (as before described) is brought about; but in the present cases of change of form, when a capital organ has lost its function, that favourite remedy is always doubtful, even in affections of the lungs - when it is usually carried too far, for the disorder is thereby transferred thence to the bowels-fatally. External artificial inflammation, as before described, is much more likely to ease afflictions of the lungs or liver, though nought will relieve those of the bowels-its twisting, obstruction, knotting or intussusception (call it what we like) we again repeat being incurable. With rowels, seton or blister, employ the fever powders (Page 35 ); occasional clysters, also, are of considerable service in every case of internal inflammation and fever of the system: though, as must be evident, when the straight gut is entirely empty, no hope remains, and the labour is thrown away abortively. 


\section{CHAPTER II.}

Fever-and first of Simple Fever.

1. As almost every horse that is taken ill, be it in any form whatever, exhibits some of the symptoms of fever(indeed we never find an exception) the absolute necessity of every man's making himself fully master of the doctrines laid down throughout this and the preceding chapter, must be obvious. He cannot, without the knowledge herein conveyed, set himself about preparing the remedies that are strictly applicable to each separate species of attack, nor can he come to a safe conclusion when to adopt, when to omit, the first of all remedies in febrile complaints, namely, BLEEDING ; restoration of health awaiting its proper use, destruction attending its misapplication. This truth is exemplified to the letter in what I shall have to say regarding the Epidemic Fever, lower down, Page 52.-The fevers of horses, however (as I have just shewn), bear very little analogy to those of the human body, and therefore require a different treatment; the mode of living, and mind, or consciousness in man, being the chief causes of fever in him; whilst by his overstrained exertions on bad food, is the horse chiefly subjected to this whole class of disorders, we advisedly term inflammatory fever.- [Another class of fever arises from overfeeding, want of exercise, and undue watering.] -Notwithstanding this self-evident fact, most writers on farriery ( $\mathrm{J}$. Clark, for example) have described a great variety of fevers; but their observations appear to bave been drawn from the works of 
medical authors in the human practice, and their reasoning seems to be entirely analogical. William Osmer was nearly the only exception to this reproach until the time of James White; and the latter confessed himself a long time ' unable to distinguish more than two kinds of fever,' though allowing that these were often accompanied by other obstinate symptoms. Of those two kinds, the first is an original disease, and therefore termed simple fever; whilst the other, being dependent on some internal inflammation (as just now described), is very justly denominated symptomatic fever, - shivering or rigor of the nerves being the most notable of those symptoms. See p. 26. For example-whenever the lungs or the intestines are inflamed, the whole animal system is thrown into disorder, and a symptomatic fever is the consequence; but if a collapsion, or closing up, of the perspirable vessels takes place, as happens on ' taking cold' by so checking the perspiration, or by exciting it on suddenly entering a hot stable, the blood will accumulate in the interior parts of the body; and although a genuine inflammation may not be produced by it, yet the unequal distribution of the blood will alone occasion that derangement in the system which constitutes simple fever.

Every horse that runs a race, or is engaged in a four hours' hard chase, or does any other strong work at top speed, is thereby thrown into a temporary fever. Our business is to employ the remedies promptly, or immediate danger is to be apprehended; if cured precipitantly, the fever returnsduring life, and descends to the legs and feet.

2. The simple fever does not occur so frequently as the symptomatic, nor is it by any means so formidable in its appearance; sometimes hanging about the horse for a long time undetected by the common observer. Yet is it necessary to give it the earliest attention ; for, unless Nature receives timely assistance, she will soon be disabled from getting rid of the load which oppresses her: the blood continues to accumulate on some in- 
ternal organ, which shortly causes inflammation thereof, and these symptoms are successively observable:-Pulse quick, sharp, and unequal; hot mouth, total loss of appetite, dejected appearance and evident pain-shivering; then a hurried respiration and costiveness, with turbid urine, accompanied sometimes by colic pains. If allowed to go on unchecked, the membrane that lines the eye-lid becomes redder than usual; the inflammation may then be considered as having fixed itself on some internal organ ; thus it is that the hitherto unheeded simple fever becomes symptomatic of that event, and the patient must now be treated as for internal inflammation, as described in the first Chapter.

3. As soon as a horse is attacked with fever of any description, let him be bled freely, unless he is already weak, with a feeble pulse (i.e. slow fever, vide distemper, page 52). When the lungs may be the seat of the disorder, the operator will hear a rattling in the chest after the bleeding has gone on to a good amount, say 4 or 5 quarts; this should be the signal to cease at once, or the inflammation will be soon transferred to the bowels, incurably. Give a mild purgative afterwards ; and, indeed, it sometimes happens that costiveness is the only cause of the fever. Ascertain this fact ; examine the straight gut; rake it; inject a clyster of warm oatmeal gruel; give castor oil 8 ounces, or salad oil 12 ounces, with the laxative drench, and you shall find no further treatment is required in ordinary cases. However, in all cases bestow good nursing on the recovering horse, and adopt the whole process, which we call

The Restorative Means of reinstating health, and of avoiding relapse in this entire series of disorders. For this purpose give soft food, viz. good gruel and bran mashes, in small quantities, and often; administer the fever powders until the urine is voided readily and free from turbidness, but no longer, unless a relapse in this particular renders a repetition necessary. Warm cloth- 
ing, with a liberal allowance of litter, frequent hand rubbing and bandaging the thick legs that always comes on, are goodly conducive to recovery. When the fever runs high, it is advisable to insert rowels about the chest and belly, in order to prevent the inflammation fixing itself on the organs. Affter you have conquered the principal symptoms, and the disorder appears to be going off, the horse looking more lively, and the appetite returning, let him be led out for a short time daily, in some sheltered situation, and give now and then a small mash for the purpose of restoring his strength and vigour. Give the tonics for a week or ten days. Keep the staling and dunging in right trim, the first by means of the powders, the latter by the laxative drench or the purging ball, according to circumstances; as there remains a constant tendency to costiveness, especially when the tonics have been employed a long time.

\section{Fever Powders.}

No. I.-Powdered Nitre........1 ounce. Camphor...$\ldots \ldots \ldots 2$ drams.

Tartarized Antimony....2 drams-mix, for one dose, and give every twelve hours, until the desired effect is produced, as above described.

No. 2.-Powdered Nitre........1 ounce.

Unwashed Calx of Antimony ..........2 dra.mix; as before.

No. 3.-Antimonial Powder ....3 drams. Camphor ..........1 dra.mix; as before.

N.B.-With liquorice-powder and syrup those powders may be made into balls, if required in that form. The reason why these various prescriptions are given, is that the practitioner may vary them from time to time, according to the existing circumstances of the case : thus, No. 1. is adapted to the first stages, when great internal pain is evinced; No. 2. is preferable when this distress subsides; No. 3. induces the staring coat 
to smoothness. An alteration, however, is proper when the urine continues obstinately turbid, by substituting for the camphor in No. I. three drams of powdered rosin.

\section{Tonic Ball, or Drench.}

Peruvian Bark...........l ounce.

Prepared Kali.........1 dram-mix,

with mucilage enough to form the mass for one ball; to be given on several successive days.

N.B.-The efficacy of the bark and kali is greatly enhanced, by giving those materials in the form of drench, mixing the ball in 3 pints of gruel, nearly cold.

\section{Laxative Drench.}

Socotrine Aloes, powdered $\cdots .3$ drams.

Prepared Kali............. dram.

Mint Water.............

Water.$\ldots \ldots \ldots \ldots \ldots \ldots$ pint - mix

for one dose. In cases that require thorough purgation, the quantity of aloes should be increased, or the drench as above be repeated at the end of 12 hours, whereby a brisk cathartic effect is produced.

4. Of the Laxative drench, it is worthy of remark, that 3 drams of aloes given in this form are equal to 5 in form of ball, besides acting sooner and more effectually, and that too upon the most sympathizing organ of the animal, the stomach; loss of appetite being the earliest symptom of all fever whatever. In addition to those reconimendations of the drench, when the fever is symptomatic of inflamed lungs, and a difficulty of swallowing is among the symptoms, no ball can pass without a struggle, if at all, and this is ever attended by irritation of the disorder. But other objections existed to the giving aloes in solution, however disguised, the dislike of bitters being very strong in the horse, and the drench was more or less spilled in the giving. This 
difficulty has been surmounted recently by the invention of a flexible stomach tube, or pump, sold by Long, of Holborn, and others, which being introduced to the gullet, any liquid passes into the stomach freely, affording the practitioner also incalculable facilities in other respects, as when the usual emaciation attending inflammation points out the necessity of supporting the strength of the patient by a generous supply of oatmealgruel, and thereby enabling him to sustain the drains by rowel and blister, by bleeding and purgation, to which he has been necessarily subjected.

5. As we shall find frequent occasion to refer to this improved mode of administering medicines in liquid, in all cases that require immediate operation to effect any given purpose,- -when the hours' delay always experienced in the solution of $a$ ball in the intestines defeats the benefits expected from it; as, also, in those cases wherein the stomach and the small intestines require to be mainly acted upon, we may be allowed thus early to insist with no common energy on the immense advantages that are to be derived from the use of the stomach tube, as an improved vehicle for drenching ; leaving, however, the horn and the bottle in the hands of those who will not yet resign their use. That which we have in use is manufactured by Reid, of Regent Circus, Piccadilly ; and is adapted to further purposes, when connected with some other apparatus, to be noticed hereafter. [See Chapter XVI. "Stomach Pump."] True it is, that the stomachs of some patients seem better adapted to dissolve balls than others, so that the medicine operates to the full extent of our wishes ; its effects are found commensurate to subdue the disorder, and we recommend its use in similar cases; but mark the difference of a cold, dry, and perhaps empty stomach, already diseased : the ball descends whole, and gets into the cœcum ere it dissolves, and an otherwise brisk purgative has been known to retain its form and its effects, until it arrives in the large gut, and there effected much harm by super-pur- 
gation. Hence have arisen some lamentable errors respecting the best possible prescriptions ; and hence, too, the disrepute into which one entire class of excellent restoratives (tonics) has been cast by Bracy Clark, and one or two more, of whose mistaken practice, in this respect, it was observed in the Grooms Oracle, 1828, that " those animals which awaited the knacker's axe, are ill calculated for trying such experiments upon, fairly." Besides which, those objectors invariably made up their tonics in balls much too hard to operate on the stomach, where alone they could possibly effect any good; very contrary to the expert manner of $M r$. White, the father of tonics, whose prescriptions for balls were calculated for immediate solution; and the same mode of compounding those valuable restoratives was directed in the Grooms' Oracle (p. 280, edition of 1830). It is but a fair conclusion to these remarks, to allow, that for the original idea of employing a flexible pump upon hoven cattle, the public are indebted to Dr. Monro.

6 . When any doubt exists, as to whether the patient labours under the genuine inflammatory fever, the reader had better refer back to pages 25 and sequel, and consult the next following pages, before he resolves upon bleeding, as errors are sometimes committed in this respect which endanger the lives of horses so mistakenly treated. See Index, Bleeding, Fever. Such doubts are most likely to arise in cases of epidemic fever, in which patients of the very same stable receive the contagion under totally different circumstances, of previous constitutional health or disorder, of weakness (debility), or robustness, or tenderness ; to some of whom the operation of bleeding largely is found highly beneficial, to others the sure harbinger of death. See pages 52-55.

\section{Symptomatic Fevers.}

1. These are generally occasioned by high feeding, close stables, want of regular exercise, and by an injudi- 
cious scanty supply of water; sometimes sudden transition from a cold to a hot temperature, as coming off a journey late and entering a crowded stable, is probably the frequent and immediate cause of it. Horses that are taken from camp or grass, and put at once into warm stables, are extremely liable to contract those internal inflammations which give rise to symptomatic fever: indeed, to this cause alone is to be attributed the invariable cough that attends the coming up from grass or straw-yard, to which thousands fall victims every year. Suffering a horse to stand in damp clothing, or replacing such without sufficiently evaporating the sweat, has been ascertained in a great number of cases, to occasion that collapsion of the perspirable vessels before noticed, (page 32.) which causes either simple fever, as above, or the more aggravated inflammation of some vital organ, which we are now considering. When fever is symptomatic of some organic disorder, it is not accompanied by shivering, as in cases of simple fever, nor is it so sudden in its attack; but when, through neglect, it is not subdued by a prompt administration of the remedies prescribed, the symptoms increase in violence gradually, until they present a formidable appearance. On the other hand, when caused by great and long-continued exertion, it generally comes on suddenly, and the disease assumes a dangerous appearance in its very earliest stages. Wounds, severe inflictions, strains, and acute disorders, are accompanied by fever that is symptomatic of the pain endured, and requires prompt measures.

2. The symptomatic fever has many symptoms in common with the simple fever ; which are, loss of appetite, quick pulse, dejected appearance, hot mouth, and a weakness of the whole frame, termed debility. If to these be joined difficulty of breathing, and quick working of the flanks, with coldness of the legs and ears, we may conclude that inflammation of the lungs is then the specific cause of the fever. Again, if the horse hangs down his head in the manger, or leans back upon his collar,

D 2 
with a strong appearance of being drowsy, the eyes being also watery and inflamed, we may now conclude that the fever is symptomatic of an accumulation of blood in the vessels of the brain, and may expect an attack of the staggers is approaching. In this latter case, however, the pulse is not always quickened; on the contrary, it sometimes falls below the natural healthy number of beats, nearly constituting low fever. Again, when to the symptoms of fever are joined yellowness of the eyes and mouth, inflammation of the liver is thereby plainly indicated. Should an inflammation of the bowels be the cause, the horse is violently griped, lying down, kicking, and getting up again. Inflammation of the kidneys will also produce feverish symptoms, and this particular affection is denoted by painful staling or entire suppression of urine, and aversion to the least pressure on the loins. In like manner, when any affection of the bladder (its neck) is the cause, the horse is frequently staling, voiding only very small quantities of urine, and that with considerable pain. Besides those affections of the organs of life, extensive wounds, and particularly those of joints or tendons, will also produce symptomatic fever of a very inflammatory nature. [See Inflammation, page 29.] Sometimes it so happens that two or more of those internal parts suffer inflammation at the same instant, from the same cause; and indeed, whenever an attack of this nature has gone on unchecked for any length of time, the organs sympathize with each other; and, when this takes place, the symptoms will uniformly be complicated.-[See Chap. IV. Sections I and 5.] Still, however, the essential remedies are the same; that is to say, copious and early bleeding, with rowels and blisters, green food and mashes.

In the next and succeeding sections, we come to treat separately, and more minutely, of those particular attacks on the organs of life, which by their inflammatory nature occasion the fevers we have just now been considering in a general manner. Of these organs, the 
first mentioned (the lungs) are liable to a greater variety and more lasting attacks, than any other viscus of the horse. This arises from the very great exertions he is put to, in quick work especially, which tax the respiratory function to perform to the utmost of its capability, as well whilst actually going, as in the extreme pulmonary action that ensues; hence it is that we trace, not only the most evident disorders of the horse, from a "slight cold" to " a confirmed roarer," but those others also which lie dormant, and are only called up by accident, by ill-usage, or the seasons, and the influence exercised by the lungs on the other organs of life.

3. The glanders, although an inflammatory disease, is accompanied by none of the foregoing symptoms in its earliest stage, because the thin discharge from the nose, which is its own primary, unchangeable, and visible seat, carries off awhile any acrimonious tendency; until at length the tubercles (which subsequently ulcerate), creeping along the membranous lining thereof, reach the lungs-the left lobe, almost invariably, and inflammation begins. This constitutes one of the varieties just spoken of, but is by no means to be treated as simple inflammation, being a thing of itself, for which there is not to this day, January 1,1832 , any specific remedy obtained-nothing certain; nought but quackery and pretence. Not always, however, is the disease found upon either lung, even when fatal; for in such cases it has entered the system - the circulation of the blood, and, running along the course of the absorbent vessels, becomes farcy. 


\section{CHAPTER III.}

INFLAMMATION OF THE LUNGS.

Catarrh: Epidemy, or Distemper. Cough: Chronic Cough, Broken-wind, Roaring, \&c.

1. As well for the frequency of its recurrence, as the situation of the parts, does this species of attack demand our first attention: its character for incurableness abates not our hopes of alleviating its greatest virulence; and the success which attends the judicious treatment of mild cases, inspires us to future exertions. Not by any natural defect in the animal, but principally by mismanagement after very strong work, are these delicate organs, so indispensable to its going, rendered liable to disorder more than any other which give life and being to the frame. Every affection of the lungs is referable to inflammation for its origin, but differing in violence according to the portion thereof which may suffer; the effects also differ:-cold, catarrh, and cough, then, are but modifications, in degree or extent, for the several portions thereof which may be attacked with the symptoms described in the preceding sections (page 39). That broken-wind should follow, with roaring, hectic cough, adhesion of the parts (see page 30), and other complaints, is more to be attributed to the rough inadequate means employed for the cure of the original disease, and a too hasty return to labour, than to any imminent danger in the disease itself.

Notwithstanding this, it must be allowed that its progress is often very rapid, and even fatal, unless proper 
remedies are employed at an early period after its appearance : decay of the substance of the lungs has been found to have taken place at the very commencement; and even when the symptoms disappear, part of the function of respiration is lost by the growing together of the pleura and ribs, or other such derangement of adhesion before spoken of.

2. Symptoms of inflamed lungs : loss of appetite, an appearance of dulness, and disinclination to motion, thirst, with difficulty in swallowing liquids, unusual quick heaving of the flanks, hot mouth, and sometimes a cough. All these are usual, in a slight degree, at any and every attack upon the lungs; but when considerable weakness or debility, and a tottering gait, mark the commencement of the disease, we seldom find it terminate favourably. If the disease is suffered to gain ground through an inert or improper mode of treatment, all those symptoms will increase, respiration become extremely quick and laborious, the pulse more frequent, and at the same time weak. A striking appearance of uneasiness and anxiety may be observed in the animal's countenance; the nostrils are expanded, the eyes fixed, and the head inclining downwards; the legs and ears become cold, and the weakness is so considerable, that he is incapable of moving in the stall without difficulty. At length, he does not lie down, unless so much weakened as to be incapable of standing, when he drops down. 'The disease, however, is not always so rapid in its progress as is here described; and not unfrequently it happens that a considerable remission of the symptoms is observable, which is occasioned, probably, by an effusion of water in the chest, as was remarked upon at page 34, as taking place on bleeding the patient. This remission is sometimes so very conspicuous, that we are led to pronounce favourably as to the termination of the case; more especially as the patient takes to his food freely, looks lively, has warm ears, with pulse less frequent, and in short the symptoms of fever disappear in a great measure. Still, 
however, there is uncommon quickness in the respiration, generally accompanied by cough, the hind legs swell, and the horse very rarely lies down: a rough unhealthy appearance is observable in the coat, the skin feeling as if stuck to his ribs, and the weakness continues; after a while, the inflammation, being unchecked, resumes its former violence, and then speedily ends in locked jaw, and death.

3. This event has, in all cases under our observation, arisen from neglect of the restorative means, otherwise termed nursing, spoken of in a preceding page (34), and to which the better-fed grooms pay the least attention. The bleeding has been carried to its proper extent, let us say; $i . e$. sufficient to produce a sensible effusion of water in the chest, at the time of, or soon after, the operation (page 51): hereupon, the foregoing favourable symptoms cause a false notion to be entertained, that the animal is "going on well," whereas, nought, in general, is more fallacious, with the higher-bred horses in particular, especially when any of these unfavourable symptoms remain :-1 st, He seldom li:s down, and, what is more, nobody coaxes him to do so;-2d. His flanks heave too quick for the healthy state, and the hot stable air which caused it is seldom changed; - 3d. A short cough is observable at intervals; - 4 th. His coat becomes rougher at the chest and belly, with partial hide-bound; -5 th. The redness on the inner coat of the eye-lid, before spoken of, remains unsubdued; ultimately, his hind legs thicken considerably, and seem unequal to his support, until at length he drops, and dies without a struggle.

4. Sometimes, no such favourable remission of the symptoms occurs, and the inflammation terminates by the second method before mentioned, i. e. suppuration(See page 25.) In this case, also, the fever is in some degree lessened; and the horse beginning to feed a little, and looking about him, he is too soon pronounced "doing well ;" whereas, his evident weakness, a tickling cough, and the discharge of foul matter from the nostrils, 
resembling the worst stage of glanders, instruct us how little reliance is to be placed upon the relaxation of the minor symptoms, for little hope of life is left while those flagrant evils remain unsubdued.

5 . The first thing to be done when this dangerous disease is observed and well marked, is to bleed copiously, even until the horse begins to faint from loss of blood. I have seen 6 quarts drawn at one operation, and with the best effects ; sometimes, indeed, the disease will be wholly subdued by thus bleeding freely at its commencement, always noting, that in this favourable result, the redness of the eye-lid inside has been reduced considerably by the operation; but if not so, then the contrary, and you must bleed again. In case of any doubt as to the identity of inflamed lungs, draw but a small quantity of blood, and note well the period of its coagulation: if this be slow-say in 20 or 30 minutes-this state of the blood shows that the case is desperate, and you must take a large quantity. Purge subsequently with the laxative draught, giving two doses, as directed at page 36 ; or, should the dung be found hard in the straight gut, rake it forth, give a pint of castor oil before the bleeding, and after it a clyster. Probably, in this case of hard dung in the great gut, the mild purgative ball below will be found more eligible than the drench.

6 . Perhaps the symptoms do not decrease with these evacuations. The case is then an obstinate one, and, with a view of diverting the inflammation from this important organ, let rowels be inserted about the chest and belly, and blister the sides extensively, the latter being the most eligible form of exciting external inflammation. Clothe the patient afterwards warmly, but not too hot; hand-rub the legs, and bandage them at night; do not neglect for an hour the admission of good, fresh, wholesome air, noticed in the preceding page as the main preventive of the much-dreaded relapse, which so frequently occurs, even after very favourable symptoms may have appeared, and thrown the attendant groom off his guard. 
7. After the bleeding, it has been the usual practice to bleed afresh if no abatement of the symptoms is observable; but among these we must not reckon increased debility on the one hand, nor a great increase of the pulse on the other-bleeding repeatedly in such cases being found fatal, even under the sage eyes of the Pancras professors, according to their own statements. One copious bleeding, of 4,5 , or 6 quarts, and that from a large orifice, is always found of more efficacy than full as much or more at twice; in truth, if the operation be judiciously performed, and followed by the above-prescribed treatment, with good nursing, hand-rubbing, bandaging, and, above all, fresh air in a loose stable, we seldom fail to subdue the symptoms; but nothing will complete the cure if wholesome air be denied the patient, who will himself prove the fact, by going (being loose) to that part of the stable where he may enjoy it most freely. See what has been said in the preceding pages regarding fever (page 34): observe the restorative means there recommended for reducing the unfavourable state of the three evacuations : defective dunging must be amended by the laxative drench, preferably, if the case be urgent; if not, by a

Mild Purgative Ball.

Aloes of Barbadoes ....... 5 drams.

Castile soap $\ldots \ldots \ldots \ldots \ldots 2$ drams.

Oil of caraways $\quad$........10 drops.

Mix for one ball; and if the water come sparingly, or is in a very turbid state, add prepared natron, 2 drams.

8. The urine, however, does not always come off correctly with the purgation, but continues bad, and is ever accompanied by the feverish symptoms; then give the fever powders, No. 1 and 2 (page 35 ) in succession, and No. 3 will contribute to reduce the staring coat, which is symptomatic of the disorder within. When the feverish symptoms give way, but debility remains, give the tonics for a few days (page 36), and the following afterwards: 
Alterative Balls.

Salt of hartshorn ......... 2 drams.

Opium ............... 1 dram.

Powdered aniseed.. .6 .6 drams.

Mix for two balls, to be given on successive mornings: these may be further administered six or eight mornings, if the first two appear to do good.

9. Although the disorder may have run so high, that the suppuration before spoken of has taken place in the lungs, and consequently no reasonable hope of recovery remains, yet will this treatment preserve the animal's life, so that he may be employed in drudgery and the slow occupations of the farm-yard or streets. When the lungs have discharged the foul matter completely, as will be seen by the nose becoming clean, great debility ensues, so that the patient is sometimes carried off through weakness; to prevent which, the restorative means (pages 34 and 45) must be pursued with unremitting care; and, in addition, give prime sweet hay, little and often, oats that have been steeped in boiling water, oatmeal gruel occasionally, and a small malt-mash seldom. Let not fresh air be omitted (let us repeat), nor a run in the meadow in the finest parts of the day, taking care to avoid sharp winds, and to put on body clothing, and a breast-piece. Beware of a relapse.

10. Of those affections of the lungs which are either influenced by disorders of the other organs, or possess influence over them, see below, under Catarrh (section 8); the fatal effects of its extending to the liver in epidemy, and the reaction which results from its connection with the stomach, are fully stated in Chapter IV. section 5.

\section{Catarri or Cold; Cough, and its effects.}

1. A simple cold on the organs of respiration bears so near affinity to the more violent symptoms of inflammation thereof, just above described, and is so well known, that we might safely dismiss further details with a single ob- 
servation only-namely, that they are evidently the same disorder, but this is less severe, and the attendant fever is considerably milder than accompanies inflammation of the lobes of the lungs. Of course the immediate danger is less, but the effects of catarrh generally last a long time, even the whole of the horse's life; whence chronic cough, and the whole series of subsequent insidious attacks on these organs, we come shortly to describe. Several of these, however, differ from each other little more than in the degree of the attack, and the particular part which may be mainly affected; and, as will be seen under the next following head of information, viz. Chronic Cough, Broken-wind, and Roaring, that the remedies are all of the same class, none specific, but all useful in alleviating the disorder. To neglect of the first symptoms, to improper treatment afterwards, and to insufficient nursing, may safely be ascribed the ruinous effects produced by an apparently trifling disorder, too often described as "only a little cold ;" whereas, the blear eyes, and defluxion of the humours from the nose, are genuine symptoms of the true disease, which becomes violent by neglect.

2. Catarrh consists in an inflammation of the membrane which lines the internal parts of the nose, throat, and cavity of the chest, which is soon after attended by the symptomatic fever before described (page 38), and then is confirmed by a cough, but withal so slight as to delude ordinary observers into a belief that "nothing's amiss." A stoppage of the mucus that is well known to be secreted by the said membrane occasions the cough, and a thin watery discharge from the nostrils. This change in the consistency of the secreted mucus, and its increased quantity, marks the right period for bleeding; - the which potent remedy, if delayed, sometimes proves fatal, especially when catarrh prevails generally among cattle, owing to unseasonable weather, and is then considered epidemic (see this lower down, page 53) for this reason: the strength of the patient being much reduced 
by a continuance of the discharge, he would be unable to recover even a moderate loss of blood ; but if the operation is performed at the commencement, to the extent of three or four quarts (no more), he will require but to be evacuated of dung and urine, and the cure is completed by the nursing and soft food before insisted upon. See the preceding pages on "Inflammation of the Lungs," for the treatment is the same.

3. If the first feverish symptoms run high (see page 38), I prefer giving the laxative drench, at page 36, as being quicker and more copious in operating than the ball; but, if the costiveness has been obstinate, give the mild purgative ball prescribed at page 46 ; and after the purging subsides, give the fever powder prescribed in page 35 , morning and evening, until a considerable quantity of urine is voided, when a repetition twice or three times in the course of the next week will suffice. Keep the patient moderately warm, give bran mashes; and if a tumour rise under the jaw, or sore throat is evinced to the touch, rub on the part a little mild blister ointment two or three times.

O One thing worthy of remark, respecting this minor attack upon the lungs, that does not exactly amount to violent inflammation, on account of the cold that caused the collapsion of the perspirable vessels (page 33) being milder, is this-single cases occur but seldom; for the adverse state of the weather, with its variableness, being mainly conducive to the disorder, numbers of animals are commonly seized with it, all about the same period, causing great dismay to the owners, and conveying wellgrounded notions of contagiousness. Hence the doctors are wont to treat their patients all alike, injudiciously imagining that because this horse fell ill by infection from that horse, therefore must the disease and the medical treatment be the same. Nought, however, could be more fallacious than such a conclusion, seeing that the attack would fix itself on that organ, or portion thereof, whose functions might be least perfect in the 
individual seized with the distemper; and of course, as the symptoms would vary, so must the medical treatment, as we shall prove shortly. In like manner, when single cases occur, at a distance of time or place, we know that the cold check which inflicts catarrh affects the individual variously, according to particular circumstances, as to previous health, to high keep, moderate or low diet, to its exercises, and so forth ; and will it be said, that because the adverse season has caused many animals to feel its evil effects at the same period, that therefore the medicines should be the same for all constitutions alike, without regard being had to variations in the symptoms? Assuredly not. We have therefore divided these into five classes, underneath; indeed, all catarrh resolves itself into one or other of these classes, whether solitary cases or epidemical.

4. BLEEDING has been repeatedly recommended in this and all the foregoing inflammatory complaints, as a powerful remedy, as it certainly is, when employed at the proper time, and to an adequate amount, whilst the patient has strength sufficient to surmount such a drain from his powers. In no instance is the mind called upon to exercise discrimination in those respects, like what is required in catarrh ; in one series of symptoms the operation being beneficial, in another destructive. How, then, are we to form a sane opinion when to bleed for a cold, and when not? This question deserves close attention. Generally speaking, when the afflicted animal is drooping with debility, with a cold sweat or a profuse one, and when redness is not perceptible on the membrane which lines the eye-lid, no man should bleed, though the number of pulsations at the moment may be too many for sound health. But a much better criterion for judging by this thermometer of health, is the nature or kind of vibrations, as the pulse swells up under the finger; because the number may be raised to 40 in a minute, or far beyond, by various causes, as brisk exercise, fear, want of fresh air, or the action of physic 
within him ; but its hardness or twang, and the absence of that gradual swell under the finger, so well recognised in health, prove beyond question that bleeding is then proper. It is proved another way, also: when the bleeding has proceeded so far as to restore this healthful swell of the pulse, when the redness of the membrane which lines the eye-lid goes off, when we ascertain by a rattling that effusion has taken place in the chest, as noted before (page 34 ), we may conclude that bleeding, in all such cases, has been employed beneficially. Moreover, when the subsequent treatment has been conducted judiciously, as directed, we seldom find a second bleeding necessary or desirable.

5. The propriety of keeping a finger upon the artery while the bleeding goes on, to watch for any change in the vibration, must be apparent to all. We have spoken of some other points proper to be observed in bloodletting, at pages $27,46,48$, and 49 ; to which may here be profitably added, that tying up the neck, with the view of raising the vein, is not necessary, and may be harmful. Raise the vein by smoothing along its course with the finger moistened, then press with the smaller fingers just below; hold the fleam in a line with the vein ; let the blade be wide-shouldered, so as to make a large orifice. Facilitate the flow of blood by introducing a couple of fingers into the patient's mouth, and rubbing the bars a little. If a second bleeding be deemed necessary, very soon after the first, come a little way farther down. When the skin is pinned, do not draw it up much, and carefully avoid pricking the vein. Draw the blood into a measured vessel, fairly, not trickling down the sides; but do not press it so very hard as some do, against the vein : slightly does best.

6 . For all those inflammatory complaints we are considering in this Chapter, the neck vein is preferable; but local bleeding being desirable sometimes, as for foot lameness, the toe is then selected for the operation, i.e. at the union of the crust and the sole, cutting it away in 
a narrow line with the searching knife : promote the flow by means of warm water bathing. When the hind quarter requires the relief which bleeding gives, draw it from the vein which runs across the inside of the thigh. Do not bleed from the plate vein, nor from the corvet ; the latter being more difficult to operate upon by the generality of persons than the toe, and the former has been adopted for lameness in the shoulder, which is merely an imaginary disorder, except in cases of contused wound, and then the neck vein is preferable.

af After bestowing those remarks on the doctors' best remedy in all cases of inflammation, we return to the consideration of catarrh in its most prevalent state, considered epidemic. This general sort of attack, when many horses are affected with it at one and the same time, is not exactly confined to the spring of the year, when animals shed their winter coats, but sornetimes breaks out in autumn, when cold rains occur prematurely, or succeed to an uncommonly hot summer.

7. Nor is any season entirely free from this destructive malady; unseasonable weather at any time of the year producing catarrhal fever in several forms, all requiring different treatment, though all have their origin in inflammatory affections of the lungs. Much ingenuity has been displayed in endeavouring to ascertain the precise portion of this important organ which may have been subjected to the attack under existing circumstances; but every useful purpose will be attained by drawing attention to the several symptoms that mark each deviation from the foregoing description of catarrh and inflammation, and to note down when alteration is to take place in the treatment of each severally, and to remark upon the danger frequently incurred of mistaking one series of symptoms for another that is materially opposite. In fact,

8. Epidemic Feveri, or the Distemper, is that catarrhal attack upon horses, and indeed other cattle, which has been supposed infectious, from the number and 
fatality of its victims; though epizootic fever is the term now applied by the learned to this epidemy of cattle. When it prevails, the fat and well-conditioned horses should be bled and physicked as a preventive : they then escape contraction of the disorder, if they do not lessen the chances of infection. (See p. 49.) Separation of the sick from the healthy is obviously the first step to be taken; and if the untainted cattle can be sent out of the district, or beyond some hill, the contagion is thus prevented from spreading, to them at least. Whatever other symptoms may afterwards supervene, the first, we observe in nine cases out of ten, is cough, accompanied by dulness and debility of the limbs, loss of appetite, wet nose, and disinclination to drink, owing to sore throat; whilst, soon after, dimness of sight, if not glossy eyes, shew how much the digestive organs are now affected. But if great prostration of strength is perceivable behind, we should pronounce that all-important organ, the liver, to have been balefully influenced by the evil state of the lungs, as said at page 40 , materially ; (see further at Chapter VI. section 1,2.) Coldness of the limbs and ears is evidently the effect of stagnation of the fluids; for there is no other sign of inflammation. In such cases, and they are the worst type of distemper, bleeding is destructive of life; clysters worse than useless. Give the distemper balls and powders, as directed below : no other hope remains of restoring the secretion of urine, which may afford a favourable prognostic; otherwise death ensues.

9. But, when the debility does not extend to the hinder limbs, the other symptoms of fever being the same, moderate bleeding, with clysters, do good ; in addition, the redness of the inner surface of the eye-lid is a certain indication that the operation is now proper, and if the redness is not lowered by the first bleeding, let it be repeated in moderate quantity. After giving the laxative drench at page 36 twice, and the purging has subsided, give 
The Distemper Ball.

Crude sal ammoniac...... $1 \mathrm{oz}$.

Nitre ............. 1 oz.

Soap $\ldots \ldots \ldots \ldots \ldots \ldots . . \ldots 4$ drams.

Camphor ...........2 2 drams.

Linseed oil and mucilage to form two balls. Rub down the camphor in the oil, and mix. Give one, morning and evening, for 3 or 4 days; or, if more convenient, give the fever powders, No. 1, or No. 2, at page 35 , until the urine is voided in good quantity and quality, but no longer. Let the restorative means, or nursing, before insisted upon (pages 34 and 47), be put in practice with all assiduity; for this second class of distemper bears near affinity to Inflammation of the Lungs, and to simple catarrh: and if not arrested in its progress, this class assumes the worst symptoms of the first or fatal. Do not rowel in either case.

10. A third species of epidemic attack is announced at once by sore throat, and inability to eat or drink, though evidently possessing a desire for both. Apply fomentations to the throat; but as the fever is not so high as in the former species, no draining of the system by bleeding, or otherwise, could do any good, the animal dwindling away to a skeleton without it. Employ the restora. tive means before recommended (page 34), give the distemper balls and powders until the urine is voided freely, and no longer; in aid whereof, commence with using the flexible tube, mentioned at page 37, daily; the liquid nourishment thus introduced to the system assuages the stomach, and prevents the disease from fixing itself there, besides running off the fever by means of the bowels. Let the nursing continue until the horse is completely restored to oats and hay diet, with the proper evacuations. If recovery appears attainable in a week, some hopes of ultimate success may be entertained; but if not conquered in that time, the distemper will triumph over our treatment. 
11. The fourth species of distemper is still milder than the preceding: the cough is slight, fever imperceptible, but a running from the nostrils comes on very similar to what we noticed in inflammatory fever. If you bleed under these circumstances, you instantly reduce the patient to the condition of the first class-the disease thereby strikes at the liver, and all is over. But should the nostrils present an uncommonly red appearance, the running matter being very acrid, then assist nature in getting rid of the offensive fluids, by rowelling the patient; and by giving the distemper balls and fever powders, with the view of carrying off the fluids by this means also, until that end be accomplished. Unless this treatment be adopted, the nasty nose will become glandered. See Chapter XI. Glanders, Section 5, and apply the steam of Venice turpentine, as there prescribed.

12. The fifth and last class of epidemic fever we shall have to notice comes on with a tumour on some fleshy part of the body. The animals thus attacked are already in low condition, or lean, in whom the vital heat is so little, that the tumour has no power to rise into inflammatory fever, but the blood of such patients is found devoid of serum, and flows languid and dull, as is also the whole appearance of the horse: his cough, too, is a weak one.

13. Low Fever is the term that has been applied to this and the fourth class of attacks, when happening in single cases, and not during the prevalence or influence (influenza) of an adverse season on many animals at the same time. Indeed, great inanition of the faculties and functions seems to mark the whole series of epidemic fever, with scarcely the exception of the second class, whence the term slow fever is applied, in the southern counties, to the slow circulation of the blood, that is the common type which marks the first, third, fourth, and fifth class of epidemy. Typhus fever, then, in the horse, is not ideal, as is supposed by some doctors ; even though we had not further evidence of the fever being a 
putrid fever, in the offensive nature of the fæces, the urine, and the perspiration; nor in its communicability to man as well as horse, nor in the state of the solids on dissection, and the liability of absorption incurred by one operator at least-that is to say, ourself.

As to the tumour, or boil, which denotes this fifth class, it is to be treated with the suppurative process, in the same manner as the critical tumour or abscess of the more ardent fever caused by inflammation, as described at pages 27,28 , whereby a complete radical cure is obtained at once, and renovation of strength will depend upon the nursing, so often mentioned.

14. William Osmer, by whose judicious discrimination of these symptoms, the world was first enlightened as to the treatment of epidemy, has the following remarks at page 111 of the new edition, lately printed, of his "Treatise on the Horse;" a large book, worthy the careful perusal of all who can find leisure for the task ; a man of whom our friend James White thought so so highly, that he founded the third and fourth volumes of his Works mainly on the horse-intelligence derived from Osmer-adding other matters theretu. "For the 5th class of distemper," says this celebrated original, " apply poultice of bread and milk, with lard, twice a day, until the matter fluctuates, when it may be opened. The practice of giving cordials in such languid cases might seem reasonable at first sight, but is, nevertheless, a mistaken notion; the circulation of the blood being incapable of so receiving an impulse to bring the tumour to maturity, fit for opening. Therefore, when the ripening has stood still for several days together, I have discontinued warming medicines, and adopted the distemper balls before prescribed (page 54), increasing the quantity of camphor, however, with a view of thinning the fluids, and curing the disease by the common secretory ducts. But, to my surprise, what has happened, but that the tumour, instead of resolving, has, upon the urinary secretion increasing, come to suppuration? Nay, more, I have 
known that bleeding (contrary to all expectation) has caused a tumour to come to suppuration, which before made no advances thereunto. By thus adapting my treatment to the various symptoms as they arose, I lost but few horses in the distemper; though, when this disease first made its appearance, and previously to making those distinctions (says the candid Osmer), I certainly did endanger the lives of many patients!"

The Cough Ball, proper to meet that symptom, is prescribed below, at page 60 ; one to be given each succes-sive morning for a week. But it often happens that this general symptom of catarrh (cough), whether epidemic, or not so, obstinately teazes the animal a great while; and, as long-continued use of the opium occasions costiveness, it must not be persisted in ; but this new symptom should be removed by a laxative, either the drench, (page 36), or the ball (page 46), according to the intensity of the obstruction.

\section{The Cough,}

However, still continues, long after all the more dangerous symptoms of catarrh have subsided: and, if we do not abate its violence, may last the horse a long time; whence it acquires the fine term-

15. CHRONIC Covgh, and brings about that affection of the throat, known as roaring, or else brokenwind. No specific for cough is yet known ; but this defect is compensated by the great number of prescriptions and simple remedies that supply the place of one; and, indeed, when we employ several of them in succession, they seem to aid each other in lowering the symptoms, so as to dispose the disorder to work itself off. Of these remedies, the emollient decoctions-1st of linseed, and $2 \mathrm{~d}$ of coltsfoot, given frequently during the day (hourly), in a vessel, from half a pint to a pint each time, are both goodly correctives of the tickling and soreness which catarrh leaves behind it. The admixture of honey, treacle, or sugar witil either of those decoctions is very 
desirable when the cough is dry and hectic; but, when soreness is still evinced, mix butter and coarse sugar intimately together, and give small balls, three or four times, at morning stables, fasting. Should viscidity seem to retard the mucus in the throat, give the following

\section{Cough Drench.}

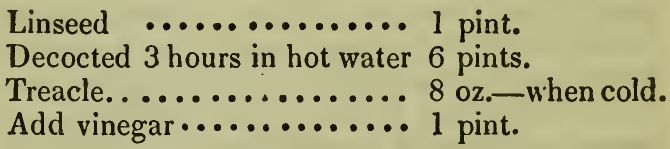

Mix ; give about half a pint three, four, or six times in the course of the day: here is quantity sufficient for half a week's consumption.

16. When the disorder induces weakness in coughing, an infusion of garlic with the linseed decoction gives relief; and if the obstruction be very great, as if he were choking, blistering the throat removes this cause of complaint.

No. 1.-Blistering Liniment:

Lyttæ, powdered ......... I dram.

Oil of turpentine ........2 drams.

Sweet oil ............. 1 oz._Mix well.

No. 2.-Blistering Ointment :

Lyttæ, powdered ........4 drams.

Oil of turpentine $\ldots \ldots \ldots \ldots . . .1 \mathrm{oz}$.

Hogs' lard ..........4 oz.-Mix well.

Besides the above, and those recommended in cases of the more severe attack (vide Inflammation of the Lungs, page 42 ), other remedies, adapted to particular symptoms, are at hand. For example, if constipation is apprehended, give the laxative drench (page 36), or the nild physic (page 46); if turbid urine, give the fever powders (page 35), or the distemper ball (page 54); but neither of those derangements is to be apprehended if 
hot bran mashes be given at night, when the head should be rubbed dry, and the eyes wiped out. If the glands of the jaw swell up, resembling strangles, or the eyes become watery, the frequent hot mash soothes both symptoms; the first should be further stimulated with the mild blistering liniment, whilst the ichorous discharge at the eyes will cease upon inserting a rowel under the jaw. Remember to give fresh air and walking exercise in warm clothing, as before ordered in the page just referred to. Relapse often takes place months after the cough has been subdued, and, in fact, at every change of the coat ; this has been defined as "PER IODICAL CoU GH," but I see no reason for seeking to make distinctions where none really exist, but in the frequent recurrence just adverted to. Somewhat of the same complexion is the next head of our inquiries, while the two succeeding affections of the lungs, viz. broken-wind and roaring, have been discoursed of in the books, as appears, more with an eye to disputed dealings in such cattle, than with any remote hope of effecting even a temporary cure. Let us not add to the number. Horses which have been long so afflicted, cough whenever they drink cold water; therefore should they have a small quantity of warm water mixed with it; or, better still, give little or none but bran mashes. The old cough, and symptoms of brokenwind, frequently subside by this treatment.

17. Chronic Cough has been adverted to as one of long continuance, proceeding from any of the preceding attacks, which have been partially cured only, no other symptom of catarrhal inflammation remaining but the cough. As said higher up (page 48), the original cough is occasioned by inflammation of the membrane that lines the nose and throat; a stoppage of the mucous secretion follows, which occasions cough; and this continuing a long time, a thickening of the membrane ensues, which causes constant irritation to cough, or that sonorous kind of breathing which is termed thickness of wind, or roaring. Cure there is none, when the disorder has been suf- 
fered to run on a long time unchecked; but considerable relief may be afforded by moderate treatment adapted to the attendant symptoms. Correct any obstruction of the evacuations : in case of costiveness, give a laxative ball (page 46); if the urine be turbid, or in small quantity, give the fever powders, No. 2 (page 36); if rough.. ness appears on the belly only, then worms are the cause, and give the remedies prescribed under that head. Frequent doses of tar water alleviate the irritation.

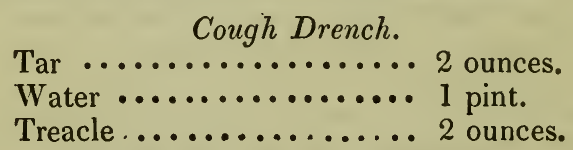

Mix ; and give this quantity 3 or 4 times a-day, or whenever the cough is troublesome. A blister to the throat, extending nearly from ear to ear, and along the whole line of the windpipe, is found efficacious when the irritation is ascertained to lie so high up. Try the following

\section{Cough Ball.}

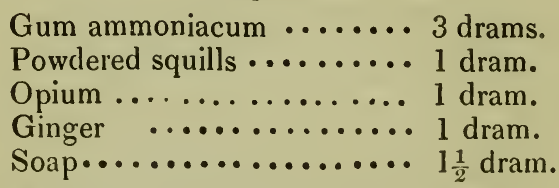

Mix, with syrup and linseed powder, enough to form the ball for one dose : give five or six mornings in succession. Do not give camphor with the opium, as Mr. White prescribed, this being one of the mistakes in practice which he had to correct.

18. But medical treatment is less required than a close attention to diet, most of these chronic patients being ravenous eaters; and to this cause we may sometimes trace the disorder. Many eat their litter and become cribbers, and drink immoderately when they can get at it; whilst too much hay and chaff diet will make any 
horse cough, as will ordinary oats with denial of water. On the other hand, the cooling diet before recommended (page 47), as carrots, lucerne, tares, always give relief. Let the horse be watered 3 or 4 times a-day, very moderately, and fed often, but sparingly. Eggs beat up with sugar give relief when the cough is a dry one; and if much pain, with apparent viscidity, is evinced, eggs in vinegar relieve it materially.

\section{BROKEN-WIND.}

1. Cough, of a dry husky nature, attends this last and incurable stage of catarrh in both its sub-divisions of simple broken-wind, and " thick in the wind ;" the former being the effect of a rupture of the air-cells of the lungs into each other, caused by brisk work upon a full stomach: the latter proceeds from the same causeover-exertion-acting upon the wide fat chest of the draft horse, invariably; whence that snorting and burly manner that characterises our finest London teams. Yet, all horses that lie by a while evince thick wind, in a small degree, upon first going out, owing to the accumulation of fat upon the lungs, that coagulates and clogs up the air-cells; and their bursting into each other (as said) literally causes broken-wind. How are we to remedy such defects - the one of nature and mistaken keep, the other of accident or maltreatment?

2. In like manner, high-bred horses, in high keep, always "put on flesh," as the training grooms term it, though unafflicted with " chest too wide," but the con. trary extreme of bad conformation, known as " too flat in the chest," and when taken out and put suddenly on strong work contract thick wind: the same injudicious exercise being continued, brings on rupture of the cells, and incurable broken-wind-roaring. The means of avoidance are thus distinctly marked out : feed oftener and in smaller quantities, and observe the same rule as to water. Compel no great exertion soon after feeding or watering him, but let his work begin at the lowest rate 
that he can go decently, increasing it gradually, if need be, up to the extent of his powers, but not until you have well worked the loose fat out of him; so shall you avoid contracting thick wind by sudden gallops, or converting this into broker-wind, by continuing it at too high a rate, or at too great lengths of ground.

3. A cure for absolute broken wind being hopeless, all we should reasonably undertake is the alleviation of the disorder. The craving for food observable in brokenwinded horses, points out this disposition as one cause of its continuance, if not of its origination; therefore, when the quantity given is necessarily reduced, add to its succulence by giving it of better quality, and observe a cooling diet. If violent coughing comes on occasionally, and the horse preserves his flesh, bleed moderately, give the laxative ball or drench, and follow this with branmashes: give also the cough ball at page 60 ; let the exercise be regular, and the air of the stable fresh and wholesome. Allow carrots, sliced and given from the hand, which will divert the horse from cribbing and eating his litter, to which such afflictions ever dispose him; also turnips, and well-sweated mangel-wurzel, two or three times a-week, but no more. Give neither vetches, clover, nor grass, since these contribute to internal fatness, that enemy to free respiration.

4. RoARING.-This is another of the evil effects of ill-treated catarrh, spoken of above; and being incurable, let us not occupy time, nor call attention to the niceties of its situation, nor to the law-suits of which it has always been the prolific source. For this, like those other affections of the organs of respiration, admits of considerable alleviation; so much so, in some cases, as to give a faint assurance (always deceitful) that the disorder has ceased. This temporary fallacy, however, has been achieved by good management-such as, if practised at an early period of catarrh, would have prevented roaring of any kind-viz. gentle exercise, augmented by slow degrees daily, until the groom finds how 
much the horse can possibly do without distress and consequent roaring. When a roarer has an unnatural bend of the neck (and windpipe), exercise him with the nose out, so as to restore the natural straightness, and the roaring will be reduced greatly. If blistering the throat has been previously employed, or at the commencement of the disorder, with proper attention to the bowels, and to reducing any feverish symptoms that may appear, by bleeding, \&c., many an useful animal might be preserved to us, though not to the full extent of his former powers -certainly not. Give the cough remedies at pages 58 and 60 , if you would lower the symptoms awhile.

5. Wheezing is occasioned by the inflammation and thickening of the membranous lining before noticed (page 48) having fixed itself low down the windpipe, where it divides into two branches, on of which conveys the air into each lobe of the lungs. Some old ones wheeze only after feeding and lying down, at each expiration of the air, most audibly; whereas the genuine roarer only roars in the wheezing manner after being put to his top pace. Give less hay, more corn; feed and water oftener; keep down feverish symptoms, and give occasionally the cough drench (page 58), and the ball (page 60), if required.

6. Piping is that stage of the disorder which consists of a strict contraction of the windpipe higher up than the preceding, whereby the air, rushing through a very confined space, is operated upon much after the fashion of a pipe or whistle. The cure is almost hopeless for aged horses, which generally get worse and worse in spite of any efforts we can make. Blistering the part appears to offer the likeliest means of assisting nature; and giving the drench just recommended (page 58) affords present relief.

7. A Whistler is near akin to the preceding, except as to situation, the contraction being now at the throat apple or glottis, that much-injured spot, where brutish dealers attempt " to cough" their new purchases. 
8. The high blower is one which has the like affection, but it is now situated in the head, or rather the membrane lining the cells of the nose. Very little of the disorder is perceivable in the stable, but upon going out, the state of the horse's respiration is pitiable: he snorts a rumbling noise from mouth and nose, froths, and rolls about as if he would tumble. 5 We know of no cure for either of these; but we do know that scarcely one of the horses so affected with chronic disorders of the lungs escape diseases (founder) of the fore feet. The bowels also are affected with flatulent expulsions, by the commotion so much snorting and blowing occasions in the depressions of the midriff.

9. Whatever the symptoms or degree of broken-wind, the disorder is always liable to assume virulent inflammatory appearances upon any extra work, that always leave the patient in a worse state than previous to this new attack. Sore throat, and sometimes suffocation, ensue: opening the windpipe is adopted in the latter event being apprehended. For confirmed sore throat (see page 48) the mustard embrocation and bran poultices are the ready remedies; though the means of keeping up these latter by means of an eight-sided piece of cloth is not well known, it ought to be acquired-consult bandaging, in chap. xvi. When dulness and refusal of water are the early symptoms, we may infer distemper: blister the parts, and bleed to the amount of 4 quarts.

[F Respiration is frequently much obstructed in severe affections of TuE sтомACH; so much so, at times, as to induce a belief that the lungs then suffer an original disorder: it goes off, however, as the following varied treatment is found to effect its object in each separate case.-See page 70 . 


\section{CHAPTER IV.}

Affections of the Stomach.

Inflammation, Poisons, Worms, Apoplexy, Staggers.

1. Although some persons believe that the horse's stomach is not susceptible of inflammation, yet is this no less the fact, as we have opened several, in which the disease was manifested in change of structure, in ulceration, and discoloration. If the objectors had said that inflammation of the small intestines, and of the stomach, were so nearly alike as to require no variation in the treatment, we might have consented to subscribe to their opinion. But however this be settled, the stomach, it is well known, partakes of every illness that affects the animal, as is evinced by the loss of appetite that attends all (even external) disorders : a wound, or a prick in the foot, communicating by a kind of fellow-feeling with the stomach; besides which, we constantly recognise refusal of food as the first symptom of a something being amiss with the animal, and carefully set about ascertaining what that something may be. In the foregoing observations on disorders of the lungs, I explained this point, and also in what manner taking an extra quantity of blood transferred the inflammation of that organ to the bowels by effusion; and have now further to add, that to diseased stomach alone is to be ascribed all disorders of the head (except $a$ cold) -as staggers, megrims, vertigo, epilepsy, and all spontaneous disorders of the eyes. Such is the fellow-feeling or companionship that exists 
between one organ and another, whereby this influence or transfer is carried on. Cértain veins, also, that are spread over the stomach, issue out of $i t$, and communicate with the liver and kidneys, by means of the great vena porta; whereby is effected that quick action of certain medicines upon these latter organs, and the almost immediate evidence of urine, which happens on taking any of the resins, nitre, or the prescriptions here ordered for effecting that salutary evacuation. (See these, at pages 35, 47,54 .) Aloetic purges sometimes go off in the same way, and thus defeat our hopes in this respect, but ought to excite no alarm when the quantity of staling is taken into account. Furthermore, I have shown (at page 53) that in one class of epidemic catarrh, whenever the disorder extended thence to the liver, it takes the afflicted animal off his hind legs, which is the sure precursor of death, without a remedy.

2. When inflammation attacks the stomach, it soon diffuses itself to the small intestines, and liver also; or, if those intestines be the original seat of disease, it frequently extends upwards to the stomach, the first symptoms of acute pain being distinctly appeased by this diffusion over a more extended surface. In the examination of horses, therefore, that have died of this disease, we seldom find the inflammation restricted to one particular organ : it more commonly happens, indeed, that the whole of the abdominal viscera exhibit a diseased appearance, though in different degrees, the original seat of the inflammation having suffered considerably more dilapidation than those lying remote; the kidneys, for example, which usually retain their healthy appearance amidst all the ruin that is going on (provided they were not heretofore injured), and secrete the urine to a desirable amount; thus seeming to invite us to effect a cure by administering diuretics, that are so well calculated to promote the discharge by cooling means-as nitre, carrots, oatmeal gruel, and resinous substances.

3 . The external coats of the stomach, which are con- 
nected together by membranous tissues, is that portion of which we have just been speaking-membrane being alone susceptible of feverish affections; but inflammation of the internal surface (also connected to the former by membrane) sometimes takes place, in consequence of improper substances-poisons, bad food, or cold water, being taken into it, as well as the worms which adhere to and penetrate the otherwise insensible or velvet-like portion thereof. Leaves of the yew-tree have been frequently found destructive of cattle ; and some low vegetables, growing in swampy places, are obnoxious to the horse kind, and are generally left untouched, unless the appetite is depraved by cribbing or otherwise. Mares in foal take the leaves of yew with avidity, and die of sleepiness, unless attended to speedily. In such cases, give the

\section{Anti-Poison Ball.}

Farina of croton nut ..... 10 grains, with Meal and mucilage to form the ball.

Wash it down with small drenches of oatmeal gruel (warm), and vinegar, equal parts: repeat the drench frequently. In six hours repeat the ball, unless its restorative effects are previously visible. But, for reasons already assigned (page 37), the efficacy of the croton on the stomach will be greatly enhanced if given in the liquid form - the drench very small. The same instrument, the stomach-pump apparatus, may be used in subtracting the yew-leaves, or those poisonous substances undermentioned.- See the pump described in Chapter XVI.

Arsenic is dangerous as a medicinal tonic in vulgar hands, and liable to be mischievously employed, if not maliciously. Would the injured owner wish to ascertain the latter fact, he will find, on examination, the stomach and small intestines very much inflamed : let a portion of the contents thereof be cast upon the fire, and a smell like that of garlic will be given out if arsenic be present. 
Hemlock, notwithstanding its bad name, is eaten with impunity by working horses, though cows have been poisoned with it often. Water parsley, when eaten in quantities, operates after the manner of yew-leaves, and is to be counteracted by the same means. In like manner is dropwort generally refused, though brood mares, and horses having vitiated appetites, take it with the same evil effects. The anti-poison ball, with plenty of the drench, is the only curative known: if fever supervene, and the animal is tolerably conditioned, bleed moderately.

4. The symptoms of poisoning, in addition to sleepiness, are small weak pulse, the extremities cold, the appearance dejected; respiration disturbed, unequal; an alarming prostration of the animal powers - and death : sometimes there will be a cough, whether the poison be vegetable or mineral. When the strychnos nux $V ., 1$ dram, has been employed, locked jaw closes the scene in 2 or 3 hours, if not preceded by delirium, torpor, convulsions, tremblings-death. The general treatment is to give mucilaginous drenches, or oil freely, as decoction of linseed, and gum arabic dissolved in water, with sulphuret of potass, in 4-dram drenches. Clysters of oatmeal gruel, warm, soothe the inflamed gut; and if the disease is attended by purgation, use the linseed decoction and wheat-flour gruel for this purpose. By persevering herein, I have succeeded in 4 cases out of 5recently-incurred cases. But the whole practice just laid down has been superseded, successfully, by the use of the stomach-pump, mentioned just above, and more fully described in Chapter XVI.

5. Botts are that species of worms which invade the stomach, and are mostly found in agricultural horses; always on that velvet-like portion of it which is insensible to hard substances, and therefore they cannot ordinarily inflict so much mischief as hath been too vividly ascribed to them. Mr. White, we have reason to know, several years before his decease, corrected his early notions 
respecting the prevalence of this disease, agreeing that many symptoms attributed by him to "worms," might arise, for the most part, from other causes-as a cold, and consequent collapsion of the perspirable vessels, from organic diseases, indigestion, concretions, \&c. Notwithstanding this candid avowal, neither he nor any one else agrees with Bracy Clark, that they were designed by the great Author of all to act upon the food by trituration, or as pepper does in the human stomach! The inflammation which botts produce in the stomach is indicated by symptoms somewhat different from those just described ; indeed, the effect may more properly be considered as ulceration of the stomach than inflammation, since, upon examining horses that have died with this complaint upon them, I have always found ulcers of considerable extent in the muscular coat. The symptoms of this disease generally come on gradually: the horse becomes hide-bound, has a rough unhealthy coat, loses flesh and strength, though feeding heartily, and has frequent tickling cough; still the symptoms are usually disregarded, and the proper remedies neglected, until the botts have penetrated deeply. In some instances, it is true, these insects detach themselves, and falling upon the digestible portion of the stomach, are passed off with the dung. In such cases, if the stomach has not been much injured by them, the horse gradually recovers, and assumes a gayer coat, for this passing off usually happens in summer. Sometimes, however, the botts seize hold of the sensible portion, whereupon the ulceration is so considerable as to throw the whole system into disorder; for the lungs, which are particularly disposed to sympathise with the stomach, as was observed higher up (pages 40 , 43,66 ), become highly excited in consequence. The inflammation that is thus inflicted on the lungs is extremely obstinate; the midriff and lining of the chest partaking of the evil effects, often baffle our endeavours, for we do not in general judge rightly of the cause, and so do not remove it. 
This sympathetic inflammation of the lungs, which has been derived from the sufferings of the stomach, and which often terninates disastrously, may be known from the original inflammation before treated of (page 42-49) by an occasional cough coming on after feeding, by rough coat first appearing on the belly and flanks, whereas the rough coat that attends the or:ginal disease begins on the chest. This, also, is one of the series of cases in which bleeding for diseased lungs does no good; but, on the contrary, bereaves the patient of what little strength remains; and although it does not kill, reduces his flesh, and his rank as a horse, irrecoverably.

One additional observation here may not be deemed inapt to our purpose; whenever the lungs are afflicted greatly with catarrhal inflammation, and any other viscus is labouring under functional derangement of any kind at the same time, the danger is great, bleeding destructive. Such is the case in three out of the five cases into which epidemic fever divides itself (according to Osmer), the liver being then the sympathetic sufferer. We sometimes hear this influence of one organ upon another called companionship, fellow-feeling, and mutual sensibility; but all are applied and received as meaning the same thing as is just described, and was before adverted to at pages 40 and 65 .

6 . Upon the subsidence of any inflammatory complaint, whatever organ may have been the seat of attack, the stomach returns to its former healthy tone with protracted difficulty; so that emaciation continues to threaten us with relapse, and too often does occur fatally. In such cases, as constituting an essential point in the oft-recommended ' restorative process,' or nursing, the approved custom has been to give tonics, although their efficacy was not uniform, and by Bracy Clark is flatly denied. But such failures arise from practitioners not sufficiently preparing the bowels beforehand by purge or laxatives, and furthermore by the hard balls, in which tonics are compounded, descending 
out of the stomach before they can possibly dissolve, and communicate therr good effects where alone they could be of any service. And this would be the case, notwithstanding they might be compounded of materials well disposed to dissolve without delay - as was the case with most of White's prescriptions of tonic balls. Nevertheless, I prefer tonics intended to act immediately upon the stomach should be administered in the liquid form; and as they are usually compounded of bitter ingredients, give them by means of the tube described at page 37. Of this class of restoratives is the

\section{Stomachic Laxative.}

Barbadoes aloes ................2 drams.

Rhubarb, ginger, and cinchina, of each 1 dram.

Carbonate of soda $\ldots \ldots \ldots \ldots \ldots \ldots \ldots 2$ drams.

Strong extract of camomile ......... 1 pint.

Mix, and give the same four or five succeeding days.

7. Worms of three kinds are found in the horse: the most frequent, and that which occasions the greatest havoc, has just been spoken of, as residing in the stomach. Indeed, ' the bott question' has caused a good deal of learned disquisition, more than it deserved, and is unworthy of a place here. 1st. The bott is of a reddish colour, seldom exceeding three-fourths of an inch whilst in the stomach, for when it increases in size, it seems to detach itself, and comes off nearly half as much longer, and big withal. At one extremity it is furnished with two small hooks, by which it is found attached to the insensible coat generally, and then does not seem to cause any considerable uneasiness. It is astonishing with what force these worms adhere, and how tenacious they are of life: they have been known to resist the strongest poisons, nor have we yet discovered any medicine capable of destroying them ; whilst the strong purgatives given with the hope of carrying them off, have been hitherto addressed to the bowels only-causing them to stick faster to the unmoved coat of the stomach. 
The 2nd species of worm inhabits the large guts-ccecum and colon, evidently engendered in bad provender, and crudities remaining therein long undigested; which teaches the necessity of emptying the bowels occasionally, with balls composed of bitter, and therefore anthelmintic materials, as below. This worm is very slender, of a blackish colour, and reaches two inches in length, seldom more. It causes great irritation, loss of condition, and staring coat about the belly. After a while frequent fits of coughing are observable, of a deeper and more cavernous tone than the catarrhal cough. The 3rd kind is a whitish flat slender worm, frequently 7 or 8 inches in length, and is generally found in the lower part of the small intestines. This kind is not so frequent as either of the preceding, and appears to be much the same as the second, but differing in size and colour, principally by reason of the nutritious chyme in the midst of which they exist.

8. Worms of all three kinds are sometimes destroyed and issued forth in spring, by the horse taking grasses of an anthelmintic nature (i. e. bitter), that thus occasion slight purgation. We may always be assured of the existence of worms, when a whitish or straw-coloured powder is observable immediately beneath the anus. When the fact is thus demonstrated, keep the horse in the same pasture that has produced it to the end of the month-after which the same herbs change their quality and powers by ripening, flowering, seeding, \&c. The remedies proposed for worms are numerous: savin, rue, box, Æthiop's mineral, antimony, sulphur, emetic tartar, calomel, and vitriolated quicksilver, have each its advocates: when costiveness prevails, the two last, if given with the aloetic ball, at page 46 , so as to purge briskly, particularly the calomel $\frac{1}{2} \mathrm{dram}$, are excellent remedies; but given merely as alteratives, they effect no visible good. I have generally found the following ball very effectual, giving the preceding night calomel from $\frac{1}{2}$ dram to 1 dram. 


\section{Purgative Worm Medicine.}

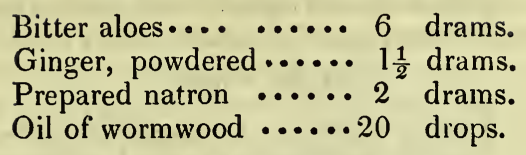

Mix with syrup enough to form the ball for one dose; unless the means are at hand (i.e. the drenching tube, page 37) of giving the same in the liquid form. Do not give the calomel on the same day as the purgative, least of all along with it, as commonly practised. Neither is the practice of preparing the bowels by bran mashes at all consonant to the effects hoped for from this prescription. An interval of a week at least should elapse if repetition of this worm medicine is deemed necessary. The above ball divided into two, and given on successive days, is better adapted to horses with weak insides, long bodied, reedy, and easily moved : for such, frequent small doses, given four mornings following, often succeed in bringing away the worms, when the more drastic medicines have failed.

Alterative Worm Balls.

Common aloes $\ldots \ldots \ldots \cdots 1 \frac{1}{2}$ drams.

Soap...$\cdots \cdots \cdots \cdots \cdot$ l dram.

Savin, the leaves powdered, 1 dram.

Mix with syrup enough to form the ball, and give daily 4 or 5 times; unless the drenching tube is at hand, and then it is preferable in the liquid form. In this case omit the soap, this being a mere vehicle for making up the ball. Box or rue may be substituted for the savin at pleasure, and with advantage, sometimes, the mere alteration being well calculated to meet any peculiarity in the individual's constitution.

9. The 2nd kind, or small dark worm, (as well as botts) sometimes descend to the straight gut in large quantities, occasioning much uneasiness in the horse, as is exhibited. 
in his manner. Inject by the clyster-pipe a solution of aloes, 6 drams in 2 quarts of warm water. Linseed oil effects the same end, and equally well, destroying the intruders at the lower gut with much facility: rake the gut. Ball for Worms.

Emetic tartar ......2 2 drams.

Ginger, powdered...... 1 dram.

Mix with meal and syrup to form 1 dose, to be given in the morning before feeding, for a week or 10 days, though its effects would be more efficaciously employed against the botts if given in the liquid form.

\section{Apoplexy, Staggers, Epilepsy.}

1. Many advantages attend this classification of diseases under their causes, and their respective seats; as the inquirer is thus induced to pay attention to any derangement at its commencement, and while the byestanders would give to the varied attack several different names, we still adhere to the right course of applying the remedies to the single cause of all. ' Stomach staggers' was the term White thought most felicitous, after fluctuating years in deciding; thus acknowledging, that in the stomach alone resided the cause of that one symptom which denotes the whole series of attack, namely, falling down. Of these, apoplexy, or dropping down suddenly, breathless - though an in ward noise is heard, and the heart continues in motion, generally terminates in death, the veins of the neck being found filled with blood. Megrims, which likewise consist in dropping down, are of longer continuance, and never prove fatal. Both owe their origin to ill-cured disorders of the stomach, re-acting upon the nerves; whilst the apoplectic sufferer has, in addition, a determination of blood to the head, and pressure, if not extravasation thereof on the brain. The less immediate cause of such falling fits is found in the closing up of the lower orifice of the stomach, or else stoppage of the bile that enters the gut near it; whence the yellowness 
in the eyes that is observable in staggers, whether mad or sleepy, or simply the stomach staggers; fulness of the stomach from over-feeding, or taking indigestible food; or torpor of the stomach itself, causing pressure upon the bile-duct, being common to, all three species of staggers. Epilepsy is the general name for all such falling fits as attack suddenly ; though it must be allowed, that previous indications of the disorder coming on may of ten be detected by the patient observer of the following symptomatic symptoms.

2. Before the attack the horse seems drowsy, the eyes issue tears, the appetite is diminished, the pulse seldom much altered, unless he is of full habit, and the mad staggers are coming on, when the beats increase: but if, on the contrary, the sleepy staggers come on, it is previously evinced by a languid pulse : costiveness and a deficient secretion of urine accompany those other symptoms, with belly distended, and breathing somewhat troubled. But mad staggers often attack the horse suddenly, as it were, without those previous indications being noticed, until too late to be of any service. The stomach staggers simply consists of a stomach so distended with food, as to be rendered incapable of carrying it off; when the air that constantly disengages itself from the mass ascends to the head, and causes vertigo, or giddiness.

3. Bleeding in all cases, and emptying the stomach in these latter, is obviously the sole proper treatment ; particularly in mad staggers is bleeding necessary, though then very difficult to perform; whilst mere falling down through vertigo, with occasional plunging, is soon relieved by back raking, and giving the laxative draught, although we may not find such a fulness of blood as might warrant us in drawing off so much as two quarts. But when the stomach cannot thus be relieved of its load, the debilitated powers must be roused by stimulants, as under, and the food softened by liquids, as salted water in small quantities, or thin gruel made salt. Inject a gallon clyster of the gruel, warm, and repeat the laxative 
draught : after partial recovery, a disposition to costiveness returns, which must be amended by the same draught, or the Purgative Ball, at page 73, divided.

\section{Laxative Draught.}

Barbadoes aloes $\ldots \ldots 2$ drams.

Castile soap .........1 dram.

Common salt $\ldots \ldots \ldots 4$ oz.

Water........... I pint-mix.

Stimulating Draughts.

No. 1.-Fœtid spirit of ammonia..I oz.

Camphor............. dram.

Mint water .......... 1 pint-mix.

No. 2.-Spirit of hartshorn $\ldots \ldots .1$ oz.

Powdered valerian.. .66 drams.

Mint water.......... 1 pint-mix.

4. If the disposition to sleep returns, or is not removed by the bleeding and laxative, insert a rowel under the jaw, or blister the head high up on the jaws. The idea that the staggers are contagious must be reckoned among the mistaken notions; arising, probably, from some hardworked teams, with bad food, irregularly served, being found all in the same condition at times. Although this whole series of disorders be properly attributed to an affection of the brain, yet do we find, upon dissection, the generality of cases afford no further appearance of disease than a distension of the larger ventricles with a fluid as limpid as water; excepting always in sudden death, when the blood-vessels are found to have discharged their contents on the brain.

5. Blown animals, with no other previous indisposition, are carried off in the way just described. When the stomach is gorged with food, whether from its being taken suddenly, or from its remaining undigested, and the operation commonly performed on cows cannot be employed on the horse, all other remedies may be superseded by the use of the "Stomach Pump," as in the case of poisons 
(page 67), and recommended at page 73. Moreover, when much filled, and torpor affects the stomach, as observed above, it refuses to be acted upon by the stimulating draught, or the laxatives just prescribed, and no other means of cure can be adopted but this newlyinvented instrument.-See it described in Chapter XVI.

6 . Here the observation shall not be thrown away, that has been insisted upon pretty much at large in another place, viz. that all those disorders of the stomach which originate there, and communicate such astonishing effects to the head, may be obviated from the first by paying more attention to the manner of feeding than is generally bestowed upon this department of stable economy. The same quantity of nutriment, given at shorter intervals and regularly, doing more to keep the stomach in order, and to restore its lost tone after fever, than the whole Materia Medica put together. Change of food, no matter of what nature, is another powerful aid to restore healthy action of the stomach.

QS This whole subject of stable management has received, as it deserved, very extended attention in the Conversations on Conditioning, published by us in 1828 and 1830, and entitled The Grooms' Orache, or Pocket Stable Directory. 


\section{CHAPTER V.}

Diseases of tue Bowels:-Inflammation, Colic, or Gripes.

1. "Colic pains" is the first announcement by which we hear of any acute disease of the belly, whereever it may be situated, or whatever the symptoms; whereas no mistake can be so full of danger to the life of the patient, as exhibiting the medicines that cure the colic, when the real attack is inflammatory. We shall shortly draw attention to the symptoms that distinguish the one from the other; mean time, one leading fact must be kept in mind, namely, that flatulent colic, which does not go off by stool in a reasonable time, followed by a remission of the pain, ends in inflammation of the bowels; whilst we find, that an imperfectly-cured inflammation of those irritable membranes, inflicts an injury that disposes them to contract " colic pains" during life, upon every slight occasion of taking cold. Working horses, which fall ill from being much exposed to hard weather, contract the genuine colic, or fret, without inflammation, provided the dunging be in tolerably right trim; for such cattle a warm gruel drench, with 2 ounces of oil of turpentine, affords almost immediate relief: give plain gruel in plenty afterwards, lukewarm. When this "taking cold," which consists in a collapsion of the perspirable vessels, is severe, inflammation ensues at once; the same effect is produced when horses, which may have lain out at grass, in camp, or journeying, are brought suddenly into warm stables - a fact this, that is not sufficiently attended to by people in general. 
2. Symptomatic fever (see page 38) indicates the existence of inflammation, from whatever source it may arise; which may also owe its origin to the change of form noticed higher up (pages 30,42), as adhesion of one organ to another: thus do the large gut and the liver adhere, and after committing a few days' ravage, cures itself by a natural process, viz. sloughing off, and coming a way by stool. Stones, and large lumps of earth in the intestines, cause the well-recognised colic pains, and these are sometimes greatly relieved by the same natural means ; but we cannot always know when these are really present, and causing the mischief, whereby the remedies are usually carried to extremes, and the disorder too: inflammation is also known to supervene sometimes, through the great pressure those extraneous bodies necessarily occasion.

Entanglement of the bowels is another cause of the inflammatory symptoms in a distressing and hopeless degree : there is no remedy for " the dry gripes," as we hear this fatal affliction vulgarly termed, whether arising from simple entanglement, or from a tumour forming on the small gut, and hanging pendent by a cord, which causes strangulation of a knot of the colon, and consequent inflammation, gangrene, and death. This is another of the evil consequences of careless or mistaken stable management, alluded to at a preceding page (77) in terms of admonition.-See page 30, where the subject of Inflammation is treated of, generally ; and this, which arises from change of form, is described particularly. 
The symptoms by which the genuine Spasmodic colic is known.

1. Pulse, natural or lower, though a little quickened during the paroxysms of pain, and fuller.

2. Sudden in its attack, but without fever.

3. Lies down and rolls upon his back, as if relieved thereby.

4. Legs and ears of their natural warmth.

5. Relief is afforded by rubbing the belly, flathanded.

6. Intervals of rest.

7. Relief obtained from walking about.

8. Strength scarcely affected.

9. Lining of the nostrils natural.

10. Inner lining of the eyelid natural.

11. Motion of the guts little; unless when purgation comes on.

In both cases the afflicted horse paws the ground with his fore feet; but when the pain proceeds from entanglement of the gut, he does not so paw the ground.
INFLAMMATION of the Bowels has these contradistinguishing symptoms.

1. Pulse much quickened, but small, and scarcely distinct.

2. Gradual in its approach, with previous symptomatic fever.

3. Lies down; but suddenly jumps up again, seldom rolling on his back.

4. Legs and ears generally cold.

5. Belly exceedingly tender, and painful to the touch.

6. Constant pain.

7. Motion evidently increases pain.

8. Rapid and marked prostration of strength.

9. Great redness within the nostrils.

10. Lining of the eyelids very red.

11. Peristaltic motion excited: anus hot. 
3. Careful attention to these symptoms will enable any one of common perception to detect inflammation of the intestines at its earliest stages; and, as it generally attacks the better bred and high-conditioned horses, we presume assistance would be given with the promptness which the urgency of the case demands. Take blood at once, to the amount of four, five, or six quarts, from a large orifice [See page 50]; let the purgative that follows be a mild one, even though costiveness prevails, and though we may reasonably deduce the disorder from that origin. If this be so, give the laxative drench (page 36), and repeat it in 8 hours. Meantime, soften the bowels with clysters of warm water, or thin oatmeal gruel, with a solution of Epsom salts, $\frac{1}{2} \mathrm{lb}$., or table salt lib. Repeat the clysters assiduously; and let each be largely administered, whereby the seat of constipation is soothed, and the cause of the disease is thus drawn off. Often, very often, the attack originates in costiveness alone; procuring a complete evacuation of the straight gut constituting the cure : in this case back raking is found very useful. But when the inflammatory symptoms do not abate by these means, recourse must be had to other remedies. Thereupon, blister the whole of the belly: (see page 58 for blister). Sheep-skins, newly stripped off, and placed over the sides and loins, possess the same property of drawing the extra heat from the interior to the exterior.

4. Bandage the legs, with a view to restore the circulation in them, and to lessen the flow of blood to the inflamed part. Clothe with breast-piece and hood, warm, but the body-cloth light, thin, and loose. Attend to the nursing, as before insisted upon, in the cases of inflamed lungs (pages 34 and 47). Give fresh air, and a walk out daily; and, when the recovering patient can bear it, the run of a paddock, or homestead, during the more moderate part of the day. Adopt soft food, as bran mashes, stout gruel, green food, carrots, mangel wurzel, (a little, well sweated) turnips, but no corn until he will eat a double handful with avidity. Return to full feed 
and to hay with great caution: look to the main evacuation many days after all the feverish symptoms subside, and give a clyster when aught is amiss.

5. Scouring. But, instead of costiveness, a looseness, with febrile symptoms, sometimes attends an inflammation of the bowels, though by no means so dangerous as the former ; the purgation, if not too violent, carrying off the disorder. This feature of the disease is commonly produced by the improper use of physic, in quality or quantity, or by neglecting the horse during the operation of any purgative medicine, however proper or well-timed this may be in itself. Great pain is evinced; the patient frequently looks round at his flanks; his breathing is laborious, the pulse quick and small, the mouth hot; but the ears or legs not so cold as in the preceding or constipated feature of inflamed bowels. When the looseness can be traced to green food, those symptoms are scarcely perceptible at first, and it should not be restrained, but encouraged by mashes, then gruel and the like: put on warm body clothing; give nothing cold. In these cases bleeding does harm; for the fever scarcely ever runs high enough to warrant such a drain.

6. If the extra purgation continues more than half the day, and does not abate in violence, then should measures be taken to put a stop to it. Give the arrow-root, wheat-flour gruel, or linseed tea, with the following

Scouring Drench.

No. I.-Chalk powdered....10 oz.

Catechu ........2 drams.

Opium...$\ldots 22$ scruples.

Mix in the gruel, and give every six hours while the purgation lasts; when these ingredients should be diminished and gradually discontinued. The following is better adapted to a cold constitution; to be given at the same intervals : 
No. 2.-Opium ............... 1 dram.

Chalk, powdered.......... 4 drams.

Compound tincture of tragacanth $10 \mathrm{oz}$.

Mint water.............. 1 pint, mix.

Apply fresh sheep-skins to the sides, hot; and employ the mustard embrocation extensively. If the purgation still continues, give the anodyne draught; and administer the opium in a clyster of wheat-flour gruel.

Anodyne Draught.

Opium ............1 $1 \frac{1}{2}$ dram.

Water gruel...........2 pints-Mix.

Mustard Embrocation.

Camphor.............. oz.

Flour of mustard........8 oz.

Oil of turpentine........2 oz.

Water of pure ammonia $\cdots 2 \mathrm{oz}$.

Mix into a thin paste, and rub for a considerable time on the belly, extensively.

7. It sometimes happens, when a horse has taken purging physic, that gripes and violent sickness occur before the medicine comes off. In this case, a plentiful exhibition of thin water-gruel, warm, with clysters of the same, fail not to procure the desired evacuation, and relief from pain. If the patient, in consequence of the excessive purgation that sometimes ensues the foregoing treatment, is tucked up, with the hind legs dragged under his body, he will require nourishing and nursing: a handful of crushed beans, some excellent oats, a small and good malt mash, are goodly restoratives of his lost vigour. Sometimes a scouring takes place, accompanied by the yellows; but as this latter symptom proves that disordered liver is then the cause of scouring, the reader must then consult what is said farther down, (pages $88-94$ ), regarding the liver, when calomel is proper after the main feature, yellowness, has been reduced. 
8. Molten Grease is not strictly an original disease, but is derived from another, namely, inflammation of the lungs, of no great violence indeed, but therefore more assuredly transferred to the bowels, and that always of a fat subject. The slimy appearance thus produced among the dung has procured for this disorder its very vulgar name. To overmuch exercise, suddenly undertaken, of a well-fed horse, is justly attributed the feverish symptoms and inflammatory action of the whole system of blood-vessels that attend molten grease. Notwithstanding the fine learning which was at one time thrown away upon this topic, by White and others, with a little acerbity to boot, certain it is that the afflicted horse loses flesh every day of its continuance; the superabundant fat, which first caused the disorder, literally coming away with the dung. Since the decease of White, indeed, we have seen proofs of the fact ; vessels forming themselves in the midst of great bodies of fat (on the kidneys, \&c.) expressly calculated for carrying it off by means of the circulation. In addition, the means employed to reduce the inflammatory symptoms conduce to the same end, by putting in practice all the drains we are masters of. Of these, bleeding is the most obvious; to be followed by repeated purgations (never over strong) adapted to the state of the bowels, which are usually costive, requiring such a ball as is prescribed at page 46 ; but if the dung be uncommonly hard, give castor oil 1 pint, previous to the operation, and follow it, in this case, by preferring to give the laxative drench, at page 76, before any other.

9 . On the contrary, should a looseness prevail, give arrow-root, wheat-flour gruel, linseed tea, and follow the whole routine of treatment prescribed for inflammation of the bowels, with that feature of looseness described at page 82 , under the old term " Scouring." Once bleeding is sufficient in the constipated cases, but if the lungs be still inflamed as well as the bowels, the reader who has attended to what was said higher up (page 55), as to two of the organs of life being attacked at the same time, 
(the lungs being one) he need not be told of the great danger that is now to be apprehended. Bleed again, to an amount agreeable to the urgency of the inflammatory symptoms, and employ all the means of recovery before recommended (pages 34 and 81), with the nursing, air, and exercise, so as to ensure a complete recovery, and avoid the much-dreaded relapse.

\section{Colic, Gripes, or Fret.}

1. Spasmodic affections of the bowels so much resemble inflammation thereof, that some dangerous mistakes are daily made in treating the one for the other, by giving stimulants in cases of inflammation, when the direct contrary practice (sedative) is then required. This grave error may be avoided in great measure by paying attention to the foregoing observations on the distinguishing characteristics of these two disorders of the intestines, at pages 78-82, especially the " table of symptoms" that marks the more minute variances in parallel lines. In addition to the symptoms of the genuine colic there described, we may remark, that its origin is commonly a cold in the bowels, acting upon the nerves, which occasions certain portions thereof, viz. several inches of the large gut, to contract upon its contents ; whence the suddenness of the attack noted in the Table (No. 2), and the relief that friction on the belly affords (No. 5), as well as that derived from walking about (No. 7), whereby the nervous affection is alleviated, and temporary intervals of ease are obtained, as noticed in the Table (No.6). All which symptoms are so totally at variance with those set down in the parallel Nos. as characterising the more fearful inflammation, that any misapprehension herein should be held unpardonable in the commonest helper of the stable. Upon revising the great number of such cases, in which the lives of valuable horses have been sacrificed to inattention on the part of the attendants, one is led instinctively 
to lament that the grourd-ash exercise has been neglected, or misapplied, in their bringing up.

2 . Like the molten grease affection, we find colic occasionally attended with costiveness, but more frequently by flatulent purgation, if distension of the gut be not always the true origin of the spasms; and intervals of relaxation therefrom bringing on a looseness without any other symptom, this may be considered as the natural termination of the attack; our business is then to assist its working off by mashes and clysters of warm water or plain gruel. On the contrary, fever, however slight, with an unquiet indication of pain, evinced by his looking at his flanks, prove that costiveness is then the true cause of the spasmodic colic, which soon begins to rage within, the horse pawing, striking at his belly, and looking wildly at his flanks, alternately. If not arrested in its progress, these outrages increase in violence, when his glassy eyes, hot mouth, and cold ears and legs, tell us plainly that inflammation has begun; [See page 78$82]$, and we must then change our whole course of treatment according to this change of symptoms, as before recommended. Upon the first symptom of pain without looseness, give the laxative drench, at page 36 , and repeat in 4 hours, so as to procure a good stool ; an operation that may be facilitated, excellently, by adding to the first drench castor oil half a pint, or salad oil one pint, and in ordinary cases little more is required than giving the sedatives, as under. But, when the paroxysms come on violently, bleeding is indispensable in the very first instance-some practitioners do not wait even for this, but bleed for all colic that is without purgation, and with it, too, provided the pains do not yield to the sedatives within an hour. Give copious clysters of salted gruel, after drawing forth the dung, if any be in the straight gut that is hardened, not otherwise; and in that case, having thus arrived at a certain knowledge of the true cause of the spasms, the purging ball, at page 46 , should follow any other remedies we may have adopted: 
continue the clystering. The dry gripes is the term that usually distinguishes this kind from that which commences with purging. See also " entanglement" of the gut, page 79.

3. Flatulent colic is so termed from the windy nature of the complaint ; but the treatment in both cases is the same, with the single exception of laxatives, which are obviously rendered unnecessary by this natural result. When the natural purgation is great, give the Scouring Drench, No. 1 or No. 2, and consult the whole article on Scouring, at page 82. Give sedatives, viz.

\section{Colic Drench.}

No. 1.-Strasburg turpentine....3 oz.

Tincture of opium $\cdots \cdots 1$ oz.

Ale, warmed $\ldots \ldots \ldots 1 \frac{1}{2}$ pints.

Water gruel, warm.... 2 pints-Mix

for one strong drink, to be given between the paroxysms of pain, as part of it is commonly spilled; or it may be given at twice, or 3 times with advantage. Most practitioners prefer the oil of turpentine, which is quite as efficacious as the above, but its hanging about the lips of the patient annoys the horse extremely. If the relief obtained be partial only, the repetition of half the drink is advisable; or give instead,

No. 2.-Tincture of opium .... $1 \mathrm{oz}$.

Oil of juniper....... 1 dram.

Oatmeal gruel, warm .. 1 pint-Mix.

4. General Observations. As prompt relief in all cases of spasmodic colic obviates the risk of its becoming inflammatory by continuance, and the aforementioned materials may not be at hand upon all occasions, warm ale may be given, of good quality; if not, a glass of brandy, or two of gin may be added, as may powdered ginger, two drams; but spirits are far from desirable, and the "gin and pepper" dose of the old H 2 
farriers still less so. When the patient perspires freely, this evacuation should be encouraged, the sweat scraped and wiped off, and the clothing changed; and when walking or trotting exercise can be adopted, a draught of wind should be avoided, as should also cold water. Warm bedding is desirable; and a profusion of straw from the first, for the horse to tumble upon and roll in, prevents injuries.

Q A A fter hard work, or a long run, horses of tolerable breeding refuse food, and fall off in condition rapidly, if they do not droop at once. This is not invariably an attack upon the bowels, as is usually supposed, and mistakenly treated as such, but of THE LIVER; or rather, its spleen increaseth very much in size, whilst the lobes of the liver shrink in proportion, and in some cases decay entirely. To ascertain this fact of enlargement of the spleen, an examination of the straight gut is to be set about by introducing the whole arm carefully, when the state of the spleen can be felt, if enlarged, by its lowermost angle distinctly reaching the pelvic cavity. We are just now apprised of cases in which horses so attacked have died with the spleen, weighing 12,15 , and 20 pounds respectively. Before this disorder has carried on its ravages to such an extent, the exhioition of calomel, 1 dram per day for a week, adapted to circumstances, according to the modes prescribed at page 93 , invariably brings about the healthy action of the liver, and a reduction of the spleen, so that it can no longer be felt to press upon the upper extremity of the straight gut. 


\section{CHAP'TER VI.}

Liver Complaints-Inflammation, Jaundice, Rupture, Ulceration, Cholera.

1. Fever is symptomatic of every evil affection of the liver, and of these yellowness is the most obvious; hence "the yellows" has been used to designate any derangement of the functions of the liver, which causes obstruction of the bile, and occasions its being taken up again into the circulation. [Old Snape calls it choler repeatedly, at page 31, in his "Anatomy of a Horse," folio, 1683 ; a work which we may venture to assert will never be excelled.] This is discovered by the eyes appearing of a dusky yellow colour; the mouth, lips, and saliva also acquiring a yellowish tinge; the animal refuses his food, is dull and sluggish; his urine is of a dark brown colour, and when lodged on the ground appears blood red. The further consequence of the bile being prevented from entering the gut is, that costiveness prevails for lack of that stimulus to the expulsion of its contents; whilst the little dung that may come away is hard, and resembles yellowish or greenish clay; the pulse is irregular in the beats, though not in general much accelerated: in this latter respect, and the yellow discolorations, we run no risk of confounding molten grease with this disorder of the liver. If those symptoms be not reduced by judicious medical treatment, death ensues by the enlargement of the substance of the liver, and rupture thereof; though this misfortune sometimes happens without any previous warning, with fleshy working horses in particular, which may have suffered from any previous inflammatory affecH 3 
tion whatever. Death from this cause is known by the animal struggling very little, or not at all, and the notable enlargement of its carcase when down. Pampered stallions, also, that have been much used, drop in this way; they are then said to have "ruptured a bloodvessei," by the stable people, by reason of the blood which comes off by the bowels, or is found upon after-death examination within the abdomen, coagulated sometimes, to the amount of 2 or 3 pails full.

2. This fatal termination, in every case, is only to be averted for a time by repeatedly bleeding largely from the neck vein, to be followed by very mild physic, as the laxative drench (page 30), or the purgative ball (page 46). As happens in other inflammatory attacks, weakness, tottering, profuse perspiration, and cold ears and legs, with slight pawing behind, show the ruin that is going on within, even in the mildest cases, when a kick or two from a horse which never kicked previously, or the stamping of one leg uncommonly wide, or a little unaccountable restiveness, equally indicate now the acute attack, which, however, soon subsides. At other times, a manifest prostration of strength deters the practitioner from having recourse to the fleam, even in the smallest quantity; nevertheless, no other hope of relief remains, in general (unless in the distemper), and there is some gleam of it, when the taking of a small quantity of blood affords a little relief: a very hazardous experiment, truly, and requiring the exercise of much cool observation. If this turn out favourable, then repeat the operation in 6 hours, and blister the sides extensively. Examine the membrane of the eyelid for the yellow indications of a disordered liver, which now appear in a small degree, and assure us that we have not mistaken the seat of the disorder, at any rate.

3 . This same obstruction of the bile in very hot seasons, occasions it to overflow the liver so much as to inflame the peritoneal membrane that supports the bowels, the consequence whereof is excessive purgation, 
with cold ears and legs. Yellowness about the eyes proves that this is the real cause of the pain and the purgation; and warm bran-mashes, or plenty of warm water, salted, are the sure and speedy remedies. Let no delay take place; and look back to pages $52,83, \& 88$, for what is there said of the corresponding diseases that predispose to this state of the bile. Try the ball at page 93 .

4. Adhesion of the large gut to the liver is the effect of a slight inflammation of this organ, though probably of some continuance, caused by a vitiated state of the blood, of long standing, but not virulent. Ulceration of the thin extremity (of the right lobe) takes place, and the consequence is adhesion, or the growing together here spoken of, and alluded to elsewhere (pages 42,79 ). The cure is effected spontaneously, in numerous cases we have examined, by the ulcer sloughing, and coming off by a little extra purgation, though commencing with costiveness. This symptom is accompanied by the usual fever, weakness, and yellow appearances, though not in a high degree. Laxatives are plainly indicated as the most eligible means of assisting the cure, and the drench, at page 36, will sooner reach the parts requiring relief than purging balls, the which, if made strong, cause so much commotion as to hurry off the patient by inflaming the intestines, the liver, and the whole inside. Through this lamentably-mistaken treatment, and that other of giving cordials in cases of adhesion, is this effort of nature to relieve itself of an accumulation of offensive serum converted into the immediate cause of dissolution; whereas, if left to itself unphysicked, and allowing a week's comparative rest, we never found a case that did not terminate favourably; whilst in every case of death from adhesion that has come under our notice (and they have been many), in which we could ascertain what course of treatment had been followed, all terminated in loss of life by strong physic.

5. Quite as often we find the thick upper end of the right lobe of the liver adhering to the midriff, attached 
indissolubly, unless by tearing it away with considerable force; the afflicted horse carrying the disorder with him to the knacker's, always, we believe, when it has been fairly contracted. To inflammation of the lungs, with the evil influence those organs then exercise on the liver, is to be ascribed the adhesion (or cohesion) at this particular portion of the liver. Indeed, the earliest symptom is that of catarrh in its worst feature, consisting in the cough that returns, seemingly, after the inflammatory symptoms have been subdued. People in general, then, believe that the horse has "caught a fresh cold," whereas the disorder is mainly to be ascribed to want of the wholesome air, before recommended in the recovery from inflammation of the respiratory organs (see pages 34 and 40 ), in neglect of the restorative means, of nursing and plenty of liquids. Heat and dryness of the parts are the immediate cause of the adhesion, and a dry husky cough its first symptom; incapacity for performing his usual work in the same style, loss of strength, or absolute refusal to go, nark the stages and progress of a disease we may safely pronounce incurable, though so easily prevented at first, and capable of alleviation afterwards: for this purpose refer to "chronic cough," and to catarrhal complaints generally; for it is upon the lungs our remedies must be brought to act, although the liver is sometimes so much deranged by the inactivity thus imposed upon it, as to cause obstruction of its functions, an accumulation of bile, and consequent costiveness, with " the yellows" in a slight degree.

6. $\mathrm{J}_{\mathrm{AUN}} \mathrm{UICE}$, or the Yellows. This disease is also indicated by that yellowness of the eyes and mouth which denotes imperfect secretion of the bile, with dulness and lassitude, want of appetite, and "symptomatic fever." (See pages 38 and 87.) The term given to it, being no other than the one visible symptom-its colour, we may arrive at a more sure manner of treating the disorder, because yellowuess or jaundice does not exist without some derangement in the bile, which is owing, more or less, to IN F LA M M A TION OF THE LIVER. Simple Jaundice 
being last in degree, but always depending on increased action of the liver; or, in other words, the increased pain of that action causing inflammation. We have shown what dire effects are produced when this increased pain is caused by adhesion, of two sorts, and by rupture; but when the disease has not extended to these extremes, and is confined to mere enlargement of this organ, with increased heat and evident pain, the same medicines do for both degrees of attack, call them what we may. As before observed, inflammation of the liver, proceeding from what cause it may, is sometimes attended with costiveness, at others with scouring; in the first case give the laxative drench (page 36), and if the horse be of very full habit, give the purging ball (page 46) a few days afterwards, or repeat the drench until the desired emptying of the bowels has been fully effected. As before observed, do not give calomel and the purgative on the same day; but with a much smaller quantity of aloes we may mix them with advantage, upon the old principle, that the mercurial acts mainly upon the liver. With this view, give the laxative ball once every 12 hours; thrice, when it occasions moderate purging.

\section{Laxative Ball.}

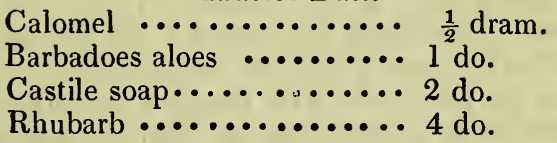

Mix with syrup enough to form the ball for one dose.

So far for that symptom of the yellows which consists in costiveness; on the contrary, when the bowels are already relaxed, the prescriptions before directed for simple scouring are proper here; but we now introduce the calomel with the same view of carrying the curatives directly to the liver.

Scouring Ball.

Opium ............... $\frac{1}{2}$ dram to $1 \mathrm{do}$.

Calomel .............. 1 do.

Castile soap........... 2 do. 
Mix with syrup enough to form the ball for one dose. Give one every 12 hours for 3 or 4 days.

6 . In well-marked cases of inflammation, when the feverish symptoms run high, bleeding may be resorted to with advantage at the first attack ; but, upon drooping and apparent despondency, a species of sigh is emitted, and constant inclination to lie down, evince weakness and abasement of the animal powers, the operation would hasten death. These, indeed, are symptoms which accompany and declare the very worst stage of the distemper, as observed higher up, pages $52-55$. - See also Chapter IV. sec. 1, 2; and note the discrimination marked out at page 88 . In addition to all this, we stop these labours to remark upon the present EPIDEMIC among horses, that it differs in no essential point from those of former years, as described in the pages just referred to, and already printed off; nor does it differ materially from the distemper, described by Osmer, as happening in his time, to whose book the inquiring reader should turn for further information. Let him beware of bleeding, as directed at page $52-55$, when great debility ensues the opening of the bowels, which becomes necessary, for the disorder has then reached the liver; and as soon as the commotion has ceased, give the calomel, as directed at pages 88 and 93 , and adopt the restorative process so often recommended (see page 34 ), with the tonics and fever powders, according to the circumstances of scanty urine or other derangements of the evacuations. Give the distemper ball at page 54 ; and as soon as a little remission of the symptoms is observed, give the quinine balsam, 4 ounces, in warm water, two pints; than which a finer restorative in all cases of debility, liver obstructions, and chronic pains, is not to be founc in the whole Materia Medica. See Balsam, in Chap. XVI. But all this danger and trouble will be obviated by promptly adopting the simple measures recommended in section 3 , page 90 ,- as hath been proved on man and horse, while we are yet at press. 


\section{CHAPTER VII.}

INFLAMMATION OF THE KIDNEYS.

1. This is the only disorder affecting these organs, but differing in degree according to the cause thereof, which is fourfold-lst, Bad food, as mow-burnt hay and musty oats-2nd, Some injury inflicted either externally by a blow, or internally by the passing of any hard substance, as a stone-3rd, By using cantharides too strong in blistering or rowelling, or the indiscreet exhibition of corrosive sublimate in any way-4th, By the free employment of diuretic medicines. Of these evils, the latter is of the most frequent recurrence, and leaves the kidneys in a feeble state, unfit to receive the further stimulation too frequently practised, if the substance be not entirely carried away-of one kidney at least, the other performing alone the whole function of separating the urine from the blood. Therefore should we avoid the further use of such medicines in inflammation of the kidneys, liver, and bladder's neck, viz. turpentine, the resins, coarse aloes, Castile soap, \&c.

2. At the first attack, the horse stands straddling, as if he wanted to stale, sometimes voiding, after painful efforts, a small quantity of " bloody urine," or such as appears to be so when lodged on the ground. But as the disorder becomes more violent, the urine is entirely suppressed, and the "symptomatic fever" before spoken of, at page 38, is strongly marked. By passing one's hand over the loins, we can ascertain by the patient's flinching, in what degree he suffers, and whether both kidneys are affected, or one only. In the latter case, the 
corresponding leg behind becomes stiff and ill to move; whilst the rigidity extends to both hind legs when both kidneys are affected. That the pain is very acute, and the danger great, we may learn from the horse's looking sharply round at his flanks, and then dropping his head slowly as be brings it to the original position.

3. Commence operations by bleeding freely, giving previously a pint or 20 ounces of castor oil, or a larger quantity of salad oil. In cases of costiveness, instead of so much oil, give the purgative ball at page 46 ; or, if the case be very urgent, give the laxative drench at page 36 twice, which then becomes a brisk cathartic. Inject frequent copious clysters of thin gruel, or salted warm water, which soothes the parts adjacent previously to the physic coming off, and after it has set. Cover the loins with warm skins of sheep newly slain, after having rubbed over the parts the mustard emhrocation, page 83. After this treatment, clothe the patient slightly, but never induce perspiration, which retards the cure; but rather keep the stable cool, continue the allowance of water, tepid, in small quantities, often; hand-rub the legs, and bandage them up.

4. Provided the symptoms do not abate with this treatment, repeat the bleeding and the dose of oil; but do not give the stimulating diuretics under-mentioned (section 6), notwithstanding "suppression of urine" be one of the corresponding symptoms, and all the people of the stable may urge its necessity (as they do) from this very suppression, when it is ruinously improper; but as soon as the suppression abates a little, prefer the cooling diuretics, as the fever powders (page 35), or other preparations of nitre; give green food, carrots, and other natural diuretics.

5. If this course be not assiduously pursued, the bladder becomes affected by the quantity and quality of the urine sent into it, and a profuse staling they term diabetes ensues, as sometimes happens. In the further progress of the disorder, if not without any previous warning, the difficulty of staling just adverted to occurs; not exactly 
because no urine is secreted by the kidneys, but by reason of the bladder having lost its function of expelling its contents (called palsy, or rather torpor); or that the neck of the bladder is disordered. But, to whichever of these causes a "suppression of urine" is owing, the practice of further stimulating the kidneys to a still greater secretion, proves ruinous [see Bladder]; therefore, when blistering is resorted to, avoid the use of turpentine as well as cantharides and hellebore, with all the preparations of mercury; should physic be deemed necessary, as it sometimes is when a collection of hardened dung is the only cause of a suppression of urine, a mild purging ball is alone necessary to remove it. - See page 46 .

6 . So intimate is the connexion between the kidneys and the bladder, in their natural ailments, that some difficulty exists in ascertaining which of them may at any time be the seat of attack. Nor is this circumstance of much importance, the treatment being similar. Pass a hand into the rectum, and smoothen forwards the neck of the bladder with the balls of the fingers; if it be full and hard, the disorder lies in the neck thereof, and the above treatment (sections 2,3 ,) will lessen its inflammatory symptoms : this manual operation usually causes the water to pass off, and may be repeated without damage if the hand employed be a small one. The fever pow. ders, Nos. 1 or 2 , may then be given, as the water has been partly absorbed, and is transpiring by the skin; or give nitre and resin, equal quantities, powdered, half an ounce, twice a-day; or common turpentine, half an ounce, made into a ball with meal, and ginger, half a dram, once a day. 


\section{CHAPTER VIII.}

Affections of the Bladder, and of its Neck :Diabetes, Incontinence and Suppression of Urine, Concretions, \&c.

1. These are, many of them, suppositious disorders of the bladder, being in fact dependent on affections of the kidneys, as hath just been said; and the reader must refer to the preceding pages if he requires more information hereon. The generality of stable people, however, looking to the immediate symptom only, assign to each particular affection the term that is denoted by that symptom; and the master of common-sense-writing on these matters, (James White) having adopted the same vulgar course, we follow him, for the sake of rendering our labours more extensively understandable.

2. Every one of those symptoms of disorder, when fairly ascribable to the bladder, consists in torpor, or cessation of its functions of receiving, retaining, or expelling the urine regularly; whereby it comes thus by too much or too little at a time, not at all, or involuntarily. Relaxation being hereby clearly indicated, give the tonic balls, and still avoid the medicinal diuretics. Observe, that profuse perspiration, brought on by strong work, while the horse requires to stale, occasions torpor, by reason of the urine being reabsorbed, and carried off by the skin, in this mauner reversing the function of the bladder.

3. Dia BETEs.-Excessive staling, when it happens, is the effect of irritation of the kidneys after actual inflammation may have ceased; and being thus simply a 
relapse, the same treatment as that just above described, must be continued. Green meat, as carrots, \&c., is found serviceable, when less water will be craved for, and it is then to be given in small quantities, frequently moistening the mouth. Though some symptoms of fever be present, do not give the fever powder in this particular case. Tonic balls and opiates best allay the irritation of the kidneys. Give No. 1, morning and evening, whereby the urine will be evidently reduced, if the case be a recent one. If not so, after taking 3 or 4 such balls, recourse must be had to Nos. 2 and 3 in succession, the change alone being desirable. The old prescription of lime-water is without any recommendation.

Tonic Balls.

No. 1.-Opium ............ 1 dram. Powdered ginger ....... 3 drams. Yellow Peruvian bark..... 5 drams. Mix for 2 balls, and give 1 morning and evening.

No. 2.-Emetic tartar......... 4 drams. Opium ............. 1 dram.

Mix for 2 balls, and give as before.

No. 3.-Salt of steel .........4 4 drams. Aromatic powder ....... 2 drams.

Mix for 1 ball, and give it mornings and evenings. Should the opium in No. 1 and 2 occasion costiveness, give once the laxative drench, page 36 . Should these tonics be found of little avail in the form of balls, give the same materials in water gruel; mix them well, and give, not warm.

4. Suppression of URine, although mentioned as a distinct disorder, is nevertheless but one of the symptoms of inflammation of the kidneys, as said at page 96 ; when also that other subdivision of this whole series of affections we term bloody urine makes its appearance, and must be treated as there described. The suppres- 
sion, or non-appearance of the urine, however, is sometimes occasioned by inflammation of the neck of the bladder, and by a spasm thereof, that prevents the escape of the water, and we should then speak of it as "retention of urine." When this is the cause of the suppression, the hind legs become stiff, and sometimes incapable of supporting the patient: give an opiate in warm water, by means of the stomach tube, page 37 , and if the bowels be not in right trim, give the laxative drench there prescribed, with opium 20 grains in it; repeat the same in six hours. Another cause of the retention of the urine, and the most frequently occurring, is costiveness, the hardened dung pressing the gut against the neck of the bladder: the remedy in this case, is plainly a dose of physic, (page 46), and back raking the straight gut, whereby the bladder is immediately relieved of its contents; give afterwards the fever powders, No. 1, page 36, two or three times. Be careful not to mistake these last mentioned affections for genuine inflammation of the kidneys: pass a hand over the loins, to ascertain whether the kidney is painful, as before directed; examine the state of the bladder by introducing a hand into the rectum; and by smoothing its neck forward, the urine will be voided, whereupon we know the suppression does not depend on inflammation.

5. Incontinence of URine. An almost constant dribbling of the water in small quantities, though described by some writers as a distinct disease, is but a symptom attending one or other of the foregoing affections of the kidneys ; for the bladder itself is little susceptible of inflammation, naturally or accidentally. Mares, however, which have been quacked with irritating substances, as Spanish flies, with a view to hasten the period of horsing, are afflicted with this incontinence of urine, hy reason of the inflammation thus produced in the whole pelvic region. STONE, or earth balls, in the kidneys, or while passing the ureters into the bladder, as well as after reaching this receptacle, occasion the water 
to pass off unequally, or to suppress it entirely. In all cases where inflammation is well ascertained to exist, whether of the bladder, its neck, or ascending higher up to the kidneys, bleed to the amount of four or five quarts, give purging physic, and employ clysters; but when these and the neighbouring parts are suffering much pain, avoid the strong purgatives, and adopt castor oil, or the laxative drench, at page 36 , twice.

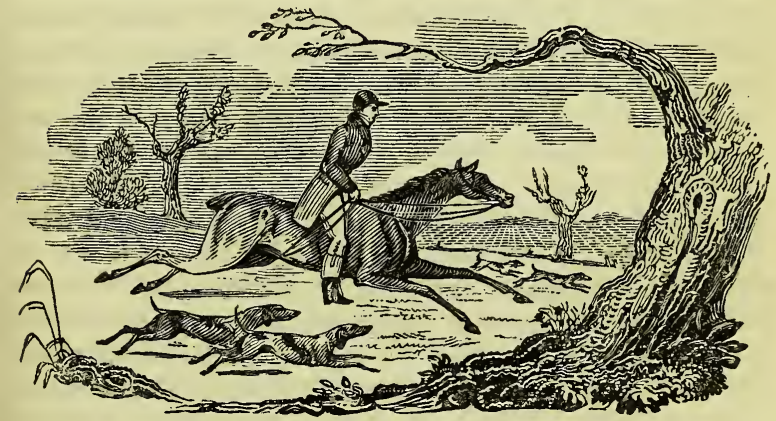




\section{CHAPTER IX.}

Diseases of the Eyes:-Inflammation, Moon-Blindness, Accidents.

1. Inflammation of any internal organ, as hath been said when treating of the stomach and the lungs, affects the eyes; simple catarrh or cold occasioning an immediate blearing, and all disorders of the stomach that affect the blood vessels on the brain, cause a pressure on the internal structure of the globes that gives them a certain glossy, wild stare, as we see exemplified in all cases of staggers for example. Of course, when the eyes lose their accustomed brilliancy, through the existence of those constitutional disorders, the cure can only be effected by the general treatment before recommended in such cases, rather than by any topical applicationsfor the vision will still be imperfect while the original cause remains. When, however, any internal disorder has lasted some time, and the eyes appear permanently affected, as we shall notice presently, then a different course is to be pursued; but, whatever success attends our endeavours to reduce the symptoms, such eyes ever after retain a disposition to moon-eye, or to go blind in one eye or both.

af Soreness, a blearing and inflammation, is frequently brought on by filthy stables, and the vapour arising from urine and rotten bedding: the palpable cure for which, is the removal of the cause outside the stable, or kicking out the groom, through whose negligence the complaint had gained admittance: washing with luke- 
warm water alleviates the pain ; then, dry the eyes well before going out to encounter a bleak wind.

2. Horses which have been so afflicted at any time, purchasers would do well to reject in the first instance. They are known at once by hollowness of the orbit, and a certain wrinkle towards the inner corner of one eye, if not both, or by a difference in the size of the eyes! both defects proving that the mass of fat, on which the inner part of the eye moves, has been reduced in quantity by disease, and so allows the eye-ball to recede in its orbit or socket. For the purpose of ascertaining this fact, bring the horse to the stable-door, so that the light may fall equally on both eyes, and if one pupil contracts or recedes before the other, that eye has been diseased, and is prone to become so again. Similarly, if a faint spot appear on the centre of the pupil, subsequent blindness may be looked upon as certain. A thickening of the eye-lid, or a continual flow of tears, proves that inflammation lurks in the lid, or in the haw; but we are not justified therefore in cutting out the haw, as Taplin recommended, and some persons foolishly practise-for both symptoms cease upon washing with the eye-lotion, prescribed below. Not so soon, however, when the globe itself is inflamed, and loses its natural transparency by the thickening of the outer film, though the pupil may still be discerned through it : in this case the lids are partially closed, and the haws also protrude, in consequence of the globe being drawn inward. Would we ascertain in how much this thickening prevails? Pull the horse up briskly towards the light, flourish the hand before his eyes, place a finger on the pulsation, or the palm on his heart, and if he have any breeding in him, a sudden flutter will be distinctly felt, if the sight be good.

3 . Should the inflammation proceed from any other cause than those just now spoken of, and arise from some external injury, as a blow, or from a bit of chaff or dust getting in, or a cold, merely washing it with the lotion will not subdue the symptoms in obstinate 
cases. It will then be necessary to bleed moderately, and give the laxative drench (page 36) once or twice, according to the previous quality of the horse's dung; unless this be in a very bad costive state, when a more decisive purgative should be adininistered-namely, the ball at page 46 , for this is commonly found to be the main cause of the complaint. To high feeding, then, without a due proportion of exercise, is to be attributed the prevalence of bad eyes in any stable; the effects whereof are augmented by close and crowded stabling, by darkness thereof, and the hartshorn exhalations constantly arising from the dung, the urine, and the perspiration so engendered. These cases require great attention and care ; for, unless the proper remedies are employed on the first attack, the disease (though it seems to go off awhile), will be frequently returning, so as to justify, in some measure, the mistaken notion that the moon has some influence on the disorder. The bleeding, therefore, should be prompt, and bear some proportion to the violence of the inflammation, and the condition of the animal. Should the vessels on the white part of the eye and inner part of the eyelids appear to be distended with blood, immediate relief may be obtained by scarifying the membranous lining of the lid with a lancet. In fact, this operation is serviceable in every inflammatory attack on the organs of vision. Let the cold lotion (p. 107, No. 1,) be used in all cases, and if feverish symptoms appear (see page 39), give the powders at p. 35.

4. Not only give physic, but keep the bowels in a lax state by means of bran mashes; reform the state of the stable as to light, air, and smell; and upon going out, adopt a shade or blinkers, to keep off dust, and to regulate the proper degree of light. A seton placed immediately under the eye, I have found a very serviceable remedy; but unless the operation is nicely performed, an unpleasant mark remains behind. When, however, the patient has been attacked with this disorder before, and is also out of condition, neither bleeding or physicking 
can do much good, and, what is more, if either is carried to excess, does infinite mischief. With regard to other topical applications than those mentioned, or those remedies that are applied directly to the eyes, I must confess that I have not seen much benefit derived from them; except, indeed, when the inflammation has abated considerably, and left behind an opacity, or film, on the surface, called a cataract, and then common salt, or fine sugar, powdered, and blown into the eye, has sometimes proved useful, at others doubtfully so; but the adoption of pounded glass, mixed with honey, has been found by $M r$. White's successors to lie among the mistaken notions to which all practitioners are liable, more or less, and which the candid mind discards upon the accession of new information. But a more efficacious remedy than this kind of mechanical friction (which is very likely to increase the inflammatory symptoms), is the employment of mercury, with a view to excite the absorbents to take up and carry off the deposite which constitutes the disorder. Therefore, take

Corrosive sublimate $\ldots \ldots \ldots 8$ grains.

Water...$\ldots \ldots \ldots$ half a pint.

Mix, and apply to the lid (being closed), and all round the orbit, twice a-day with a sponge.

A simple poultice of bread, or of turnips, not hot, placed over the eyes at night, is well adapted to reduce inflammation; but mix no greasy matters in this or any other application to the eyes. The cataract of large working horses is generally very thick and obstinate; in such cases, dissolve in water 2 ounces, a scruple of white vitriol, and with a feather put a drop on the film morning and evening. Of these remedies 3 or 4 applications effect the cure.

5. This kind of inflammation generally comes on rather suddenly, unlike some others, which depend upon, and relate to, constitutional disease (as said at page 103), sometimes attacking one eye, at others both are affected. 
As no apparent cause for this sudden attack occurs to the groom's mind, he very commonly attributes it to hay seeds or dust having fallen into the eye, and little or no attention is paid to it; notwithstanding this neglect, the disease frequently goes off without any treatment whatever, and in some cases its disappearance is as sudden as the attack. In a short time, however, the symptoms again appear, as unexpectedly as at first, and again go off, continuing this uncertain fluctuation for a considerable time, the eyes sometimes appearing of their natural transparency, quite free from inflammation, at others watery, inflamed, and opaque on the surface. At length the internal parts of the eyes seem to partake of these repeated attacks, and a cataract is produced; that is to say, the thickening of the crystalline lens is confirmed. If this takes place on one of the inflamed eyes only, it frequently happens that the other becomes perfectly sound and strong, and your moon-blind horse, which may have troubled his owner for a year or two, becomes quite as serviceable as ever for ordinary purposes.

6. From about 4 to 6 years old is the age when bad eyes mostly prevail; that is to say, when the animal system is first filled with juices, and the minute vessels that cover the brain and the eye partake of the constitutional vigour, are susceptible of the general excitement, and very liable to feel the effects of any check upon their own action, or of a collapsion of the perspirable vessels noticed higher up, at page 78 . Some horses derive a disposition to moon-blindness from their sires, and then go blind at the earliest age just mentioned; a fact that has been frequently proved, since the period of Mr. White's writings, beyond a question of doubt. When a stallion has no positive defect in his eyes for which we ought to reject him, yet, if he have a great portion of white in them, we should look upon him with suspicion; such an indication of some latent vice or mischievousness in him being certain, as it is in every animal of his kind, whether male or female, horse or gelding. No reason what- 
ever exists for believing that horses of any particular colour, black, for example (as hath been said), are more liable to moon-blindness than any other.

\section{Eye Lotion.}

No. 1.-Goulard's extract....1 dram.

Water, milk warm $\cdots 1$ pint.

Mix, and apply to the lia and round it, with a sponge, 2 or 3 times a day; at first, oftener.

No. 2.-Opium, in tincture....4 drams. Water, milk warm ..... 1 pint.

Mix, and apply as before.

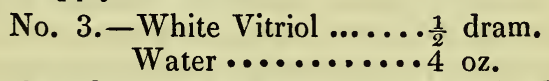

Mix, and apply once or twice. This is well adapted to reduce the projecting haw at its first appearing swelled.

7. The $\mathrm{H}_{\mathrm{a}}$, however, does not always resume its healthy state by this treatment, even when the other symptoms of inflammation have abated ; for it is not always that the disorder resides in the haw itself, the apparent projection being occasioned by the eye being drawn back into its socket by the influence of the previous inflammation on the retractor muscle, and the exhaustion of the mass of fat on which the eye moves. Follow up the exhibition of the lotion, No. 3, with No. 1 for several days, to the whole region of the eye, until it feels cool without it. Bleed moderately, if the horse be in good condition; keep the body open, as directed before; but should the swelling remain, and put on an ulcerated appearance, cutting out the offensive part may become necessary. How much of this projecting cartilage is to be thus taken away, depends on each individual case, but should by no means be undertaken by any one who has not studied the anatomy of the part: for, if too much haw be thus liable to disease, too little, or none at all, will soon produce blindness.

8. W A R TS on the eye-lids, when troublesome, occasion the horse to rub and bring blood, whereby more are pro- 
pagated ; let them be cut off with a pair of scissars, and touch the lips of each wound with lunar caustic: keep up the horse's head a few hours, to prevent rubbing.

9. Eruptions on the lids occasion itching and rubbing, with its attendant blemishes; therefore, apply the ointment Hydrarg. Nitratis, of the shops, after reducing its strength by an equal quantity of hog's-lard. Use a soft painter's brush or sponge for the purpose, and apply it once a day : keep his head up.

i In all those diseases of the eyes, one thing is worthy of remark, namely, that the horse never loses his appetite in consequence; unless the disorder begins in the stomach, as mentioned before, he rather seems to eat more voraciously; and we may instructively add to this fact, that the robust horse and greedy feeder is mostly subject to contract simple inflammation of the eyes, that is not traceable to any other cause. See Symptomatic Fever.

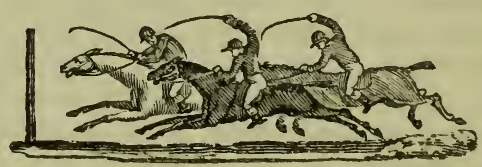




\section{CHAPTER X.}

Vices:-Cribbing: Biting the Crib, or Wall; Windsucking; Weaving; Eating Litter.

1. The vices of horses are few, inherently; most of those we observe and lament in a domestic state, being taught or induced upon them by the lord of the creation-poor, mean, and abject in every respect as regards brutes, and the horse especially so. Kicking, whilst in a wild state, and perhaps battles on the score of pasturage or the female, being his highest offences, until man tethers him up, and adds to in-door dry keep, certain injudicious treatment, from coltship upwards, whence is derived some inveterate habits. Of these, shying and starting are taught, as it were, by the want of firmness, and injudicious precipitance of the rider; and are only to be amended by a direct contrary conduct, as is more fully, and completely set forth in " Rules for bad Horsemen," by Thompson and Hinds, Chapter VIII. So is cribbing taught, or let us say, superinduced by the conduct of the stable people; for the horse in a state of nature never did become a cribber; not because he has nothing to gnaw at, but because he has his liberty; then, bring him in from the forest and tie him up, all anxious, healthy, and robust as those horses are, and they almost invariably take up some such vice from having nothing else to employ themselves upon. The cure is thus clearly pointed out, or rather the preventive is prescribed in a single sentence, viz. give your horse something to amuse him. 
2. Whichever of the above terms we bestow upon the particular symptom that distinguishes the inveterate vice of cribbing, still is disordered stomach, and consequently depraved appetite, with staring coat and anxious countenance, the immediate attendant upon the whole series. To the correction of the stomach then should we address our first labours for its removal; or rather, the people of the stable should be hence instructed how readily they might have prevented its occurrence. by attending to the wants and temper of their horses, as regards appetite. For the origin of any such habit has been, lst, neglect of feeding at the proper periods, and denial of water; 2nd, permitting a robust, hearty, mettlesome horse, to stand idle at empty racks ; 3rd, by currying one that has a thin skin in the stall, or other place where he may find something to gnaw at, and when he so offends, giving him a rap and a curse ; 4 th, by detaining a healthy, fretful horse in-doors at a time that he ought to be exercised, especially when others have gone out from the same stables ; lastly, cribbing may be brought on by imitation, when also some of the foregoing causes usually concur to render it inveterate. Young horses are mostly liable thus to acquire the habit by example, as well as upon cutting their teeth, when the feverish gums require cooling, which is further promoted by the brisk inhalation of fresh air ; they thus seek to supply the want of it naturally by sucking the wind, which is one of the features of this disease. Here it is worthy of remark, that whatever be the age, none but good horses in other respects fall into this vice; whence I was induced at an early period to infer, that a restless desire to be abroad, impatience under restraint, and the fretfulness that is thus engendered, shortly communicating with the most sensitive of the organs of brute life, the stomach, depraves its functions, and causes a vast reduction of the animal's powers. Subsequent close observation of the progress of several cases, confirms this first impression. 
At the commencement of this habit, it is true, the disposition to crib may be so trivial as to occasion no visible harm, except wearing away the teeth, generally on one side of the frontals, the horse doing his work as well as ever, and keeping up condition ; but who is there to say, that such a beginning is not the unfailing forerunner of a ruined nag? Such a horse is already an unsound one.

3. Let it not be supposed, however, that cribbing is entirely incurable. Had this been the case to its full extent, we might have passed over the subject in silence, as $M r$. White and other writers have done; but many well-authenticated cures having been wrought upon inveterate crib-biters and wind-suckers, within these few years, imposes upon us the willing task of giving some account of the principles upon which they have been effected. Richard Lawrence considered crib-biting as depending upon disordered lungs, a mistake he and others must have fallen into upon observing the great distension of the carcase, occasioned by the wind being sucked in and driven forcibly into the cellular membrane ; but the flatulent colic which accompanies the symptom, and the inflammation that succeeds it, clearly teach us that the stomach first, and bowels afterwards, are the organs materially affected by this vice, and require correction ere the patient irrecoverably loses condition and strength. Previous to this appearance of leanness, people in general do not pronounce cribbing an unsoundness that would justify the return of such a horse upon the vender's hands : it is nevertheless an evil affection, that grows into a habit, and requires very judicious and expensive treatment to prevent the vice from reducing the serviceableness of the horse.

4. Wind-sucking is not always accompanied by biting or resting its teeth on the crib; but the horse pokes out his neck (sometimes without aught to bite at) or reins it in, with the lips alternately open and shut, whilst he is heard distinctly at several yards' distance, to suck the к 2 
wind with all his force. We hear of several cruel practices to prevent cribbing, as burning, lacerating, \&c.; but they are all equally useless and barbarous. The old fashion, of buckling a strap tight round the neck, has the effect of arresting the action of the wind-pipe, which accompanies the suction, whilst it is on, but no longer; besides the danger that is incurred of causing the air to lodge in the membranous lining of the pipe, and to bring on roaring. See pages 47,61 .

5. No truth in animal management is better recognised than this one: "remove the cause of any thing amiss, and the evil effect thereof ceases ;" so, having set down in a preceding page the several causes of cribbing, we might say that the vice would cure itself, if man did not interpose as above, and add inflictions thereto, of currycomb and brush, and ground-ash, and missiles, and the displeasure of a harsh guttural voice from lungs like leather. What is worse, all the while that the afflicted horse is undergoing this seeming correction of his vices, he is not given to understand that he is doing wrong, but recurs to his favourite amusement by way of consolation under trouble, as soon as his tormentors leave him. Whereas, if any reasonable person attempts $a$ cure, of course all this brutal behaviour will cease, and the following treatment be adopted. 1. That the food be regular, and given with kind sounds of the voice, whereby a certain chiding word and angry look will become doubly effectual whenever a repetition of the offence requires coercion: let the horse know what you want him to do by rewards, and what you want him not to do, by a single chiding word, and he will desist, if but to hearken at the unwelcome sound. Hereupon, a few slices of carrot or apple, from the jacket pocket, patches up the short-lived quarrel, until the offence is again perpetrated and again reprobated, when the same reconciliation takes place as before. One day's work at this will teach him your supreme desire. 2. Between his feeds and hay, muzzle up occasionally; put him to stand where there is no crib to 
bite at, no wall to gnaw, no post to rest his teeth on, or whichever may be his chief propensity. 3. A post or rail being prepared beforehand, with nettles or culrage, the exercising groom stops the horse to take a blow at one of these, and chides him for the attempt to bite, with reproaches for a repetition, or a reward for obedience. With the same view, he prepares a rail, smeared over with aloes or any other bitter material, and fastens his horse to it. 4. Whenever the cribber has fed as much as necessary, he should have a slight snaffle with plyers, fastened to the head-stall, to champ upon, which improves digestion, and affords amusement. An hour before going out, rein up, with his tail to the manger, as well to put his head in order, as that he may hearken to good advice. 5. Discontinue currying upon the belly, the flanks, and under the arm, however thickskinned the individual may be. 6 . Take out of the cribber an abundance of exercise-full 3 hours morning, besides afternoon; bestow great attention on him for a week at least; sleep in or over the stable; study the particular temper of the horse, and ascertain how he acquired the evil habit, that this at least may be counteracted. If he inveterately suck whilst down, or during walking exercise, a bit of listing is to be stitched on to the plyers of his snaffle, on each side.

6. Lastly, Crib-biting may be rendered physically impossible, by applying the new anti-crib-biting apparatus, invented by T. Yare, of Dean-street, Soho; which has been found effectual to all its purposes, especially when accompanied by the foregoing treatment. The principle upon which it is constructed, is simply a mechanical obstruction of the teeth meeting with the object sought to be bitten. This is effected by means of a bent iron rod, resembling the annexed figure, being fixed to each side of the muzzle, by connecting bars across, underneath the jaws and over the nose, the whole being fastened to a strong cheek-stall and ear-

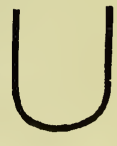
к 3 
band by several straps. With this contrivance on him, the crib-biter may take up his corn, or pull his hay, without the power to gnaw the manger, whilst he must take time to masticate his food properly. Mr. Yare obtained the silver medal of the Society of Arts for his ingenious contrivance; and undertakes the cure of cribbers of every degree, in which he is eminently successful.

7. Eating litter arises from depraved appetite, and classes with cribbing; for the stomach having been distended with wind so sucked in, requires some hard substance to keep it in that state : such a horse will swallow straw, earth, wall, and the like, and thus further extend the evil. The medical treatment consists in completely emptying the stomach and bowels, by giving the drench (page 36) twice or three times, and purgation ensues. If the ball is still preferred (notwithstanding our recommendation), give the following-

\section{Purging Ball.}

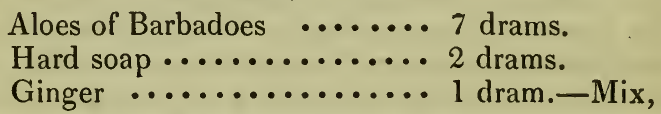

with syrup sufficient for one ball. Previously hereto, give bran mash; and after the ball, half a pint of warm mash or water. Un the physic coming off, give plenty of bran mashes.

8. Weaving is a restless kind of see-sawe motion of the head and body from side to side, with the forelegs straddling, which plainly tells that the animal is deploring his solitary confinement. This propensity is to be amended by similar treatment to the foregoing, and giving him a companion of any sort. 


\section{CHAPTER XI.}

Tumours: - Strangles, Glanders, Farcy, SurfeitMange, Poll-evil, Fistula, Quittor, Grease, \&.c.

1. Properly speaking, all swellings on any part of the body, are tumours, though that term has not been applied to those that have been treated as such under other names. We shall not, therefore, take the whole into consideration under this one general head, but, in compliance with custom, come shortly to treat of each under its separate name, as above. Notwithstanding which, we do not deny the great advantage arising from thus classifying a number of constitutional disorders in one view, namely, their affinity as to cause and effect; for no two of those disorders appear at the same time on the same animal, unless in the course of superseding the first, through the exceeding severity of the other; whilst the whole owe their origin to the same cause, viz., to depravation of the secretions, and consequent defect in the excretions, producing evil humours in the blood; which are then brought into baleful activity by some slight incident (as a chill), that shows more or less malignity, or changes its aspect, according to the previous health of the individual attacked. This predisposition to disease is justly ascribed to vitiated organs of digestion, \&c., brought about by the manner of living; as superabundance of food and inadequate exercise, by bad food and hard work, irregularity of feeding, change of quarters, and abuse, by bad water, \&c. In this we perceive the reason why some horses, and other cattle, contract the 
single tumour of one or the other kind, whilst others, placed under the same circumstances of infection or of exposure, contract the plural species (miliary), internally or externally, as the case may be. A plague, typhus, and distemper, are all connected with tubercles on the lungs, the liver, or the skin, according to an ingenious French writer named Dupuy, who appears to have bestowed much laboured research on the subject.

2. Tumours also arise (oftener than we can know of), on the digestive organs, and mostly the small gut, fatally, as noticed at page 79 ; while those which appear singly on the fleshy parts of the budy after fevers, of which they then form the critical discharge and cure, are noticed at pages 26 and 56, as proceeding more immediately from that cause. But those which arise in the glands, being the most fearful species of external tumours, being decidedly infectious, require present attention; whereas those other tumours, that come of external violence, as well as those of the limbs, whether of the bones, ligaments, membranes, or tendons, and which occasion lameness, will be considered under their respective heads, as subdivided into spavin, wingal, ringbone, splent, \&c.

\section{Strangles.}

1. Although a disease of youth, and attacking nearly every colt once, the strangles appear occasionally on full-grown horses, and is then more troublesome to cure, as well as alarming the people with groundless fears of glanders, which never attacks young horses but by infection. Generally, the 4 th and 5 th years are the more obnoxious to strangles, though coming on a year or two years earlier, in some forward horses; the period depending, in great measure, upon the keep, and consequent filling up of the animal system, which is the main cause of the disorder, if not the only one. It consists in a swelling under the jaws, attended with cough, dulness of the eyes, and other feverish symptoms, as 
described at pages 26,38 . The kernels under the throat swell; soon after, a discharge from both nostrils of white thick matter appears; evident soreness, if not difficulty of swallowing, succeed, and the inflamed swelling bursts ; in this manner effecting a cure naturally.

2. When the disorder threatens delay, and a difficulty of swallowing tells us that some danger of choking or of starvation is to be apprehended, let the inflamed throat and swelled gland undergo warm fomentations to alleviate the pain and tension of the parts; give oatmeal gruel, warm, and prepare a white-bread poultice, to be applied assiduously to the part, and kept there, changing it twice a-day. Previously, however, clip the hair quite close to the gland and the throat, so that those applications may have the required effect. Sometimes the skin is so tough as not to yield readily to the poultice; and as the speedy escape of the offensive matter from the tumour is desirable, suppuration will be promoted by rubbing on the swelling a little of the following-

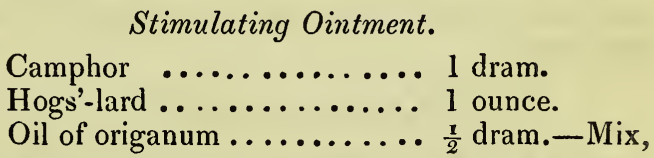
and apply previous to each renewal of the poultice. When the tumour becomes quite soft and full of matter, and not until then, it may be opened with a lancet from the bottom upwards, though the spontaneous discharge is far preferable, as leaving no room to doubt of its ripeness, nor any apprehension that a fresh sweiling might arise, though the matter still remains, as happens sometimes, notwithstanding all the care we employ to press it forth, and to cause its escape, by keeping the lips of the wound open with a piece of lint plaster. Continue poulticing, cool, until the swelling subsides; whereupon, dress with digestive ointment, strapping it on with adhesive plaster, tolerably firm. Complete the cure by 
giving alterative laxatives, as the drench at page 76 . If costiveness prevails, give the ball at page 46 .

3 . In all cases of strangles, steam the head often with warm water, put into a tub, wide enough to admit the pail's being placed therein that contains the patient's mash or oatmeal gruel, so that the steam may ascend on the outside of the pail. Though the young ones get over the strangles with comparative ease, and improve greatly in form and size immediately after recovery, yet this is not the case with full-grown horses, which retain a disposition to contract other glandular diseases in succeeding years, as the vives and glanders, owing to the tumour not being sufficiently ripe to discharge all the offensive matter. Observing this effect of opening it a day too soon, Mr. White latterly abandoned the use of the lancet, trusting to those stimulants for ripening the tumour to its proper degree. This practice is found to succeed admirably when the discharge at the nose appears to subtract from the matter which ought to fill the tumour, besides the danger of its carrying off the patient in consumption of the lungs, whence the running proceeds.

\section{Surfeit and Mange.}

1. Although essentially the same in several respects, these disorders differ greatly according to the previous health of the patient, or rather I would say, his condition. Both proceed from disorder of the digestive organs, and of the stomach principally, as is proved by a single purgation removing the worst symptoms of the first mentioned, which arises from foul feeding and lodging, or superabundant dry meat; whilst the more loathed, confirmed mange, is alleviated by good feeding, and in both the cure is mainly effected by topical applications and the adoption of that cleanliness, the forgetfulness whereof first engendered the disease. But the better fed horses never contract mange, as these are usually kept clean; 
unless the slighter attack (surfeit), is allowed to make head, or the animal get it by contagion.

2. Horses of condition, that have been well kept in the summer, will thence contract a surfeit that spreads all over their bodies equally, resembling the stings of wasps ; but this appearance is to be taken as proof of good living and increasing vigour, which a single purgative ball (as at page 46) will reduce, and a mild course of the alterative balls prescribed below will perfectly cure. If the urine be scanty or turbid, give a diuretic ball, and repeat it, if there be occasion.

3. At one time, the stable people applied the term surfeit to any and every external appearance of disorder for which they could not find a more distinct name, as was noticed at page 23 ; hence the stable phrase- "it was only a little surfeit at first, but is now become hidebound, or farcy ;" one or the other of which do often succeed the so-called little surfeit, unless the symptoms have been those of inflammation of some internal organ, as described at pages 39-41. In addition to the symptoms described, as above, surfeit is known by the pustules spreading in wider scurvical eruptions, and loss of hair from the mane. Hereupon bleed and physic, both, if the mouth be hot; if not, a common purging ball only may be given, such as is prescribed at page 46 , giving a warm bran mash beforehand, and in 24 hours after give more mash, repeating the same daily. Let the currycomb and brush be assiduously employed to loosen and bring off the scurf, which will be detached by applying the following

\section{Wash.}

No.1.-Blue vitriol............ 1 ounce.

Camphor $\ldots \ldots \ldots \ldots, 4$ drams.

Spirits of wine $\ldots \ldots \ldots \ldots 2$ ounces.

Water.$\ldots \ldots \ldots \ldots 2$ pints.-Mix,

and apply twice daily to the whole body, neck and knees, for three or four days after the physic has set. If 
the patient is off his feed, as usually happens, give a better mash, as oatmeal gruel, or of malt, and coax him with a few beans, slices of carrot, or other such means, but keep the dunging of tolerably soft consistency during the external applications : change these, and substitute the saline

$$
\text { Wash, No. } 2 .
$$

$$
\begin{aligned}
& \text { Table salt } \ldots \ldots \ldots \ldots \ldots 1 \text { pound. } \\
& \text { Water ............ } 3 \text { quarts-Dissolve, }
\end{aligned}
$$

and wash all over, well rubbing the parts, and in the course of the pustules; also the mane, jaws, throat, and belly, until the coat is tolerably dry. Put up and clothe, or take exercise clothed, according to the weather, as the horse will shiver with the application. Give a warm generous malt mash soon afterwards; and if the climate is a cold one, a pint of hot water may be put into the wash, No. 2.

As most people dislike the word mange to be applied to these affections of the skin, and the spots, with a staring coat, continue, notwithstanding the foregoing treatment, give the mineral

\section{Alterative Balls.}

Muriate of quicksilver ....4 4 drams.

Tartarised antimony ..... 3 ounces.

Ginger \& aniseed powders,

$$
\text { of each ............ } 3 \text { ounces.-Mix, }
$$

with syrup, enough to form the mass, and divide into 16 balls, one to be given every morning. With the like object, the same materials, nearly, may be given-thus :

Antimony, finely powdered.. $\frac{x}{2}$ an ounce, given daily in the corn, or double that quantity for a large horse, and with it about as much powdered ginger, also, as will tend to improve his coat, and carry off the eruption. With these powders, continued for three weeks, I have given, with great success, for ten successive nights, 
half a dram of the blue pill in mass, which contains each about 15 grains of mercury.

4. Obstinate mange, however, that which has been brought on by poor and beastly living, or is of long continuance, does not subside before this treatment, though accompanied by better food : the disorder is no longer to be considered as one of the skin only, but of the blood, or whole system. Yet must not such a lean subject be bled. He must be treated with sulphur all over, changing the ointment occasionally. The wash, No. 1 and No. 2, have been used, let us suppose, to cleanse the coat, but fail to effect a cure; then adopt the following

\section{Mange Applications.}

No.1.-Sulphur vivum $\ldots \ldots \ldots \ldots 4$ ounces.

Oil of turpentine $\ldots \ldots \ldots 3$ ounces.

Hogs'-lard .......... 6 ounces.-Mix,

and apply with a brush to the scabs and sores, after the horse has been well curried and brushed, even to sore= ness, every day, until the cure is completed.

No.2.-Sulphuric acid ........ 2 ounces.

Oil of turpentine $\ldots \ldots .44$ ounces.

Mix these two cautiously together, by putting in a little at a time, and, when well incorporated, add thereto,

Sulphur vivum...$\ldots .4$ ounces, and

Hogs'-lard, just melted ... 6 ounces.

Apply as before directed. These cause the spots to appear larger on the first application, but not so subsequently; the smell is extremely disagreeable, which has put some people upon employing other medicines, as corrosive sublimate, but withal very dangerously; but nearly the same effect as these produce (barring the smell), may be obtained by giving the antimonial powders along with the blue pills, as prescribed in the last page; which should be given, at all events, unless the alterative balls are in operation, and then these powders 
may take place of the balls. If the appetite fail, coax the patient to eat; give bits of carrot frequently; and, indeed, the foregoing balls, being very small and nearly tasteless, may be given, by means of a hole bored partly through such bits of carrot. As change is desirable, discontinue No. 1 and No. 2, and apply, in a similar manner,

No. 3.-White hellebore, powdered.. 4 ounces; boil in 3 pints of water, until reduced to two pints, and then add,

Muriate of Quicksilver ...... 2 drams,

which has been previously dissolved in

Muriatic acid........... 3 drams.

Mix the lotion for an extensive application.

\section{FARCY.}

1. In many features resembling surfeit, of which it is often a consequent, farcy is caused originally by a cold or check upon the perspirable vessels of the surface, whilst the stabled horse is suffering the effects of hard work and irregular feeding upon a jaded constitution. Bad food, idleness, and filthy lodging, also engender diseases of the skin; whilst coach and waggon horses mostly suffer from these twin disorders; neglect and mistreatment always causing the first or milder attack to devolve into the more loathed farcy. Cold rains in spring, coming after a few days of unseasonably hot weather, are followed by those tubercles on the skin; and the first cold rains of autumn following an uncommon hot summer, also, give rise to a notion of epidemy, from the great number of horses so affected, as well as to wellgrounded fears of contagion. In India they term it the rainy disorder (Burusatee), that comes after a series of hot and dry weather, followed by a murky damp air, in which the principle of blight is recognised by our coun- 
try folks there, who have come from the agricultural districts at home. Drinking cold water, standing in a current of air, after going a stage in summer, or entering a hot stable under the same circumstances in winter, are the certain precursors of all those disorders of the absorbent vessels which produce tumours, unless, indeed, the state of some vital organ-usually the lungs - be such as to incur a more imminent disorder from the like cold or check. See Chapters III. IV. V. That farcy is at its first appearance a local disease, is proved by its submitting to local applications for a complete cure; that it becomes ingrafted in the entire system by neglect, is ascertained by its contagiousness and ultimate incurableness. We are not to infer, because the buds which constitute farcy run along the course of the veins, that this is an original disease of the blood, though its heat and influidity contribute thereto; for this appearance is alone caused by inflammation of those numerous absorbent glands which occupy the whole animal frame, being so small exteriorly towards the coat as to be scarcely visible, until they become tumerous and break, and discharge their contents, after the same manner as those larger ones of the jaws, described above. Though they draw their corrupt nature from the vessels to which they are attached, they do not communicate their own evil state to the blood until the corruption extends far and wide, and the disease is incurable. Before this event, however, it acquires the nasal symptoms of the glanders, and communicates either disease to others, according to the state of health the receiver may be in at the time; thus proving the identity of the two-poisons, as $M r$. White insisted upon terming both, asserting that certain parts only of the body are obnoxious thereto. Thus we find the internal parts of the nose particularly liable to be affected by "the poison ;" the skin is very susceptible of its action, and the lungs do not escape the contagion ; for upon dissection, I find numerous tubercles on the left lobe, corL 2 
responding with those on the outer surface, which constitute the disease.

2. Inside the legs, and along the belly, the veins being larger, so are their attendant absorbent vessels, and consequently the buds are more luxuriant and difficult of cure. Sometimes no particular buds appear, but one hind leg assumes a general enlargement; and if fever prevail, whilst the nose is inflamed inside at the same time, it may be considered the very worst kind of attack, the inside of the leg soon becoming entirely ulcerated. The same is the case when the tubercles or swelling appear first about the pastern, and ascend upwards to the thigh. They are commonly fat patients that have this diffused swelling of the leg, which is now nearly connected with the cause of grease, and yields to a purgative and a diuretic, as directed below for grease. But not so when accompanied by the chancred nose, which discharges an offensive ichorous matter, and is succeeded by a gland under the jaw, swelling, and becoming attached to the bone. When this happens, the farcy is connected with glanders; and $\mathrm{Mr}$. White at one time termed it " the farcy-glanders." In this case give the farcy balls, No. 2, and wash the buds with the escharotic mixture below. But, if a single tumour of good size make its appearance on any fleshy part of the body or neck, let it be brought forward by the means prescribed at pages 26 and 56 , for it is then complicated with some disorder of the blood; and so it is if two sizeable tumours appear, only they will not in that case come to perfection, and must be reduced with the actual cautery, afterwards treating them as common ulcers. This is a stubborn and very infectious species of the farcy, closely resembling the Indian Burusatee, spoken of in the preceding section; and, when many animals are carried off by it, people consider it epidemic, and apply the epithet murrain to its ravages among horned cattle, horses, and sheep. In the first section, the causes which conduce to this general 
attack are assigned to unfavourable seasons : it forms the 5th class of Epidemy in Osmer's arrangement, page 106, of his Treatise. A well-timed bleeding, purgatives, and other drains, are found successful preventives in hot countries and forward seasons.

3. In all other cases of the tubercles appearing partially on the forelegs, neck, or knees, the disorder is of the mildest species; unless in those other cases, where one side of the horse is first attacked, and suddenly it shifts to the other side, which shows that the infection has been a long time incurred, and has entered into the animal's system. Whatever be the cause, or whatever the degree of attack, the buds are to be reduced by escharotics or the actual cautery, and afterwards the sores will put on a healthy appearance in the generality of cases, upon being washed with a strong solution of sulphate of iron, or the escharotic mixture below ; but, however favourable these symptoms, the cure is not to be relied upon without the aid of internal medicine. Employ the following balls awhile as directed, beginning with No. 1 ; but should this disagree with the horse's inside, as happens with certain weakly constitutioned animals, discontinue its use until the appetite returns, and the purging and much staling subsides. Half a dram of opium made into a ball, with meal and mucilage, effects this end in ordinary cases; and more securely, if a second ball be given in 12 hours after. Hence will be seen the necessity of watching closely the operation of these strong medicines.

\section{Farcy Balls.}

No. 1.-Corrosive sublimate ...... $\frac{1}{2}$ dram. Aniseeds, powdered ...... I ounce.

Mix well, with syrup, sufficient to make three balls, and give one morning and evening, continuing the same for 8 or 10 days, provided, as aforesaid, that the medicine does not disagree : for a very strong horse, the quantity of the mineral may be increased, after the first days,

L 3 
gradually, to double the quantity, and so should the aniseeds.

No. 2.-Sulphate of copper $\ldots \ldots .3$ drams. Corrosive sublimate ...... 1 scruple. Bark, powdered.......2 drams. Ginger, powdered..$\ldots \ldots 2$ drams.

Mix with Venice turpentine, sufficient to form 3 balls ; give one morning and evening, as in the preceding direction, increasing the strength of the active materials, by either adding to the weight of each, or dividing the like mass into two balls only. Let the same caution be used as in giving the ball No. 1 ; both medicines being calculated to disagree with the bowels of the strongest horse, after being used some time.

\section{Escharotic Mixture.}

Muriatic acid........2 drams.

Muriate of quicksilver .... 1 dram, mix, and Add water........... 4 drams, then Rectified spirit.. .6 .66 drams.

If considered too strong, add more water. Be careful in the application, as it destroys the skin wherever it may touch, and is therefore a more convenient application, when used by a clever hand, than firing the buds.

4. For ordinary mild cases, however, the wash recommended at page 119 is found sufficiently powerful for horses of fine quality. Some, however, use the blue vitriol alone, powdered, or in solution; whilst others adopt the lunar caustic. When the sores appear inflamed, or clogged with filth, let them be washed with a solution of burnt alum-1 ounce in a pint of water; and as the cure proceeds, much grooming, dressing, hand-rubbing, cleanliness, and regular exercise (not violent), will contribute greatly to complete restoration. The food must be generous and sufficient, under a course of the foregoing balls particularly; no mashes, unless it be of malt, when the patient appears to droop a 
little - as he will at the end of 2 or 3 weeks' treatmentnor give any water quite cold. Promote the action of the absorbent vessels, and those of the surface (lymphatics) particularly, by giving the antimony, the nitre and resin, and other restoratives, as prescribed for surfeit (page 120). By thus increasing the secretions and excretions, the remains of the disease are carried off; to which end, also, the dunging should be watched, and not suffered to acquire hardness. Reduce this unfavourable state by green food or mashes, if the animal put on flesh, which is seldom the case; but if his condition has been low, and it is thought necessary to keep up his stamina with corn, a mild aloetic purgation becomes indispensable: give the ball at page 46 .

\section{Glanders.}

15 An interesting, because a difficult subject, involving much curious obscurity, and too much discussion; incurable by any means yet known, though often removed; contagious, though not always communicable; evidently a disease of close stables, or other confined places, yet attacking horses that never enter one-even those at sea; and, lastly, when leaving its locality, it enters the system, and devolves into farcy, submitting to a specific course of treatment; - the glander question seems a chapter of contradictions we scarcely hope to reconcile. Yet may this much be beneficially premised of an antidote to horses engendering the disease, though not so, perhaps, to contagion-that salted hay has been given to several working teams, among which glandered subjects appeared occasionally, without any increase to the number of the infected, during the whole of 1831 ; whilst washing the nose with salt water is found to cleanse the ulcers, to lower the lividness of the membrane, and to increase the general health, on which depends the cure-if ever it has been effected.

1. The preceding four sections, which comprise our 
view of farcy, with its remedies, may be taken as introductory to the study of that opprobrium of the art, which acquired its name from one of its symptoms only-viz., swelled glands, though evidently a primary disease of the nose. At least, the membranous lining thereof becoming inflamed through hard work, chronic catarrh, or infection, discharges matter from one nostril only at first (the left), then communicates its baleful influence to the glands under the lower jaw, which swell, and become attached to the bone. The animal is then a glandered one to all intents and purposes, whether horse or man (for the disease is communicable to our species), with several degrees of virulence, according to previous health, but without hope of a cure, despite of certain pretences recently set up. Under such circumstances, what is to be done? What, but avoidance of the cause in the first place; 2ndly, as infection is believed the most general mode of propagation, we should inquire what is the true glanders; and, $3 \mathrm{dly}$, we may set down the course of proceeding whereby glanders have been removed, as asserted, and guard the reader against quackery and delusion. See page 41.

2. It is not every horse that will take the glanders by infection, though placed under all the precise circumstances of others which have caught it; $i$. e. breathing the same air of the same stable during an entire night. Nor will every horse contract the glanders, though placed in the self-same predicament as others that do incur the malady ; as witness the case of 22 cavalry horses on shipboard (narrated in Hinds's Veterinary Surgery, page 348 ), all which were variously affected, some violently glandered, others trivially, some not in the least. Hence we coine to the conclusion, that previous health constitutes the sole difference, as to the degree, and as to the whole fact. So we know, that exceeding strong work has brought on the glanders on weak constitutions; a simple cold effects the same for some few ill-fed individuals ; whilst the greater number, going over the same ground, 
in company, being hearty ones, have escaped, and do escape, both the simple cold and the glanders. To imperfectly-cured strangles, we have no hesitation in attributing several cases of glanders that happened under our own inspection; and by parity of reasoning, any ill-cured disorder of the organs of life (of the lungs principally), leaves the system in such an unhealthy state as to expose the individuals so mis-treated to incur glanders by any and every means of communication, as soon as exposed thereto, which the healthy animals shall escape, and in truth run no risk of incurring. The same was observed by us regarding the distemper or epidemy at page 53 ; the predisposition thereto depending greatly on the individual's actual health, and the wise precautions of the owner.

3. Whatever person undertakes to teach proprietors that those disorders are not contagious, is doing an irreparable injury to society, by throwing people off their guard; as he must have come to his conclusion too hastily, without sufficient preparation, similarly to our untaught ancestors, who had occasion to lament astorishing devastations of cattle of every description, by contagion occurring from time to time all over Europe. On the other extreme, we find some persons crying out " Glanders!" at every discharge from the nostrils, and invocating coercion over the property of others, with a relentless ire, equal to their own conscious uncertainty. If both nostrils run, it is not the true glanders, though long continuance of the discharge may produce that effect. If the membrane that lines the nose is of the same colour on both sides, it is not glanders, even though a spot resembling a chancre may be visible there; for this is but the orifice of the tube that brings the tears from each eye respectively, and both are now a little enlarged and watery. If the horse be affected thus on one side only, and that the left, we shall find the gland or kernel under the jaw enlarged on that side only, in two or three days; this is the true glanders. But if the 
newly-affected horse have a cough with these two corresponding symptoms, be assured he has not yet got the true glanders: if he be not an aged one, we should then pronounce this an attack of bastard strangles, that may probably degenerate into glanders; or it may be a catarrh, or (if very old and abused), the asthma, or consumption, but no real, bona fide, infectious glanders. After awhile, according to previous health, the discharge and the livid colour of the membrane, hitherto cunfined to one nostril, now affect both, and the running becomes fetid, the cartilage rotten. Has the inquirer still any doubt? Let him take a portion of the foul nutter, and drop it into water : if it sinks, he may be assured of its being real glanders, and it will likewise mix with the water upon being well stirred about with a stick; but when the discharge is the effect of a cold only, it swims near the surface, and preserves its slimy and ropy nature notwithstanding the stirring.

4. All applications at the nose, except to cleanse away the filth, having been found absolutely nugatury and delusive as cures, and the practice of scraping and trepanning proved equally barbarous and futile, we reject them all, together with any preparation of mercury the art of chemistry has devised. Sulphate of copper has recently engaged the attention of several experimentalists, some of whom say they have succeeded in curing the glanders by administering constant small doses, but with the acknowledged fact, that they thereby destroyed the coats of the stomach, which often compelled them to desist ere sufficient trial had been given of its efficacy! Very good feeding should accompany the exhibiting any such a potent remedy - an indispensable concomitant to the cure, we have reason for saying the gentlemen were very likely to overlook. Whoever would again try this species of experiment, let him give it in solution, by means of the stomach tube, described in Chapter XVI.

5. Glanders have been cured spontaneously on a large scale, under our own inspection, solely by regular 
good living; a fine sea-side country and moderate work being the only adjuncts. With such an auxiliary, Venice turpentine, diffused in steam, at the nostrils, has removed recent cases of glanders, wherein the chancres were already visible, the discharge fetid, and the gland hard and fixed. To apply this remedy, make a bran mash, hot, in which the turpentine is to be mixed; attach this, by means of a nose-bag, to the horse's head, and renew its warmth in a quarter of an hour by means of a pail of hot water, into which the bag is to be partially immersed. Afterwards cover the body, neck, and head, so as to promote perspiration; but, if this do not come on by those means, cover the body first, in a large blanket wrung out in hot water-rub dry, cover up, and repeat the same daily. In all such cases we have given salt in every form the patient would take it-in his feeds, in his water, and washed his legs and his nose with salted water. With the same view we hear of sulphate of iron being given in the water, the pail being suspended in the stable for the horse to drink at will.

Cantharides have been spoken of, vehemently, in a ponderous volume; but the author (Mr. Vines) has not enabled his readers to carry his suggestions into practice : they failed in our hands, and we have inquired in vain for any attestation of success on his part.

\section{Fistula in the Withers.}

1. At its first appearance, this disorder may be repressed with very small trouble, being little more than a saddle gall, but deeper seated. When the horse is found to trip frequently, or to fall down unaccountably, remove the saddle, and search at the withers, and along the whole of its bearing, for the cause, when the horse will flinch from the touch, and the part will be found very hot, with an inconsiderable enlargement, or none whatever. In this early stage, wash frequently with the 


\section{Cold Lotion.}

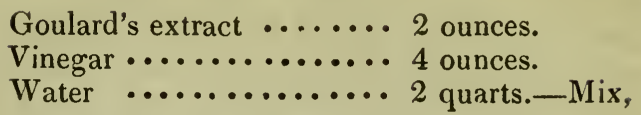
and apply with a sponge. If the case is recent, and the horse is otherwise healthy, no other treatment will be required. But such slight cases, it must be confessed, occur but seldom, the same carelessness which permitted the original fault, inducing a culpable neglect of these first symptoms-dangerous and monitory as they must prove on the road.

2. In the next stage, the cure is also extremely easy, being at first simply a tumour, that is reducible by the usual treatment, described in the early part of this chapter, page 117; but when neglected, it degenerates into a fistulous sore, proves extremely difficult of cure, and cannot be removed without severe treatment. As soon as the swelling is perceived, fomentations should be applied to promote suppuration; and when matter is formed, let the tumour be opened freely at its most depending point, so that its contents may be completely evacuated by pressure, and future accumulation prevented, by keeping open the lips awhile. When these are washed and sloughed off, heal the sore with digestive liniment or ointment; but should these fail to effect their purpose, apply the detergent lotion 3 or 4 days, until the sore assumes a red healthy appearance, and the matter issues of a whiter and a thicker consistence.

\section{Digestive Liniment.}

Tincture of myrrh ....... 2 ounces.

Corrosive sublimate .....10 grains.-Mix.

\section{Detergent Lotion.}

Soft soap, diluted .......2 2 ounces.

Water of acetated ammonia 1 ounce.-Mix.

3. When, however, the disease has been neglected in 
its first stage, and the offensive matter suffered to penetrate in pipes among the muscles, affecting the ligaments or bones of the withers, a more decisive treatment is then rendered indispensable. Still the tumour seldom comes forward to ripeness, naturally, but is ascertained to be making its way in several directions-more fearfully when tending downwards. Fomentations of warm water, in which cloths have been steeped and slightly wrung out and applied to the parts, will be found highly serviceable to this end, and may be succeeded by poultices of any material. When ripe, open the most prominent part, and insert at the orifice a whalebone probe to ascertain the direction and extent to which the fistulous pipes lead; cut down upon each of these its whole length, excepting only that one which tends towards the shoulder, so far as to interfere with the action thereof. When this extreme case occurs, the horse goes a little lame, and the knife is not to pass all its length, but a seton is to be inserted freely into its lowest or most depending part, and kept open, so as the whole of its matter may escape through, and finally the slough come off by the same orifice-which is then much enlarged, by saturating the seton tape with an irritating mixture, composed of spirits of wine, 2 ounces, corrosive sublimate, 1 scruple. In bad cases, we must not expect that the pipes will slough off without being stimulated thereto by the

\section{Hot Mixture.}

Take resin, tar, mutton suet, and bees'-wax, of each.. 1 ounce;

Melt slowly: take the ladle off the fire, and mix into it Spirits of turpentine ..... l ounce, And verdigris .......... 3 drams.

Pour into the open pipes, hot as it may be, and wrap up. Secure the sound parts from contact with this mixture, and also from the corrosive nature of the running matter, when the dressings are applied. These are to 
commence when the sloughs which the hot mixture occasion separate from the living parts, which is generally found to be effected in 2 or 3 days.

4. If the surface of the sore appears red and healthy, and the matter comes off whiter and of thicker consistence, a repetition of this painful operation will not be necessary; but many farriers repeat " the scalding," as they term it, twice in every case, though the necessity thereof may not appear by the nature of the sore. In after practice, $M r$. White did not maintain the propriety of his " very hot ointment;" nor is he known to have practised "scraping with a drawing-knife the carious bones of the withers;" nature performing this operation for us, in the constant disposition to throw off every thing offensive, by the joint process of secretion and absorption. Cleanliness being very conducive to the cure, the parts affected should be well sponged out every day at dressing; and pledgets, made of linen, rolled up with a point, should be introduced, spirally, to the bottom of each pipe, so as to draw forth what matter may descend and lodge there.

\section{Digestive Ointment.}

Common turpentine .....4 4 ounces.

Yolks of two eggs $\ldots \ldots \ldots$ mix well, and add Myrrh, in powder .....4 drams.

Gum mastich......... 2 drams.

Tincture of myrrh, sufficient to bring the whole to a proper consistence.

Should the healing proceed too fast, sprinkle on the dressing a small portion of sulphate of copper.

\section{Poll Evil.}

1. Although ascribed to some injury inflicted by man, truly, in many cases, yet have we reason for saying that abscess at the poll has arisen spontaneously; and in every case its virulence would be in proportion to the predis- 
position of the individual to contract tumours of one or the other description, as set forth in the present chapter more than once.

A bruise is the mildest origin Mr. White assigned to this terrible-looking disorder, the which, by early attention, might easily be cured; though without any such external cause, it frequently assumes a most alarming appearance, and baffles our efforts too long time, as regards the class of animals usually attacked by it. If the offensive matter be suffered to continue its ravages inwards and sideways, it frequently proves more difficult of cure than fistula in the withers, and cannot be subdued without our having recourse to those avowedly strong remedies recommended in that noisome disease. Like it, also, may a slight attack be repressed by the means set down at page 131 , though but seldom; for the less that can be seen or felt of the disorder, the deeper it is seated, and therefore the more danger is to be apprehended from its ravages upon the bone and muscle, and sometimes on the ligament which connects six out of the seven bones of the neck together, and suspends the whole by an attachment to the withers and back. It is to the great action of the neck, imparting its influence by friction (?), to the knoll bone, or poll, that is to be ascribed most cases of poll-evil and the exceeding virulence of every attack; for, at that precise point the said ligament terminates its attachment. Ordinary horses are mostly subject to this disease.

2 . When the tenderness and extent of the evil has convinced the owner that time would be thrown away in any futile attempt at repressing it, he will adopt the more bold and decisive mode of treatment pursued in the case of fistula. Bring the tumour forward to ripeness by the same means, or somewhat stronger applications : mix chopped onions with the poultices; and when the opening has been effected as there directed, let the hot mixture be made stronger by increasing the proportion of turpentine. Prepare the whole mass in 
larger quartity, so as to bear some relation to the superior size of the present opening; apply the same two or three times, until the whole evil is sloughed off completely; and wherever the matter appears pent up in sinuses and corners, by membrane running transversely, use the knife fearlessly, applying the point to these, and avoid cutting acrosswise, and also of touching the neckbone behind the knoll, where the ligament before mentioned has its upper attachment, otherwise, the liorse will carry low his head ever after. Sometimes it becomes necessary to employ a more

\section{Potent Hot Mixture.}

Hogs'-lard and common turpentine, of each......4 4 ounces.

Melt over a gentle fire, and add the following mixture:

Spirits of turpentine ..... 3 ounces.

Vitriolic acid.......... $1 \frac{1}{2}$ ounce.

Mix these intimately in an earthern glazed vessel, by pouring the acid to the spirits; let the compounder avoid the deleterious gas which then ascends, by standing to windward. Pour this to the former mixture, and apply, as in case of fistula, hot, but not "very hot." Do not keep the ladle on the fire after the two sets of ingredients are commixed, as the spirits would fly off : that must be taken as an oversight of Mr. White's successors, who ordered the contrary course.

Complete the cure, by applying the digestive liniment at page 132 , or the ointment at page 134, and follow the treatment there directed, as well as the "cleanliness" recommended at the same page.

\section{SaDdLE Galls-(Warbles) Sitfast.}

1. These are but different names for degrees of the same disorder, proceeding from the same cause (saddle pressure)-the tirst mentioned being inflamed tumours, 
whilst a sitfast is a callous one : both produce sores, the first spontaneously, or by course of treatment, the second only by an operation. The cure of both is effected by the same means; being those (nearly) employed in cases of fistula and poll evil.

2. As in the two preceding articles, repression of the saddle galls may be tried, with more reason and greater promise of success than usually attends such attempts in fistulous cases. With this object in view, apply the cold lotion prescribed at page 132 , by saturating several folds of linen therein, and renewing the same afresh many times a-day, until the tumour gives intelligible signs of decay; but if not so, and the case appears obstinate, this course must be abandoned, as in fistula and evil, and our efforts should now be addressed to its increase, ripeness, and subsequent discharge. When swellings of this kind are large from their first appearance, and much inflamed, this ought to be the treatment from the beginning-viz., procuring suppuration by means of fomentations and poultices, and then using the knife or lancet. Dress with digestive liniment (page 132), or ointment (pagel34), and follow the same instructions as those given for fistula, \&c. Seldom, however, does it happen that we find occasion to employ the hot mixture to the mere saddle gall sore, such extreme cases being of rare occurrence with horses of any relative value.

3. Sitrasts: their nature is somewhat implied by the name, and consist of indurated tumours, the remains of ill-cured warbles, or an original gall or bruise, insufficient to create inflammation, and therefore without matter; a callosity, to the touch resembling leather. Blistering the tumours, or merely washing with the detersive lotion, will cause the edges of the induration to separate, and it is then to be removed by force or the knife; the sore which remains may be healed with the digestive liniment (page 132), or any greasy ointment. Should a protuberance remain, apply the lunar caustic; 
or it may be prevented by sprinkling a little blue stone, powdered, upon the dressing.

\section{Ointment for Sitfasts.}

Camphor $\ldots \ldots \ldots \ldots \ldots \ldots 2$ drams.
Oil of origanum $\ldots \ldots \ldots 1$ dram.
Ointment of mallow leaves 4 ounces. -mix.

\section{QUITTOR.}

1. Like the foregoing disorders of the Poll, the Withers, \&c., though Quittor is justly ascribed to a bruise, or to a tread at the coronet, its malignancy depends in great measure on the horse's health in other respects. So, when sympathetic fever falls into the feet from the lungs, causing contraction and compression, the corns and canker which follow not unfrequently produce quittor; which is then cured by giving vent to these disorders at the sole, unless the constitutional health be bad. And the same when the cause is well known to be a prick or wound inflicted by the shoeing smith; though the treatment that follows, is very different under the several eircumstances. If not attended to in time, the matter engendered by the wound penetrates in various directions, though the original puncture be scarcely visible; the pipes or sinuses extending in all directions, at some places admitting the probe to pass downward under the hoof, at others forwards or backwards in the course of the coronet, or directly inward upon the cartilage; which in time (though the disorder may not proceed to the extent here contemplated) becomes as hard as the bone whence it proceeds, and occasions "lameness of the coffin joint," as shewn at $d$ fig. 6 .

2. In the first case of quittor appearing, whether from a tread, or spontaneously, the remedy is very simple, and consists in introducing any caustic whatever, as verdigris or corrosive sublimate, to the entire seat of the disorder. Take of thinnest tissue paper, smear it over 
with lard or butter, and sprinkle thereon a few grains of the sublimate; roll it up into a point, the size of the pipes, and effectually introduce one of these pledgets to each pipe : cut off the ends close, and cover the whole foot with an ordinary bran poultice to alleviate the inflammation and pain that will necessarily ersue. Keep up the horse's head in a cradle. After a lapse of 3 or 4 days, the caustic will be found to have done its duty: the core will slough off, leaving a large opening, with a red healthy appearance. Dress with digestive ointment or Friar's balsam, and if any part do not look thus healthy, wash it so far with a solution of blue vitriol, or sprinkle the part with the vitriol in powder, and place the dressing over the whole.

3. In case of quittor arising from a wound in the sole, the cure greatly depends on making an opening at the exact seat of the original injury. Dress the opening thus made with the compound tincture of benzoin and digestive ointment. A poultice will be required to soften the horn and to subdue the inflammation that ensues.

\section{Grease.}

1. Previous health and condition have great influence on the degree and continuance of this disease; whether it decline before the first slight remedies, or resist for a long time the strongest means employed for its removal, returning again and again at intervals, whenever the horse is exposed to cold after exercise. Ill-constructed stabling, with shallow stalls, is the chief exciting cause of grease; and a horse which has once suffered this disease continues ever after most liable to contract it, by being led into a cold stream of water, or standing in the cold after strong exercise; whereas another horse, with better legs, might, under the same mischievous practice, contract farcy, perhaps, if not the more inflammatory fever. Another erroneous practice is too generally fol-. lowed, of clipping the heels of horses, which by nature require to have the hair long; for, in proportion that the 
legs are hairy, the skin is thick, soft, and spongy, and therefore liable to the full effects of being thus deprived of its natural defence against cold and wet. In proof hereof, remove by spreading abroad the hair upon the shaggy heel of a waggon-horse which has been out in sloppy weather, so as to examine the state of the skin, which will, notwithstanding, be found dry and warm. Again, if such a leg swell after being clipped, the application of a flannel bandage at night will remove the complaint by morning. Generally, however, the horses most subject to grease, are those which suffer under a debilitated constitution, wherein the secretions are carried on with languor and the excretions are consequently imperfect, particularly the urinary. And this may be the case, although the horse with little work to do may appear in fleshy condition, yet his system stands in need of being invigorated; as hand-rubbing, generous feeding, with as much voluntary exercise in a loose box as he can obtain, and a laxative ball, if the state of his dunging require it, followed by tonics.

2 . Such a ball generally improves the urinary excretion also, which is found the principal curative of this disease; at least in slight cases, when the heels have been first well washed in warm soapy water, and brushed out dry and clean, and then washed with the astringent lotion 5 or 6 times a-day. If the inflammation be considerable, reduce it by means of an extensive poultice for 2 or 3 days at least, made of bran, meal, or turnips, not $h o t$, and then apply the lotion as directed. Keep the poultice moist and fresh, whilst required ; remove it several times on the first days, clip the hair close, and observe cleanliness. By this treatment, the discharge becomes less and less offensive, or ceases altogether, and cracks appear. Let these be washed in strong alum solution, and a thin film will cover the parts next day. If the urine does not flow freely, as it ought, give the alterative powder below.

3. When the disease is of long standing, or the horse 
has suffered from it before, more difficulty attends its removal, and these powders must be persevered in until it disappears. In very obstinate cases, a rowel in the thigh will reduce the swelling, and improve the quality of the discharge. A run at grass is found necessary to complete the cure; and, in the mean time, green food, as carrots, vetches, cut grass, clover, and bran mashes, may be given, a change of diet being highly conducive to the desired absorption. Should the patient become debili.tated and droop, raise his spirits with good oats, sweet hay, and a meal mash now and then : if he put on flesh and appear gross, give the alterative balls and powders; in such cases as these bleeding moderately has been found serviceable, as promoting absorption. Indeed, every change that is effected in the treatment, medicine, diet, air, and exercise, all tend to cause the all-desirable absorption, or taking up into the systern, the offensive nature of this disease, in common with most others of its class; and this is the reason, and our apology, for the number of things prescribed in carrying on the cure. Much trouble, care, and labour, are necessary to effect a tolerably perfect cure; which appears to be an appropriate punishment for the indolence, carelessness, and neglect of cleanliness, which first brought it on.

\section{Astringent Lotions.}

No. 1.-Alum, powdered ...... 1 ounce. Vitriolic acid $. . . \ldots . . .1$ dram.

Water...$\ldots \ldots \ldots 1$ pint._Mix.

No. 2.-Corrosive sublimate ....2 2 drams. Muriatic acid......... 4 drams. Water $. . . \ldots \ldots . .1$ pint.-Mix.

The latter, although strong, may be improved by adding blue vitriol, 1 dram.

\section{Astringent Powders.}

No. 1.-Alum, powdered .....4 4 ounces. Bole, powdered ........ l ounce.-Mix. 
No.2.-Vitriolated zinc ....... 2 ounces. Bole, powdered ....... 2 ounces.-Mix.

\section{Astringent Ointment.}

Hogs'-lard ........... 4 ounces. Oil of turpentine $\ldots \ldots \ldots 2$ drams. Acetated water of litharge $\frac{1}{2}$ ounce.-Mix.

\section{Alterative Powders.}

Nitre and resin, powdered, of each ...........4 4 ounces.-Mix, and divide into 8 doses, one to be given in the corn at evening stables.

Mercurial Alterative.

Calomel .............. $\frac{1}{2}$ dram.

Aloes ............... 1 dram.

Hard soap $\ldots \ldots \ldots \ldots \ldots 2$ drams.

Oil of juniper ...........30 drops.-Mix with syrup into a ball for one dose.

as Whoever has pursued the foregoing investigation of the tuberculous disorders incident to horses, the most prominent whereof and oft-recurring, we now bring to a close, must have observed how much one kind depends upon another; insomuch, that no two of them ever appear together in the same individual, unless when one supersedes another, as the farcy-glanders; he will, therefore, come to the conclusion, with us, that a vitiated state of the animal system attends every case of tumour connected with the circulation of the blood, as all those treated of in the foregoing pages most assuredly are.

\section{WATER-FARCy AND WeNS.}

1. Very obscure in its origin, and by some ascribed to chest founder, from the stiffness of the legs, inability to 
graze, and occasional lameness; yet, from its resemblance to the diffused swelling of the hind legs, which characterizes the worst stage of farcy (page 124), we prefer its old name. Although termed Antecoeur (Anticor) by the French, from its situaticn before the heart (or coeur), we coincide with the vulgar English in ascribing it to the same cause as farcy, with dropsical symptoms superadded, the effect of great debility that arises from change of coat. It is considered epidemic, and is then accompanied by sore throat. See Catarrh. An enlargement at the breast, with an extended base towards the throat, that threatens suffocation, denote this rather foreign than English disorder, that is here further attended by symptomatic fever and inflammation of the surrounding muscles, which waste away by long continuance.

2. Bleed without delay, copiously; give the mild purging ball at page 46 , preceded by a bran mash, and followed by more. Foment the swelling three or four times a-day, at least, with bran water: promote absorption by varying the food, $\& c$., as directed in a preceding page (141), and give daily, for a week or more, the following-

Fever Balls.

Emetic tartar.........2 drams.

Venice turpentine .......4 drams.-Mix, with liquorice powder sufficient to form 1 ball.

3. Examine the swelling: if upon pressure it retains the pit made by the finger, it is a sign of dropsy, and the water must be discharged by puncturing in several places, and on the lowest or most depending part of the swelling. Continue the fomentations, and encourage the discharge by keeping open the orifice with tow pledgets. Sometimes the swelling runs along the lower belly towards the sheath; the treatment, however, is the same. At other times it assumes a more distinct form on the breast, and then acquires the name of AMBURY, or 
4. AnBURY. This tumour is not very frequent, though we have found hunters of great worth so disfigured, for the thing itself neither obstructs the pace or endangers the rider. The Anbury is supposed to come of a blow from bushes, or prick of thorns, in leaping hedges, and consists in an enlargement of the true skin - on the carcase mostly. 'Those which form with a narrow base are easily removeable by tying a horse-hair tight round it, and in about a week the tumour falls off, when it is to be treated as a common sore; unless, indeed, a part of the root is left behind, as usually happens, when this must be previously extirpated with the actual cautery, the knife, or by sprinkling thereon powdered copperas. Some of these tumours have much blood in them, which proves a connection with some minor artery; the flow of blood from such an one should therefore be stanched as sonn as the tumour drops (or can be taken away), by the ligature, or by the cautery. Dress with the digestive ointment. After this treatment, purge or bleed, according to circumstances of condition and health, and as those other symptoms may indicate.

5. WARTS and WENS, which have little or no feeling in them, rise in various parts of the skin; the latter kind being seated in the true skin, have a connection with a small vein, and require treatment; whereas the nart is seated in the scarf skin, and is easily eradicated by means of the scissors and searing the part, or applying a caustic thereto, as verdigris and savin leaf, in equal quantities. If the wen come not on a sinewy part, or near a joint, extirpate the same with the knife, by dividing the skin only from the bottom upwards, and drawing it back : the swelling is to be levelled with the adjoining surface. This was the old practice; the following is far preferable. If the wen can be drawn out whole by the pincers, the cure is then effected by merely lapping over the skin and strapping it down with the adhesive plaster, the hair having been previously shaved off. With the wen a nerve-like string comes away, of good length. 


\section{CHAPTER XII.}

Wounds and Brurses :-Inflictions; Strains;

Dislocations.

1. All those disorders we come now to inquire into, their nature and means of cure, under their several subdivisions, may be considered external violences, committed by man upon his faithful servant-the horse. We turn, without relief, from the pains incurred through the ignorance or injudicious treatment of his master, to those others that are inflicted by his ambition, his pleasures, his profit, or his brutal passions.

2. All the wounds of horses are incurred under circumstances of great excitement, whether in war, in the race, or on the road; reckoning as nothing here those few which come of sheer carelessness in keeping and shoeing. Most cases of the kind we now contemplate are likewise tolerably recent, when brought to be cured, so that we can ascertain some of the attendant circumstances with sufficient accuracy for our purpose ; for example, the amount and manner of contusion, the quantity of blood spilled, \&c. Because, when the first has been much and the other little, further bleeding, to a good extent, becomes indispensable; but not so when much blood has been already lost, as is the case in incised wounds, wherein no bruise or contusion accompanies the cut, and enough has already flowed to keep down the feverish symptoms. Promptitude stands us in good stead in all such events. The first necessary opera- 
tion is to remove carefully all dirt, or other extraneous substance; washing the wound with water, not cold, and searching for stubs to its base, which should be injected with a syringe.

3 . If the wound has been inflicted with a clean cutting instrument, unaccompanied by bruise or laceration, and the divided parts do not gape much, they may be neatly sewed together, so that the cure shall be effected by the first intention. This may also be accomplished better in some cases, by bringing the parts together, and keeping them in position by a firm bandage ; for, should the stitches rend asunder, the cure is thereby defeated, and life endangered : our choice in this respect must be guided by the part that is injured. A roller must be applied of sufficient width, and kept constantly moistened with the saturnine lotion (page 132), diluted with an equal quantity of water, to assist in retaining the parts in their situation until they unite, which may take up 4,6 , or 8 days; unless, indeed, considerable swelling and inflammation come on, when it becomes necessary to remove the roller, in order to apply the fomentations which are requisite in all such cases. At any rate, the roller will be found serviceable in stopping the flow of blood from the more considerable vessels, which have been effected by compression. The principal obstacle to this re-union of the divided parts-and which we must not attempt until means have been prepared to overcome it - is the natural restlessness of the patient; and which we can only accomplish by strong ligatures, by slinging, cradling the head, or splintering the limb, or limbs, according to circumstances. Add to these means, the reduction of the animal powers by depletion and purgation, with comparative abstinence, and we may reckon upon a few days of tractability, without any doubt as to the result.

Fever will naturally supervene from the first hour of the accident, which will change its symptoms as the cure goes on; the medical treatment whereof may be 
now instructively studied by turning to page 29. Keep up the evacuations.

4. Contused wounds, however, accompanied by laceration, are more frequent than the simply incised; still the union should be always attempted (if a desirable animal), unless wholly impracticable. Fomentation of the parts, often, then becomes necessary, in order to promote the formation of matter in the wound, and the reduction of the surrounding effusions, by forwarding the absorption thereof. Should considerable swelling and inflammation arise, moderate bleeding near the affected parts, with further laxative medicines, or more active physic, are highly proper: a poultice will alleviate the symptoms materially. As soon as those symptoms shall have been removed, discontinue the fomentation and poultice, and apply only the digestive ointment, or the liniment (page 132); but should the wound appear indisposed to heal, discharging a thin offensive matter, apply instead of this, the detergent lotion (page 132). When the granulation of new flesh goes on too luxuriantly, that is, when what is called "proud flesh" makes its appearance, the caustic powder (blue vitriol) is to be sprinkled on the wound. Notwithstanding the formidable appearance of some such wounds, nature does wonders for the renovation of the parts, the surgeon being but a humble assistant in aiding its powers. Slight wounds heal generally with very little trouble, and sometimes without the interference of art. In wounds of this kind, tincture of myrrh (the digestive liniment, at page 132), or the compound tincture of Benzoin, are found efficacious; the latter chiefly when the injury has been inflicted a long time, and the cure goes on tardily, and stands in need of stimulation.

5. Punctured wounds, or such as have been made with sharp-pointed instruments, are generally productive of more inflammation than those that have a more formidable appearance ; and if such wound happens to penetrate into a joint, or the cavity of the chest 
or belly, the worst consequences are to be apprehended, unless it be skilfully treated. The effects hereof were auticipated, when treating of inflammation, at page 29 . When a joint has been so punctured, the synovia, or joint oil, may be observed flowing from the wound. Hereupon, the first care is, to close the opening that has been made into the joint; for, as long as it remains open, the inflammation will go on increasing, and the pain will be so great, as to produce symptomatic fever, which has often proved fatal.

6. The most effectual method of closing a wound, is by applying the actual cautery to its lips; but this is only applicable to those cases wherein the wound is of the punctured kind, and small; for, when the wound is large, and of the lacerated kind, it is next to impossible to close it effectually, by any means, and death is frequently the consequence. As in the preceding cases, when the opening has been closed, if not done before, it is of the utmost importance to guard against the inflammation that may be expected to arise, or to remove it, if already present. To effect this purpose, bleeding and purging are the most effectual remedies; and a rowel near the affected joint, above it, will be found useful also. Should the joint be swollen much, employ the blister prescribed at page 58, around the base of the swelling, after the inflammation subsides a little.

7. Foot wounds, from stubs, over-reaching, taking up a nail, \&c. often prove troublesome, when neglected: in fine, this one word, NEGLECT, is the besetting sin of horse-keeping, from the crown of his head, to the sole of his foot. As soon as a horse falls lame, examine his foot, and take care no dirt enters the wound, or at least, that none remain. Apply the detergent lotion immediately, and then the digestive ointment or liniment, (page 132), and no more treatment will be necessary in ordinary cases. When the sensible part of the foot is wounded in shoeing, by driving the nails into the amella that connect the hoof and the foot-bone together, 
compound tincture of Benzoin is to be applied, which has the effect of closing the orifice.

8. Tendons, in like manner, are very liable to punctured wounds, or rather the membranous sheaths that surround those which are termed back sinews; and, what is most melancholy to relate, many such have been inflicted, in my own neighbourhood, by the fork at making up, or otherwise, through carelessness, or some worse fault, of the stable folk. Those sheaths being furnished with small secretory sacs, which produce a slippery fluid, resembling joint oil, any wound there causes the fluid to escape, under the skin, where it dries up, and is followed by great pain and inflammation; whilst incurable lameness is the consequence of severe medical treatment. If, moreover, the flexor tendon itself be wounded, the case is still more aggravated: excessive inflammation soon takes place in those hitherto quiescent parts, which occasions much trouble, and some risk. Let the lips of the wound be brought together, and retained by adhesive plaster; but, for small punctures only, the lunar caustic should be first applied, or white vitriol: in these cases, do not employ the actual cautery. When a swelling remains, reduce it with blistering, once or twice, after the inflammation has been abated by fomentations and the saturnine poultice. Bleeding is here again necessary. Gangrene sometimes ensues a high and long continued state of inflammation; in any situation, and under every circumstance of wounds, indeed, is that liability incurred, see page 29.

Saturnine Poultice.

Goulard's Extract ..... $\frac{1}{2} \mathrm{oz}$.

Water ............ 1 pint.

Linseed Meal ......... enough to make a poultice of the ordinary consistence : apply in a cloth wrapper. 


\section{BRUISES.}

1. In recent bruises, of any consequence, the embrocation, camphorated spirits, or any stimulant, if applied immediately, will disperse the effusion that soon takes place; but, after awhile, that inflammation is found to supervene, fomentations are the most appropriate remedies, with moderate bleeding, and a laxative, in either case. In slight cases, however, the contrary course is best: then wash the parts with the cold lotion, (page 132), diluted with water to one half its strength.

2 . If abscess forms, in consequence of a bruise, discharging large quantities of matter, particularly if the discharge be of a bad colour and offensive smell, the wound or ulcer also appearing dark-coloured and rotten, indicating approaching mortification, the horse's strength must be sustained by allowing a supply of oatmeal gruel, and malt mashes, in addition to his corn ; and if the appetite goes off, he must be drenched with both, or either, warm : give the cordial drench, if the malt does not raise his pulse a little: see Tumours, page 115.

3 . Should a callosity remain after the foregoing treatment, the embrocation is to be well rubbed into the part twice a day, and if this does not succeed, recourse must be had to a blister.

Embrocation for Bruises and Strains.

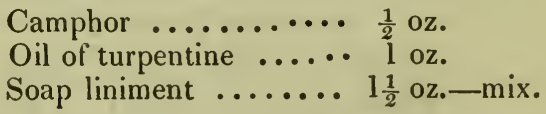

4. Blows and Bruises, as just said, (section 2), occasion swellings and abscess, when inflicted on fleshy parts, ill able to bear the punishment; the small fibres being broken, causes the abscess, and its disruption is its cure, as we have seen above, (pares 27, 116). But blows 
on the head, which we often see inflicted in the metropolis, subject horses to convulsive disorders in after life, for which there is no cure; and kicks or blows on the joints, frequently inflict incurable lameness, generally on capsular ligaments, which thereby become as hard as bone, and the joint enlarged and almost stiff. Blistering such a swelling at its highest margin, in a circle, all round, but not extensively, gives it relief, though nothing will completely cure: if the blistering be injudiciously carried on higher up the shank bone, the swelled joint will get larger in consequence; in fact, many cases of which we have been cognizant of the cause, arose from inflictions on the bone above the joint affected, but the effect had extended to the joint.

5. Horses at grass, at market houses and race stables, are frequently hurt by kicks and bites from others, most of them about the neck, back, withers and shoulders; and to such a degree do they maul each other, that a considerable swelling takes place, with inflammation, accompanied by symptomatic fever, (see page 38). Apply the repellant, viz. the cold lotion. (page 132), diluted with more water, or vinegar and water, stale beer grounds, \&c. If a tumour is found to rise up, discontinue this treatment; foment it, poultice the part, and open it when ripe, as before directed in other cases (Tumour, page 115); but as you will not now apprehend that it has any connection with the circulation, let the treatment be the same as for critical abscess, pages 26 $-28,56$.

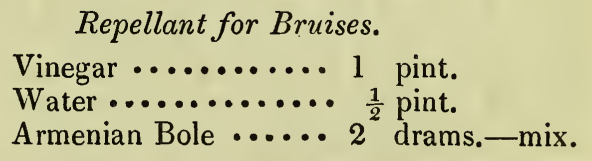

Broken Knees.

1. Generally occurring upon going a good pace, the amount of injury will be proportioned to the speed and 
the weight behind, (perhaps) propelling the horse along, whilst his knees are scraping a gritty, if not a stony road. If the mischief extends to laying open the knee joint, little hopes remain of effecting a cure; and, should the horse be one of moderate value, he would not be worth the trouble of a trial that is always expensive, and ever doubtful. However this be, we may ascertain the fact, by passing the probe to the base; by the depth it enters, and its grating, we find in how much the bone is laid bare. For further proof, apply a linseed poultice, and at the end of 12 hours, on removing it, we shall find the joint oil has issued, of a thin, yellowish cast, and we proceed, or not, at our peril. If the flow of oil continues, inflammation and gangrene ensue; this may be prevented, in some measure, by washing the knees, all round the wound, but not on it, with the cold lotion, (page 132), diluted with more water, before any poultice is put on. A digestive ointment is sometimes requisite.

2. Washing with weak lotion, indeed, twice or thrice, should precede every other application (next after sponging out the dirt and grit from the wound), to keep down the inflammation, which will always accrue, more or less, whether the skin be divided or not. According to the previous condition of the patient, will be obvious the necessity of bleeding, and other treatment, recommended above, for "Wounds" generally, sections 4-6. Rest is quite indispensable in every case, and in the worst cases, any departure from this injunction is always fatal; leading the afflicted horse to the doctor's, makes a part of this erroneous practice, and riding or leading him home, is but an aggravated version of the same error. Mere contusions may be brought to subside with no other treatment; and if the cut be not seriously lacerated, the cure is easily effected, by the bandage compressing the lips of the wound together; but in any case, should small portions of the skin hang pendant, let these be replaced so as to re-unite properly; loss of substance here being sorely felt in the sequel. 
The application of the hot iron, recommended by the compilers of "the Horse," can only succeed in case of small punctures, as described above, section 6. Mr. Cherry says, with more reason, that-

3. All wounds of the knee from tumbling down, must of necessity be contused wounds. They are not like a clean cut, where the separated parts being brought together, and kept in place a short time, firmly unite; but they are wounds with a loss of substance, which has to be supplied by new granulations. When the quantity of substance lost is but small, it is soon renewed; and, if the new formed parts are not bruised while yet tender, nor stretched by working the patient, all goes on well. The prominence, which is apparent at first, soon subsides, and the hair grows as before. How are these two opposite effects produced? Why, by more blood being sent to the part, and circulating quicker, which produces heat-by some persons mistakenly considered a morbid inflammation, though quite indispensable in carrying on the curative process of nature. The cure of broken knees is, in reality, a work of time; the injured parts regenerate slowly; nature will not allow her own efforts to be wantonly infringed upon, and very often it happens, that the best treatment devisable by man, consists in looking on and doing nothing !

4. After such an accident, the horse loses much of its value, if the hair does not cover the scar naturally, as also when any protuberance remains. Both objections, however, may be obviated in time, by the same means. In default of the heat and inflammation just alluded to, the protuberance usually resists being absorbed, whereupon artificial warmth is to be supplied by very mild blister after the wound has healed; which will not only promote absorption of the callosity, but stimulate the hair to grow thickly over the scar, of its natural colour. This being usually black, ivory black, and hog s' lard, are to be mixed with the blistering material; though some employ gunpowder and lard only. 
If a chesnut colour is required, Armenian bole is to be mixed with the digestive ointment before the scar is healed completely.

As a preventive, the knee caps of Messrs. Whippy, in the Borough, are found to answer every purpose of such a contrivance: they have our cordial approbation.

Infurctions.-Cutting; Strains, of Shoulder, Hip, Stifle, and Back sinews.

1. Cutting has its degrees and gradations of injury, according to the quantity of punishment inflicted, the part that strikes the blow, and the point that is stricken; merely touching one leg with the foot of the other, by the high bred horse, genteelly termed interfering, being productive of lameness in training, with all its consequences upon the owner's engagements. Turning in his stall, instead of backing sufficiently, on going out in the morning, principally, together with the strong exercise that immediately follows, being the prolific cause of the appalling announcement of "fell lame in training," when the bets run heavy; whilst the more ordinary horses, which do not cross the legs in turning short, as racers do, only inflict the cut or contusion in going apace. The common travelling pace inflicts the injury upon the fetlock joint; whereas the infliction is made near to the knce, only when the horse is on a swing trot or gallop, thence termed " the speedy cut," and is frequently accompanied by a dangerous come down both to horse and rider. Horses cut mostly after hard work over ploughed land, and young ones sooner than those whose bones are settled in their proper places. Such young horses require no more treatment than the protection of $a b o o t$, or defence of leather that covers the part stricken, until they acquire more strength, and grow to their proper form of going.

2. Much controversy as to the part which inflicts the cut, and the cause thereof, has amused and puzzled 
the gentlemen of many words and few ideas; but the whole affair is soon settled by two experiments : 1st, on the inflicting hoof and shoe let some tar be smeared, and upon being put in motion this will be rubbed off; 2ndly, as the cutting comes on mostly when the shoes are somewhat worn, and the toe does not point aright, take off and shift the worn shoes from left to right, and you restore the proper pointing, whilst the cutting is abated for the present. Having ascertained the part which inflicts the injury, rasp it down as much as may be done with safety, the inside of the hoof being exceedingly susceptible of every such reduction, which few feet can well afford to part with; if the fault be in the shoe, bevel it away on the ground edge, drive no nails, or but one on the inside, taking especial care that the outsides are well driven and well clenched, and hammered down again in a few days. As to making the shoe thicker at one branch of the heel than at the other, this will depend entirely on which quarter the tread is heaviest, being sometimes on the inner, sometimes on the outer; this fact, therefore, must be ascertained by the 2 nd experiment, as above. Cutting does not always depend upon the foot which inflicts it, indeed, bat seldom : the original fault lies higher up, viz. at the shoulder. This interesting fact has been fully proven in the lst Chapter of my "VETERINARY SURGERY."

3 . When a horse has been strained in hunting, his toes turn in, both before and behind; the same defects reversed, come naturally, when the knees or the hock turn in, and the toes turn out: the first mentioned defect is termed "pigeon-toed," when the quarter next to the toe inflicts the cut or bruise, chiefly the speedy cut; the second, or cat-hammed and knee-knocked defect, cause the toes to turn out, when the quarter next the heel inflicts the injury, and if the shoe is made wider at the branches than the hoof, as it ought for wellformed legs, then it is the shoe heel which requires reduction. Some horses have the fore limbs set on, high 
up at the shoulders, so that they go "low before;" and are those which wear away the inner quarter, or batter the hoof much on the ground, well known as " highgoers ;" whilst the contrary form of limbs, set on low on the carcase, occasions the tread to bear greatly on the outer quarter. $M r$. White was in acknowledged error, when he expressed his opinion, that " the toe inflicted the wound;" though he was quite correct in directing one more remedy-" keep the toe as short as possible," says be, truly ; as this strengthens the inner quarter, and causes it to grow more upright, whilst the long toe occasions it to spread, or become splat-footed.

Saddle galls, sitfasts, or warbles, though rightly accounted bruises at first, yet have we treated those inflictions among the class of tumours, to which they very soon closely assimilate.

\section{Strains-or, more accurately, Sprains.}

1. On this subject every sportsman ought to be well acquainted, since his horses are particularly liable to such accidents, and still more so to vulgar misapprehensions regarding the situation of the injury, and consequent mistreatment of the malady. Strains, or rather sprains, are almost invariably disorders of the limbs, affecting either the fleshy parts, or the joints; that is to say, the connecting parts of joints, as of the ligaments that tie them together, or of the tendons which put them in motion: these latter are the flexors or back sinews, which sometimes give way in racing, so as to sever the ligaments, whereby the horse is emphatically said to ' break down'-as more particularly described below, at p. 161 .

2. Strain in the Shoulder. More frequently ideal than real, we must still speak of strain in the shoulder, rather as a thing possible than of frequent recurrence. Shoulderslip, is another of the vaguely asserted accidents of the fore limbs; and 'swimming the 
horse,' by way of cure, an equally ignorant and inefficacious attempt, long scouted by men of sense. Not but a cause of lameness is sometimes met with in the shoulder of the lower bred cattle ; but then it lies deep, obscure and incurable: tumour of the scapula, and on the side next the ribs, is not unfrequent; it is described below, (section 6.) In all asserted 'strain' of the limb, unless the true signs are present, and the rider or driver knows of the accident that occasioned the lameness, for it could not happen at ordinary work, the disorder is merely suppositious; it then lies in the foot, or joints. Examine the lower extremities, and consult in all cases what is said farther down, as to diseases of the footstrain of the back sinews, coffin-joint lameness, splents, spavins, corns, \&c. As to the 'Signs of lameness,' consult Chapter XV. section 2.; and keep in mind, that, although the first symptoms may abate, or wholly subside, on the horse taking exercise, yet, at its return, if the disorder lies in the upper part of the limb, or any joint, the lameness is worse after the exercise; but not so in the cases of spavin, windgalls, curb, and the like: it then is evidently relieved by rest.

3 . When the lameness really lies in the shoulder, the muscles of which exceed every other in coarseness and strength, it occasions inflammation, with great heat and tension of the parts - the attack comes on immediately after the accident, and is very considerable. Whereas, any lameness in the foot (for which it is so frequently mistaken), is generally gradual in its progress, (unless proceeding from a Wound,) and does not at all hinder the extension of the limb. On the contrary, in genuine shoulder strain, the toe on the affected limb is either drawn along the ground, or the patient moves his foot in a circle outwards, at every step he takes; great pain is evinced on doing this, and at rest, the toe is thrown pointedly forward. In violent cases, - as a fall on leaping over, or on going fast down-hill, the horse appears wholly incapable of extending any part of the limb. 
4. As the disorder in these cases lies very deep, viz. at the attachment of the shoulder blade to the ribs, bleeding must be resorted to; but, if not a very bad case, and lying near the surface, fomentations of marshmallows, or of bran and camomile flowers, applied to the lower part of the chest, and withinside of the arm, will afford relief. In case of bleeding, operate upon the plate vein, and give the laxative ball, page 46 . If the injury is considerable, insert a rowel at the chest; give perfect rest, and a loose box as soon as the pain and inflammation abate, which may be promoted by the cold lotion. After awhile, take walking exercise, in hand, unless great pain be evinced, though some reluctance to move about may be expected, before those very strong muscles regain their right action: if the recovery be long procrastinated, a blister will assist it materially. A 2 or 3 months' run at grass, will not be a day too inuch to complete the cure.

5. Strain of the Stifle. In this case, the stifle will be found unusually hot and tender to the touch, with swelling. Apply fomentations, which suffice in slight cases; if not, apply a rowel, and give the mild purging ball, at page 46 . When, by these means, the inflammation of the joint has abated, leaving the swelling and lameness as bad as ever, apply the embrocation for strains, page 151. Strain of the hock joint, requires the same treatment. See Chapter XV. section 2., for ' signs of lameness.'

6. Strain of the hip - commonly termed-of the whirlbone, or round bone. Too often it happens, when any lameness occurs in the hind leg, the cause of which may be too obscure for the farrier's comprehension, he confidently pronounces it " a strain in the whirl-bone;" and this he does with all that affectation of infallibility, which at one time of day characterised the whole fraternity. Familiar as are the every-day cases of lameness behind, from disorders of the leg, we are left in astonishment at the hardihood, which, in this respect, still 
maintains its ground, in spite of experience : spavin in embryo, or strain of the hock joint, are those disorders which people most commonly mistake for hip lameness. For our own part, none of us ever saw a case of strain here, or other damage, that did not proceed from a blow or bruise, on the horse entering a narrow door-way, or in turning short into a gate-way. These are simple bruises, and should be treated as such : see page 151 . Never blister the hip, nor apply the iron to it ; nor the ayls, nor any other cure-all nostrums, burning, escharotic and destructive as they all are.

Turn to the 'Signs of lameness,' in chap. $\mathbf{x v}$; and read again sections $1-4$, on 'shoulder strain,' as equally applicable to hip strain.

B Many of those affections of the legs which cause lameness, are concealed tumours on the bones (like splents), which never shew themselves to the eye, until dissection takes place. Such enlargements we have found on almost every part of the legs, from the carcase to the hoof: on the shank, on the shoulder bone, near the elbow, underneath the back sinews, \&c., and though not large, they were sufficient to impede the action. Such bony excrescences, or tumours, frequently occur, also, on the carcases of low bred cattle; as may be observed on turning over a lot of bones in the knacker's receptacle. With this leading fact impressed upon the mind, how nuch anxiety, in investigating the cause of lameness, might be spared! how much trouble and expense, fruitlessly bestowed on hopeless cases, might be saved, by sending the afflicted animal to the knacker's at once! The more lamentable, because such horses are of small price, the owners not rich.

7. Strain of the back, is matter of doubt; Mr. White rather chose to consider it an injury, generally. When the muscles swell, they only are injured, and a partial cure may be effected, by fomenting the parts and strapping with adhesive plaster. 
Strain of the Back Sinews, otherwise 'Cofin Joint and Navicular Lameness.'

1. The back sinews (in the plural) would be more intelligibly described, as the flexor tendon and its sheath, the first descending from behind the knee, inclosed in the sheath, is attached to the bottom of the coffin bone, whilst the sheath terminates in the small pastern. As in passing to the coffin bone, the tendon must necessarily press upon the navicula, or shuttle bone, any indisposition of one part soon communicates to the others also; though the swelling and heat of the sinew will declare its superior virulence, their absence equally indicates that the interior of the foot is then the seat of inflammatory heat and of lameness, that admits of no radical cure. Between the flexor tendon and its sheath are numerous filaments, in which is secreted an oily fluid, designed to supple and lubricate the parts; but when, through over-work, inflammation supervenes, this fluid is soon exhausted; for want of it the parts adhere, and the work continuing, causes the stiffness, heat, and swelling, which constitute the disorder. Sometimes, the very minute sacs which secrete this fluid in the legs, are ruptured, when those other disorders arise, we term windgalls, and thorough pin. When the fibres, which tie down the tendons, are ruptured, or the insertion of tendon at the bones is torn asunder, this is utter ruin, or ' breaking down.'

2. When the case is a very bad one, the general health of the horse is affected with symptomatic fever, (see page 38 ,) and requires bleeding and physicking. Meantime, foment the part with warm water, or bran mash or mallows. Prepare a fine bran poultice, sufficiently large to cover the whole; mixing into it the $s a$ turnine lotion, hot, with linseed meal enough to give it the proper consistency. Look well to the bandaging, 
and compel the patient to be quiet. Take this off when cool, and foment it again, well; prepare another such warm poultice, or add hot lotion again to the former, and repeat this alternation several times, assiduously, during the first 2 days, at any rate. Afterwards apply saturnine lotion, diluted; and when the inflammation is a little abated, the embrocation for strains may be applied, two or three times only, and no more-Mr. White himself having abandoned the too pertinacious employment of this means of causing the absorption that is requisite to effectuate the cure. He also relinquished firing, at this stage; and recommended blistering only when the swellings proved obstinate, and it remains after the inflammation is subdued.

3. Prefer taking the blood, when this is deemed necessary, from the toe; but very few ordinary men can find the large vein under the toe, so as to insure obtaining a sufficient quantity-say 2 or 3 quarts : immersing the foot in warm water, causes the blood to How freely; and if a doubt exists as to the real quantity taken, the water-pail may be marked, and all above it dipped out, with the graduated or other measure. As soon as the horse can bear his foot plane on the ground, as he will by help of the foregoing treatment, the enlargement may be reduced by bandaging the leg tolerably tight. Let a long bandage of cotton or flannel, be dipped in the embrocation; pass it spirally round the part, from the heel upwards, making it fast above the knee, or the hock, as the case may be. Remove this frequently - more so at first, pass the hand gently over the swelling, moisten the bandage with the same embrocation, to which as much vinegar has been added. In a week, the patient will bear slight rubbing, and the bandage tightened daily, whereby we may expect a complete reduction of all the symptoms save one, in every ordinary case. A loose box, gentle exercise in hand, and finally, a long run at grass, may render the horse serviceable once more. 


\section{CHAPTER XIII.}

\section{Anatomical Description of the Horse's Foot.}

1. Obvious as the fact must be to every one, that the best mode of preserving the feet of our horses, consists in following nature, and adhering to its forms, yet was all inquiry into the structure and economy of this indispensable member of an animal made for progression, quite neglected, until a very recent period. So much so, that old Snape, (1687), Lafosse and Gibson, (1743), who severally published elaborate dissections of the whole subject, yet omitted to open the hoof completely, to see what it contained that might be worth preserving; on the contrary, they seemed to hit upon small particles, by means of comparative anatomy, as if by accident, and whenever they presented to us the portrait of the entire skeleton, they all gave us a representation of the hoof, untouched, as it appears during life! None of them pretended to have seen the navicula, or nut bone, the coronary ring or the cartilages, until described by OSMER, in the 2nd chapter of his treatise, about 1759. To Mr. Strickland Freeman, a Berkshire gentleman and amateur, we are under great obligations, for the first full display of the internal structure and functions of the horse's fuot (1797). Although the " no foot no horse," of the ingenious Mr. Jeremiah Bridges had preceded him, that industrious elder, (with his "six discoveries," 1752), had not the ability to anicipate such a work as Mr. Freeman's; who left nothing 
unsaid as to facts, however he might be afterwards excelled in practical illustration. This task was reserved for James White, of Exeter, who borrowed largely from Freeman's pages and drawings, and brought the knowledge of the internal structure and economy of the foot, within the reach of every o'wner's comprehension, and pocket capability, in 1801. Physiology, always a difficult science to teach, as it is to learn, was not smoothed for the general reader, by Mr. Edward Coleman's "Observations on the foot of the Horse," 1798, \&c. ; elaborate, diffuse and expensive, the two volumes of the professor seemed rather to choke up an inlet of knowledge, than to supply a desideratum, for the original work of Freeman was still in the market.

2. Thirty years ago, any ordinary man employed about the stable and the forge, might naturally imagine, (and many among them did believe,) that the internal parts of the foot were a compact body, simply enclosed by the horny hoof, to protect them from the blows and pressure they must otherwise undergo in travelling; but the least reflection on its action, would convince him, how very incomplete and inadequate such a limited protection would prove, under all the circumstances of wear and tear, to which it is hourly subjected. Let him consider one minute, that those internal parts are replete with blood vessels and nerves, and therefore, possessed of a high degree of sensibility; let him consider, also, what an immense weight is thrown upon the feet, at every step the horse takes in progression, and what painful concussions would thereby be occasioned to the animal, were the hoofs the only safeguard against so much pain and misery. But nature, ever provident of our wants, has so constructed this part of the limb, as to obviate all those inconveniencies. So, if we examine any portion whatever of animal economy, are we not filled with lively astonishment at the infinite wisdom displayed in its conformation? Nor is it too much to assert, that the internal structure of the horse's foot is 
equally curious, strikingly beautiful, and every particle fully commensurate to its purposes. Although we here find concealed within the hoof a variety of wonderful contrivances, adapted with benign minuteness to prevent concussion from the most violent exertions, and to supply the waste and wearing away that is constantly going on; yet such is still the folly and obstinacy of farriers, that they frequently destroy this beautiful mechanism, by perverting the order of nature, and many an abused animal is thereby doomed to perpetual lameness, or at least to painful suffering to the end of its days. See Chapter XV.

3. Although an elaborate description of the anatomical structure of the horse's foot, would not be consistent with the objects of this little volume; yet will it be essentially useful to all persons interested in the animal, to enter upon such an explanation of it as will enable them to comprehend what are the true principles of SHOEING; together with the method of preserving the feet from many troublesome and some incurable disorders. For several of these, which may not at first exactly amount to disease, nevertheless subtract from the horse's usefulness, his speed, and his well being; contraction, for example, of the hoof or coffin upon its very sensible contents, the coffin bone (fig. 5.) with its cartilaginous processes and surrounding vessels $c, c$; which latter may be seen in front $(a, c)$ fig. 1. exhibiting the lamella which connect that bone, so important in the mechanism of the parts, to the wall or crust; and which connection, being at any time shook, or severed by violence of the horse's pace and consequently rough concussion of the foot and road together, causes inflammation, commonly described as "fever in the feet." The effect of this species of inevitable injury, coupled with age and other infirmities, may be estiniated by comparing the annexed figure (5.) with fig. 6 on the plate, where the coffin-bone $(c)$ and the wall or crust, having lost their connecting lamellae by absorption (caused by "the fever") now adhere together, or very nearly so, occasioning the crippling gait 
termed "groggy." This mode of comparing these two figures will prove vastly instructive to the yet uninitiated scholar in the course of his inquiries, as to the dilapidations caused by age, hard work, and disease. In the annexed figure, those and all other soft portions are

fig. 5. Section of the foot.

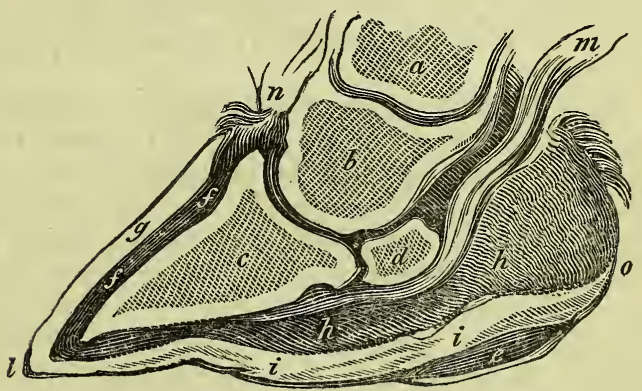

shewn in their perfect state, unimpaired by disease or the smith's injudicious driving. The hoof, properly speaking, is the whole exterior of the foot which meets the eye; the front or wall being the hardest and the heels softest; the frog and bars partaking intermediately of the same nature, whilst the hollow or sole comes off a little flakey, when in health. Finally, as regards the exterior, the upper part of the wall, where it is connected with the skin (at $n$ ), is termed the coronet, which encircles the foot from heel to heel : the lower part in front is the toe (at $l$ ), whilst the sides of the hoof are named quarters, of which the inner quarter is softer than the outer, in all manner of feet whatever, as depicted at $b b$ fig. 2 . In front, the wall or crust is highest and most oblique; but towards the extremity of the quarters becomes gradually lower and more upright, until reaching the heels (at $o$ ), where it takes a sudden turn inwards, to form the bars (at $n$, fig. 4) which 
have the frog $(m)$ between them. Finally, as regards the exterior: upon turning up the foot, we perceive the frog and bars at $m, n$ fig. 4 ; and the hollow space (c) thence to the toe and quarters, is the sole. All these are insensible to the touch in health, but liable to be penetrated and bruised from without, and to acquire disorders from within, where lies the sensible sole ( $b$ fig. 4.) along inside of it (with the sensible frog $q$ ), and partaking of the same shapes as the entire bottom of the foot, to the concavities whereof its convexities are nicely adapted and contributory.

4. Here we may instructively pause a moment, to speak of the agreement in the letters of reference to the several figures that represent the anatomical structure of the foot. All the six figures are in fact but so many representations of the same bones, cartilages, horn, \&c. under as many different aspects, or circumstances of being laid bare, or divided by cutting into sections, or other exposure of their relative situations and proper functions. In figures $1,3,5,6$, this is more strikingly the case; the letter $c, c, c$, $c$, being the coffin bone in each figure, but differing in these respects: (c) fig. 1, shews the front view thereof, with its blood vessels and lamellæ, or fibres, still adhering, as it appears upon being drawn out from its coffin, or horny defence, as represented by fig. 2. In fig. 3 , the coffin bone is again shewn (at $c$ ); a back view, with its cartilages at $g, g$, by which it is attached and suspended at the heels; at $(d)$ is the shuttle bone, or navicula, which forms a joint (giving action to the whole internal foot) in connection with the small pastern bone $(b)$ and coffin bone $(c)$.

The navicular bone $(d)$ and coffin bone $(c)$ appear again in figures 5 and 6 , shewing the functions each has to perform conjunctively, and in what degree disease has deprived them of these in the dilapidated figure 6 , which is more especially observable by comparison with the same references $(d$ and $c)$ in fig. 5 . In both figures the coffin bone, \&c. are seen in section, cut down through the centre of the whole foot, at the faint line $l, d, c, l$, in fig. 3 , and 
again in fig. 1 , at the line described by $a, b, c, l$. The navicular, as well as this same coffin bone, during life, lies completely concealed, being inserted and buried in its coffin or hoof, represented by fig. 2 ; which reaches as high on the bone, at the depression thereon at $b, b$, in figures 3,5 , and 6 .

The toe and heel. At $l, l, l, l, l, l, l$, and $l$, in all the figures $(1,2,3,4,5,6,7$, and 8$)$ is the toe of the foot, and of the shoe, in course: at $0,0,0$, and $o$, alike in figures $2,4,5$, and 6 , is the heel.

Coronet. Called the coronary ring by Osmer, and after him re-discovered by Coleman, it is seen at $b, b$, in fig. 1 and 2,-in the first externally, bared of the hair,in figure 2 we have laid it open through its whole course, forming the summit or coronet of the foot, proper. From this circumstance, the bone around which the coronary ring thus makes its close embrace-as shewn at the depression thereon $b, b$, fig. 3 , received the name of coronary bone; but this very proper term has been substituted by another-and it is now spoken of as the small pastern, by reason of its articulation at $f, f$, with the pastern, or "great pastern bone," marked $a, a, a$, and $a$, alike in figures $1,3,5$, and 6.

5. This internal muscular sole, then, spoken of in section 3 , and depicted at $(p)$ fig. 4 , with its sensible frog, $q$, is replete with blood vessels and nerves, and therefore exceedingly susceptible of any kind of injury, to which it is indeed very much subjected-externally from blows, pace, stubs, pricks, and paring away in shoeing, by weakened bars and concussion; and internally it suffers from contraction, causing foot fever, founder, corns, cracks, and frushes, and all the secret ills that afflict the foot. It is also connected towards the heel with the cartilaginous processes of the coffin bones, $g, g$, fig. 3 . The sole, (c) frog $(m)$ and $b a r(n)$ presented to our view on turning up the foot (fig. 4), are furnished with a constant supply of nutriment and means of renovation by the secretion that is constantly carrying on by its muscular 
sensible counterpart within; which is here laid bare and exposed on one half of the same figure,-the sole $(p)$ being hollow and more vascular than the frog $(q)$.

Immediately over these latter, towards the heel, is interposed an elastic, frog-like, springy substance, resembling in texture and qualities pale India rubber, marked (h) in the annexed portrait, fig. 5. Above these rests the coffin bone $(c)$ shewing the hard enamel borne on its surface as contrasted with its very porous centre; in which the blood vessels terminate, and wherein is concocted the material for supplying the wearing away of the hoof: to the bottom is firmly fastened (spread thinly over its surface) the back sinews, that descend into the foot by the line $h, d, c$, fig. 3 . How the navicular bone, $d, d, d$, (in figs. $3,5,6$ ) is thus kept in position by it, so as to act in conjunction with the small pastern $(b)$ and coffin bone (c) in all the actions of the foot, must be apparent upon a single glance; as must, also, the change of structure which is exhibited in fig. 6 . where this important part of the joint is shewn in a state of dilapidation, adhering to the coffin bone; whilst the attachment of the back sinew to its lower surface (just spoken of) is lost, withered, or dried up by age, concussion, and disease : this is the so much talked of "Navicular disease."

However this be admitted, returning to pursue our description of the healthy portrait, at page 165 , we observe the flexor tendon, or back sinew $(m)$, that descends behind all those bones of the foot and leg, is there seen attached to the lower surface of the coffin bone, as already described. At $(f f)$ is the connecting lamellæ and secretion of horn, between the coffin or wall $(g)$ and the coffin bone $(c)$, which is designed to replace the wearing and paring that continually subtract from its quantity.

$6 \frac{3}{3}$ The student, who has not made such a section as this, of a healthy foot, or, is acquainted with the subject only through the medium of other sections, should know, that all our predecessors have derived their 
instructions from a view of diseased and distorted feet only, and thereby led astray their pupils in this respect : the present is the only portrait of its sort, and was first published (by $u s$ ) in 1825; again in 1827 and 1829, in successive editions, of the "Veterinary Surgery and Practice of Medicine."

5. That change of form should take place in a piece of mechanism so exquisitely formed as this, is nought surprising, when we recollect the number of evils to which the feet are subjected in shoeing, the very great action to which the horse is impelled, and the diseases which descend into his feet from a broken-down constitution. For hereupon some functions cease altogether, others are performed adversely, or destructively, and age and infirmity then present a very different foot for our contemplation from what we had studied under more favourable circumstances. For example, the cut fig. 5, as delineated at page 165 , was taken fresh, from a five year old subject, in health, by John Hinds; that on the plate (fig. 6.) by James White, from an old worn-up horse, whose hoofs still appeared externally to be in good travelling condition; and what information does this fact present? Why, that the lamellae (at $f f$ in this, and at c, fig. 1.) which connected the coffin bone with the internal surface of the hoof, had been absorbed, and both adhere firmly together in the old subject (fig. 6.), and rendered a due performance of his paces impossible in the horse which carried such a diseased foot.

Other dilapidations, as will be readily detected, have been committed on this foot by the ravages of time: in fig. 6. the coffin bone (c) has lost its shape on all sides ; the upper angle being enlarged and become obtuse, so as to interrupt the due course of the coronary ring ; the $n a$ vicula or shuttle-bone $(d)$ is adhering to the coffin bone; the back sinew (at $m$ ) is thickened, and has lost its elasticity, owing to the internal frog-like elastic substance $(h)$ on which it is pressed, being contracted and hardened by heat, and become inelastic: having thus lost its original 
quality, it could no longer act as designed in resisting concussion - whence "foot fever," and contraction, with its thousand ills.-See p. 185.

6. Examining the component parts of the foot a little closer, and again referring to the print, (fig. 5.) on page 165 , we here observe that the secretion of horny material before spoken of, ascends (at $f f$ ) to the coronet (at $n$ ), where it enters the coronary ring (as seen at $b b$, fig. 2.) which surrounds the hoof and supplies its vessels and lamellæ with the requisite nourishment and renovation. The internal surface of the coffin or wall (fig. 2.) is lined throughout by this lamelled substance, which is a fibrous membrane, resembling very much the under surface of a mushroom; and on the sensible foot (i.e. the coffin bone $c$ ) which would otherwise come in contact with it, are found similar lamella or membranous plaits, exactly corresponding and agreeing with the former, and forming a secure union between the two. [See these latter depicted, at (c) fig. 1.] By this kind of firm attachment, the smith is taught that the whole bearing of the horse's weight should be on the wall or crust of the hoof $(g g g g$, in figures $2,4,5$, and 6$)$; the frog and the heels having nought whatever to do with supporting the incumbent weight, although touching the ground and expanding, upon extraordinary exertions only, to assist in the act of springing forward, conjointly with the elastic frog-like substance $(h)$ before spoken of.

This portion of the mechanism of the foot, $M r$. White was induced to call, in deference to one of $\mathrm{Mr}$. Coleman's reveries, "a fatty elastic substance ;" an idea, we have reason to know he long since abandoned, though his successors still retained the mistaken notion in his works, whilst the professor himself was shamed out of his fatty conceit, by Dr. G. Pearson, one of his examiners, face to face.

7. The frog is a very important part of the foot, and requires to be particularly considered, many obstinate mistakes having been made respecting the uses for which 
it was designed, and many more incorrigible practices being still perpetrated upon its external portion. United with the sole, it is composed of a tougher and more elastic kind of horn. In form it resembles a wedge, but towards the heel, where it becomes wider and expanded, there is a cleft in the middle, which continues to the heels. Whenever the frog receives pressure, this cleft separates wider than when at rest, producing the same effect upon the heels of the crust; and when this weight is so great as to bring the frog in contact with the ground, the pressure occasions the secretions internally to disperse upwards into the coronary groove; for, upon slitting open this groove as is done at $(b b)$ fig. 2 , an immense number of small orifices may be seen, into which those secretory vessels empty themselves. What, then, is to become of all these provisions of nature, if the frog be impaired by the hand of man-since no ordinary accident can injure it from without, and the internal or sensible part is rendered so liable to diseases, as we have shewn in section 3 (page 164).

The relative situation of the sensible and the insensible frog, sole and bars, may be studied with advantage, by noticing the extremely vascular nature of the sensible sole, fig. 4 , at $b, p$, and the callous nature of its counterpart at $m, n, c$, of the same figure. In fig. 2 , the hollow of the coffin or hoof again exhibits this very sensible part, at its bone surface. In fine, examine where we may, we can discover nought but an all-wise contrivance to avert those ills, which the necessities and the inconsideration of man constantly inflict. 


\section{CHAPTER XIV.}

The Art and Practice of Shueing:- 1 st. Of Sound Feet; 2nd. Of Unsound Feet.

1. Of all the disorders to which horses are liable, none are more difficult of cure, or occur so frequently, as those which attack the foot; and it is a further incontrovertible fact, that the majority of these are the consequerice of bad shoeing, and other improper management of the foot. Hence will be seen the necessity of studying the preceding chapter seriously, the better to acquire the principles of shoeing; and of paying attention to that which succeeds the present, in its details, as regards the removal of foot-lameness. By a natural and easy transition, we are thence led to a consideration of the whole $\lim b$, a mis-shapen or ill-attached set of legs very often governing the tread, and superinducing distortions and disorders of the foot. So truly grounded is this latter aphorism, that some feet are met with which no manner of shoeing whatever could amend; whilst others fall so slowly into a dilapidated shape, that they do not become lame, and probably never would go lame with moderate work, though ever so unskilfully shod. Other feet again seem especially calculated for acquiring some given disorder from their first being exposed to strong exercise; partly by reason of the powers of such horses having been mistakenly applied to the wrong purpose by their first proprictors, and more being expected from them than could be well performed. Still will it be allowed, that a series of bad shoeing will spoil the best of feet, when the horse 
is employed on fast work, particularly ; but bad shoeing or good, depends less on the shoe itself than on preparing the hoof that is to receive it-this having been the grand error in the art, from the age of Solleysel to the advent of White-if the usual mystification that is thrown around it be not a still greater error.

2 . The talk we hear of "following the shape which nature gives the bottom of the foot in forming the shoe," is quite as fallacious as describing that form as being " nearly circular ;" for we meet with no feet that have arrived at maturity undeformed by domestication, by keep, by going, and by shoeing, previously to which the colt's foot is oval, as represented in figure 4 . The outline thereof having been drawn by $M r$. White from a dissection of his own, stultifies his assertion respecting the circular form, in which he followed blindly the mistaken notions of $M r$. Coleman, who wrote instructions for "shoeing the different kinds of feet," (copying the words of Osmer) whilst maintaining that only one kind or shape was proper. In his day, the shoe applied by this staunch old veteran, was certainly more circular than the generality, and thence termed "Osmer's seated shoe," to the present day; but he directs that it be made "quite flat, of an equal thickness all round the outside, and open and most narrow backwards at the extremities of the heel, for healthy horses ; whilst those whose frogs are diseased, require the shoe to be wider backwards. To prevent this flat shoe from pressing on the sole, the outer rim thereof is to be thickest, and the inside gradually thinner. With such a shoe the frog is admitted to touch the ground, the necessity of which he had already shewn." But, notwithstanding this nearly circular form of the shoe, Osmer did not instruct Coleman and Co. that the bottom of the foot should be circular; for, the crust or wall oN w H ICH ALONE THE SHOE IS TO REST, and be fastened, does not reach to the heels. So that, although the shoe might approach the circular form, the foot is not necessarily round.-See it, fig. 7. 
3. Four weeks is a sufficient time for any horse to carry a set of shoes, whether they are worn away or not; for the hoof will have acquired a ragged and uneven appearance, the shoe will be imbedded in the heel, and the cavity of the sole be scaly and redundant. In taking off a shoe, the smith commonly tears it rudely away with the pincers, now pulling at one heel, now at the other, and finally ripping it away at the toe; whereby stubs sometimes remain, and the crust is torn, especially when it is thin or of a brittle nature, from which it can ill afford to bear any such reduction: rather, let the clenches be cut, and the nails punched, so that they may be drawn separately. Prepare the hoof for the shoe, by reducing the luxuriance at the bottom, particularly at the toe, by means of the buttress or rasp; restore the due concavity of the sole, and no more, and draw a small chasm between the bar and the crust, at $d$, fig. 4. to prevent the shoe from pressing on that part, and thereby occasioning corns. In doing this, be careful not to weaken the natural connection that exists between the bar and the crust, which would, of course, render the bar useless, and allow the heels to contract. As the junction of the bar with the crust affords a firm bearing for the heel of the shoe, it must be rasped perfectly flat, exactly on a level with the frog, so that they bear equally on a plane surface, previously to applying the shoe. Never press a scalding hot shoe to the foot, more than just to mark it. Whatever ragged parts remain on the frog, nay be taken off after the job is over, by means of a pocket-knife. Do not 'open the heels,' this being one of the smiths' mistaken notions, or one of the arts of the dealers, who would give an assumed healthy form to the foot for an especial occasion, which is certain to spoil it permanently.

4. To a foot so prepared, the shoe represented by fig. 7 is to be adapted. The web at the toe must be full an inch wide for a middle-sized nag; but narrowing away towards the heels, where the width is to be half an inch 
only: thickness at the toe, half an inch, outside; of the heels, three eighths-but on the inner rim all round the toe and quarters, somewhat thinner. By working the shoe on the ground surface, in raising the shoulder, (at $a a$, fig. 7 ,) to protect the nail heads, according to the modern practice, or fullering, according to the old, with punching, \&c., the shoe becomes a little convex on part of its foot surface; the inside edge and the ground surface becoming thereby slightly concave, as represented in the same figure, affords good foot-hold upon going over heavy ground. Dudley's malleable cast iron shoe is a good model of this modern shaped shoe, though we do not recommend it to general use : our objections were long ago stated at large, and have never been refuted-practice has confirmed them.

Let the toe be steeled; and the nail-holes may begin very near it, for the fore feet, but not so behind. If, however, the heels have been pared away and 'opened,' contrary to good advice, this begets a sad necessity for nailing in the quarters; on the outside 4 nail-holes, inside 3 or 4 . This manner of nailing, however, prevents the requisite expansion of the heels, upon which so much reliance is justly placed for the due performance of the functions of the sensible foot, as described in the preceding chapter. For large horses, the shoe must be of larger dimensions; and at the heels of all, (except hunters in full work, over a heavy country,) the iron should project a little beyond the horn, to allow of its growing without embedding the shoe within it; but when a horse over-reaches, other contrivances become necessary at the part of the shoe which is struck by the hind foot, and both must be reduced by bevelling away the shoe towards the ground.

5. Frog-pressure was long a disputed point, but now admits of none; the question having been carried to the two extremes by the obstinacy of the disputants, long time admitted not of adjustment. An examination of the internal, or sensible parts of the foot, such as we 
have undertaken in the preceding chapter, must convince every one that the function of secreting horny matter could not be duly performed, while the frog and bars were constantly suspended from the ground; nor, on the other hand, could the sensible sole (or bottom), the bars and frog, bear constant pressure, or resting upon the ground, without contracting disorder of shape, and consequent navicular lameness, or thrushes, corn and founder. The frog, then, must remain untouched by rasp or buttress, and left to wear away of itself, except removing any little raggy particles, to prevent dirt and dust from lodging there; the resistance it meets with on soft ground is quite sufficient pressure to keep the frog and bars in health, whereby it assists the expansion of the heels, and promotes the elasticity of the whole hoof.

6. Unsound feet, or those disposed to become unsound, require a different shoe and different treatment from the foregoing. Compression of the hoof upon its contents, is one of the chief causes of lameness; and this is usually inflicted, by allowing great thick-walled hoofs to press upon the heels, contracting these together, through failure of adequate resistance at the sole. Therefore, when the wall is thick and dry, let the quarters be rasped away, and further restore its elasticity, by keeping the hoof moist in the stable: wet it constantly; apply folds of wetted flannel round the coronet, or make the horse stand 4 or 5 hours a day on soft clay, or in some unpaved damp yard; but not dirty, for the stable dung and urine are the principal causes of that dry, brittle, clumsy hoof, we are now endeavouring to correct by cool moisture. Three very erroneous practices prevail at some forges, viz., 1st. drawing the sole, 2nd. paring the binders, 3rd. opening the heels ; either of which enables the wall to overpower the sole or bottom by its superior strength, and cause a ruinous compression of the sensible sole, $b, p$. fig. 4 .

7. When a horse, even with tolerable sound feet, has 
worn shoes that are very thick, or turned up at the heels -particularly if, at the same time, the crust of the heels has been suffered to grow so high, that the frog is kept a considerable distance from the ground, it would be very improper to reduce such heels all at once, so as to allow the frog to receive pressure suddenly; for the back sinews would in that case be strained to their full tension, become inflamed, ossify, and coffin-joint lameness (so called) would ensue. In feet of this description, it is necessary to remove from the toe all the horn that can be spared, and to lower the overgrown heels by instalments, if at all, so as to bring them to the right bearing' at three or four removes, or renewals, of the shoes; at the same time, form the toe of the shoe rather thin, and that of the best hard steel, in order to make up in durability what is reduced in quantity.

8. Draught horses' shoes should be made flat on both surfaces, provided the sole is of a proper form and stoutness; but if it be flat or convex, and consequently too thin-which is generally the case with hard-working horses of this description, the internal or foot surface of the shoe must be concave, or the inner edge thinned away, in order to meet and provide for the deformity. Still must the ground surface be flat; for the convex shoe which is commonly put on draught horses, in town teams, prevents them from treading securely, and renders them incapable of exerting the whole of their strength, and scarcely of laying their own proper weight to the collar : the pitiful endeavours of such ill suited creatures upon pulling up hill, would appear ridiculous if they were not at the same time deplorably painful.

9. Nailing on one side only is the nearest approach yet made to perfection, for allowing of healthful expansion, whilst affording the feet due protection, and is demonstrably serviceable in all cases arising from contraction, as Founder and its whole series of disorders described in the next chapter (XV). See also page 155 . Some horses, a little disposed to contracted heels, have 
worn their shoes out the whole month, nailed thus on the outside only, with manifest advantage; and others again, experimentally, carried them through the severest work under our own daily inspection, with only one more nail inside, next the toe; thus proving, that much less force is necessary to the requisite attachment of its iron defence to the foot than is usually employed. This is not the place to discuss the prior claim to this disuse of superabundant nails, from the long standing EIGHTitself a reduced number; but the practice of $M r$. Hinds, sen., in cases of disease, or of dilapidated brittle hoof, to say nothing of tacking on a simple web to sustain the dressings for thrush, corn, \&c., is too well known, in print, to allow of conceding that point to modern pretenders after originality.

10. Finally, it may be recommended, generally, to take as little from weak hoofs as can be dispensed with. In cases of convex foot, take nought from the heel, whilst the toe is to be kept short; such are liable to corn, and then require the bar shoe: the outer wall is then marked with rings at about an inch from each other, and the coronet is contracted, dry and shrunken.

11. Pointing the toe. Observe the tread of the foot, which frequently depends upon the setting on of the shoulder, or high or low; whence certain doubts and disputes, whether the inner quarter or the outer is to be kept lowest; to make the toe point straight forward, an affair that may be soon settled, by noticing the manner of the individual's throwing his legs about him, or of bringing them firmly to the ground. The position of the 'legs under him,' is always accompanied by the toes pointing inward, whereby the weight of the horse's body is thrown upon the toes: the shoe toe then requires a gentle curve, French fashion. Tips are far from desirable in any case, and when allowed to remain on a long time, (at grass or otherwise,) effect much harm to the crust, to the back sinew, and to naturally low heel. 


\section{CHAPTER XV.}

LAMENESS:-and 1. Diseases of the Legs;

2. Diseases of the Feet.

1. Having already treated the lameness that comes of strains, as inflictions caused by accident, or purely ideal-in which manner the several points of attack illustrated and explained each other, we come now to the consideration of those causes of lameness which cannot be mistaken, as they soon become visible in the shape of bone tumours, or of puffy enlargements under the skin; whilst those of the foot, that lie concealed within its coffin, or appear on its surface, are reserved for separate consideration. [See page 187, 5 ]. Not always, however, does it lie in our power to effect a cure of these afflictions; alleviation being the utmost we can promise in general, sometimes not so much, but in lieu of hope recommend patience, that great grandam of all the domestic virtues. At this earliest stage, it is worthy of remark, as conducive to a right estimate of the cause of certain lamenesses, that the leg behind is more liable to disorders than the fore-leg, whilst the fore foot suffers more than the foot behind. The reason for both is tolerably clear to our perception, and we deduce some good practical results from the observations made upon them : as the fore limbs suffer much from concussion upon the hard roads, and thereby incur feverish feet and inflammation of the sole, as well as the more frequent disorder we call chest founder-that falls down from the lungsfrom all which the hinder feet are tolerably free, we 
thence distinctly infer the cause, and direct the remedy accordingly. On the contrary, the hinder legs being the main instruments in propelling the body along in speedy going, and especially strained in the drag, we find the number of disorders belonging to the leg part, behind, three times that of the leg part before. This latter peculiarity arises from the injuries inflicted on the manyboned hock joints, and by straining the double bones of which the shank consists, from each other; taken all together, however, lameness is not of such frequent occurrence behind as before. Lameness arising from constitutional disorder is of frequent recurrence-indeed, often happens without any other cause, and is adverted to in Chapters I. and II. and Pages 28, 40, \&c.

2. Signs of lameness, according to William Osmerand we can have no better authority, except our own eyes. When a lame horse is made to go on, if he be lame in any of the muscular parts belonging to the foot, he will endeavour to give the foot ease, by not setting it fully on the ground; but if the lameness be in the fetlock joint, on the tendons of the leg, or proceeds from thorough pin, or be in the hock, or proceed from any swellings surrounding the hock, or be occasioned by a curb, or spavins, or canker,--all such causes will be manifest to the eye and the touch: we can have no better evidence of the cause, and may undertake the cure with confidence. If the lameness be in the stifle, however slightly, he cannot so well perform the extension of the limb, but will drag his toe upon the ground, more or less, according to the degree of injury he has received, as in the manner of shoulder strain, before described (page 156); and if it be in the ligaments belonging to the hip joint, he will, in all such cases, rest his foot fully on the ground, but will halt or step short in the trot, and yet go very sound perhaps in the walk. Vide Osmer's Treatise on the Horse, page 124. Lameness is often occasioned by repeated straining of the muscular or tendinous parts of the leg, the anguish whereof descends to the foot of 
the horse ; and acquire the terms windgall, thrush, splent, ring bone, canker, \&c. according to the part which may be affected. These will occur after very hard work, upon standing long in the stable, for want of friction at the joints, and go off again by exercise, or may be avoided by giving a loose stall, or a run in a paddock-else they require medical treatment. We sometimes find good horses come up from grass lame of a splent, or a ring bone, most unaccountably to those who pay no regard to the plague of fies ; which worry the horses, and cause almost incessant stamping, to get rid of their tormentors, with even worse effects than travelling over the hard roads would bring on.

3. Spavin. This is a swelling on the inside of the hock, and is of two kinds; the first we shall notice consists of an enlargement of the bone, whence it acquires the term bone spavin, often occasioning lameness before the swelling becomes visible, and leading us into those mistakes, and giving rise to the doubts about its seat, which were noticed when treating of "strains," in a preceding chapter [page 156.]. It occurs on the upper end of the shank bone of the hind leg, sometimes on the hock joint, at other times below it, as before remarked (sect. 1.); and is always attended with much pain, in consequence of the membrane (periosteum) which firmly embraces all bonc, being raised from its connection therewith, and suffering inflammation in consequence. When the spavin is once formed those bones unite, and it proves very obstinate to cure; whence the stiffiness of the whole leg, that deceives some of us into a belief that the disorder now lies at its superior part-on the hip, or the stifle. The lameness occasionally goes off, upon the horse being exercised, and returns again in the stable as bad as ever-but not visibly worse than before, as marks lameness of the hip and other joints. [See Page 156.] This circumstance alone should induce us to be jealous of the hock, to examine it frequently, so as to apply the remedy immediately upon its appearance; for, upon 
promptitude in this respect mainly depends the perfect cure: compare the size of the two hocks, for you cannot always detect the swelling by the touch, nor is the heat much encreased, nor does the horse often finch from the hand-but the contrary, sometimes. This latter circumstance begets in me an idea, that friction after work might prevent spavin, if, indeed, hard working cattle ever were deemed worthy of hand rubbing; but this kind of care is little to be expected from those whom cupidity has induced to incur the disorder originally, by working their teams inordinately, and too young-whence the cathammed hocks and awkward tread which brings on spavin, originally. As another preventive, make the toe point aright as near as may be, upon every removal of the iron defence. See "Art of Shoeing," page 178, and on "Cutting," Section 3.

4. In this and all similar cases is fully exemplified the trite old aphorism, "a stitch in time saves nine;" a blister being our especial remedy in all recent attackswhereas, the old and confirmed spavin is not only difficult to reduce, but is scarcely ever eradicated. At its first appearance, then, apply the blistering ointment, No. 2. (page 58); let it be done well, and not after the old fashion, up and down, but circularly: clip off the hair from the tumour, and also cut off a narrow line all round the leg; rub in well at these parts, but not extensively, tie up the head, and next day dress with hog's lard. A neglected spavin, however, requires firing and blistering also, and a run at grass of two or three months, if it is hoped to bring the horse into use again : age does a good deal, but the horse is invariably reduced in the scale of usefulness and value.

5. Splents are, in like manner, bony excrescences about the shank bone, i.e. between the knee and fetlock joints inside, and sometimes, though not so often, behind, on the corresponding bone below the hock. There are people in the South who call out "splents!" at every appearance of bone tumour on the legs, and indeed be- 
fore aught amiss is to be seen-the lameness frequently being in the foot, and sometimes consisting in a strain of the back sinew. When a splent does not rise underneath the sinew, nor so as to interfere with the action of the joint, little inconvenience is sustained by the horse, after it has fairly formed itself, and often disappears without any medical treatment, beyond a blistering or two. Above all things, avoid firing the tumour on ordinary occasions, nor employ any of the old barbarous operations, though it be seated on those critical points ; but first reduce the great heat and tenderness by employing the cooling lotion, page 132, or the saturnine poultice, page 149. After this, apply a liquid blister, page 58 , to the whole of the tumour, and in a narrow ring all round, as directed in the preceding section.

6. Ring BONE. These are bony excrescences of either pastern, that do not always occasion lameness, unless extending to the joint, or affecting the upper cartilages of the foot with its inflammatory tendency: more frequent in the hind foot than before, it may be set down as a disorder of hard-working draught horses ; rest therefore is seldom allowed by the owner, and the enlargement encreases until the whole foot is ruined. No remedy is to be found for confirmed ring bone, though firing and blistering do effect some good in recent cases, when the latter is followed up with assiduity, and rest is allowed. Between each blister, when the effects of the preceding seem to cease, wash the parts with the cold lotion, page 132. See above-section 2 .

7. CUR B is a swelling below the hock, brought on by strong work with too much loading, which sometimes occasions lameness, and more frequently afflicts well bred cat-hammed young horses in leaping, than those whose bones are firmly set by age. It may be detected by taking a side view of the leg, and comparing this with the sound one; but is not attended by extraordinary heat, and therefore firing the part at once is the most decided practice, and safe too. Afterwards, reduce the Q 2 
heat which remains by applying the cooling lotion, page 132.

8. WINDGALLs. More commonly attacking the hind legs, these tumours derive their vulgar name from the anciently mistaken notion, that they contained air ; an ignorant blunder which induced them to puncture their "windgalls," whence, however, they saw issue nought but a liquid resembling joint oil. See Strain, page 160. That operation accordingly ruined the horses subjected to its effects; whereas, slight cases not unfrequently disperse without treatment; but if the tumours be many, or of large size, bandaging offers the best means of causing them to recede. Let the roller of thin flannel be wetted with the cold lotion, page 132 ; remove twice a day; and when the heat has been reduced by these means, add to the lotion about one tenth of its quantity of rectified spirit. For bad cases, blistering is the best remedy, and when very bad, firing must be employed, but not too deep on the back sinew, nor at the joint. See Firing, in Chapter XVI.

9. Thoroughis occurs above the hock on each side, and is caused by the escape of the oily secretion, which has been ordained for lubricating the parts, closely resembling windgalls, and like these comes of hard work. Rest and treatment, similar to that prescribed in the preceding section for Windgalls, will effect all the good that can be expected.

10. Matlenders and Sallenders. The first is applied to that disorder of the fore leg which consists of a scurfy eruption on the bend of the knee, whilst the same occurring at the inside of the hock, acquires the name of sallenders. Though unsightly, and the oft'spring of neglect, they are seldom attended by lameness ; but when they are so, give a dose of physic in the first place, and if the urine come off in a turbid state, give a diuretic ball occasionally, until that objection is removed. Clip the hair close, and having washed the parts well with warm soapy water, apply twice a day one of the following - 


\section{Ointment.}

No. 1.-Acetated Water of Litharge 2 drams. Spermaceti Ointment...... 2 ounces. Olive Oil............. 1 ounce. Camphor............. 1 dram. Oil of Rosemary ......... 1 dram.-Mix.

No. 2.-Sugar of Lead ......... 2 drams. Tar .............. 4 drams. Hog's Lard ........... l $\frac{1}{2}$ oz.-Mix.

11. Blood Spavin. A disorder of the hock, arising from hard work; it requires blistering and rest, much after the manner of healing Thoroughpin and Windgalls. Disorders of the Feet :-1. Founder.-2. Thrush. -3. Canker.-4. Corns.-5. Sandcrack.

1. Lameness in the upper parts of the limbs, has been shown to arise from hard work and misapplication of the animal's powers. We could trace these to their causes with some accuracy, because they soon present to us an altered form, and some of them subside with very little treatment ; but the disorders which the same kind of misusage inflict upon the internal sensible foot-shut up as those parts are within the hoof or coffin-require more skill, or tact, in the development of their altered functions, and are only to be studied profitably after the manner directed in Chapter XIII. They had long been investigated by several degrees of scholars, with various success, according to their talents and previous habits ; which begat as many different versions of the concealed disorders that afflict the component parts of the internal foot, and caused some contradictions, by futile endeavours to fix on the precise part affected. Of these "Navicular disease" was the most refined and plausible, besides being just; and had been described by Osmer, (Chapter II) as a disease of " the shuttle bone," 30 years before. [See below, Sect. 7.] "Coffin lameness," was more ancient, and more generally applied to any disease within the coffin or horny hoof [fig. 2.]; it is a goodly Q 3 
term, and quite consonant to our own notions of the thing meant to be spoken of. From these modern attempts, however, no other good could be derived by people in general, as regards the cure, than a fine display of learned words and an astonishing facility at conjecture; for all diseases of the foot, including those that are inflicted externally, may be comprised in one wordnamely, inflammation, and its natural consequences: contraction of the horny hoof upon its softer contents, and alteration of their structure; founder, with its dozen otherwise-named adjunct disorders, follow the inflammation that is brought on violently, and is vulgarly known as "fever in the foot," because of the great heat thereof: brittle hoof is always present. See Chap. XIII. Sect. 4 . On the other hand-change of structure likewise supervenes, through the very reverse state of the hoof, viz. its softness, whereby a flatness and "pomiced feet" occasion the internal sensible parts to spread out, and the sole to sink; hereupon, though lameness comes on but slowly, it is nevertheless certain to creep in occasionally, after brisk trotting, particularly of high goers.

2 . But another cause of lameness, that remained long unknown or unheeded, arose from diseased lungs, or bowels, which, upon hard work, communicate their evil influence to the feet (before principally, and behind occasionally), but inscrutably to the people who have gone before us ; though the first-mentioned had been long noticed with tolerable accuracy as simple "chest founder," by the stable men. [See full details in "Veterinary Surgery," by the Index.] One fact, corroborative of the fore. going, and well recognised at the smithy, though not applied to any investigation of this kind, is disclosed in the constant inflammatory state of the hoof (with its concomitant diseases) which belong to great horses, of foul habit and ravenous disposition, as compared to the mild, the gentle, and reedy horses of light carcase, and consequently lean legs and cool feet. Of course, the tenderest parts of the foot would suffer from this influence more 
immediately than the more hardy; as well as somewhat agreeable to existing circumstances, of severe work, of accident, or of shoeing ; and, when upon dissection they found how the navicula had suffered in its proper action, or the coffin joint anchylosis, or the cartilages ossification, the learned persons termed succeeding cases accordingly, as near as they could guess by parity of reasoning. Hence the controversies that arose about " $\mathrm{Na}$ vicular disease," and "Lameness of the coffin joint," or of the "coffin bone." They could not demonstrate the distinction, however, during life, and did not pretend to discriminate the treatment for either, since the symptoms were all alike-namely, inflammation, tenderness upon the hoof being rapped, incapacity for going or even standing quietly; and when very acute, increased action of the pulse at the pasterns, as well as at the large artery under the arm. Bleeding was thus indicated to the practitioner at the feet affected-usually the fore ones, for the hind feet do sometimes suffer the same kind of inflammation, when the bowels have recently undergone inflammation, and the general debility that thereupon ensues has allowed its effects to descend to the feet: in both cases " the fever" has been lighted up by the convalescent horse being put to work too soon after the drains by bleeding, physicking, \&c. deemed proper for the internal disorders, have reduced his powers of going.

of Contraction is promoted by standing on foul litter, whether that be simply acidulated, or heating, both conditions being destructive of the horn, and both are generally combined : it is also promoted by fast goingpace being the destroyer alike of feet and lungs, owing to rapidly repeated concussion against the ground. We do not always detect this cause of lameness, until a change of structure has assumed some distinct form, and is capable of being managed under one of the commonly received names here adopted. Of these "Fever in the feet" is the more general term, as it is the least visible, though to the touch more palpable: one fore foot only is 
sometimes so affected, of good free going nags, by reason of its having been made the leading limb in travelling, without making the needful change. When disorders of the feet have lasted long, the sufferer is accounted " groggy," by reason of his uncertain gait and constant endeavours, when standing, to ease the weight of his body off from the tender foot.

3. FOUNDER is the properest term to be applied to such an ailment, in whatever degree it may exist; though the foregoing fine ones have been adopted by many good writers, all signify merely that the horse is supposed incurably lame. When the disorder lies in the fore feet, the horse holds up his head particularly high on going, which he relaxes upon standing still; he throws out the fore foot pointedly, whether going or standing, and brings the hind legs under him to take off the weight of the body from before. The hoof will be found unnaturally hot to the touch all over, and the pulse high, as just observed; therefore bleed to a good extent underneath the toes of the feet affected, where the hoof joins the sole (at $f$, fig. 4 ), say 2 or 3 quarts from each - an operation that usually requires repetition, in bad cases. See some remarks on bleeding at the toe at page 51 ; and observe that when the blood does not flow sufficiently, let the excision of horny sole extend towards the point of the frog (at $e$ ). Reduce the heat by a linseed poultice, extensively applied to the whole hoof and coronet, twice during the day; then, let this be succeeded by the repeated application of wet cloths, upon which powdered nitre $\frac{1}{2}$ oz. has been sprinkled immediately before, as the cooling properties of the nitre fly off in water. Or, the cold lotion, at page 132, may be applied with a sponge twice a day. This treatment never fails to reduce the heat, but must not, on that account, be continued too long, as may be known by a permanent coldress at the parts remaining when the cloths are left off a little while. Let the wall and quarters be rasped down, and the sole drawn thin, lest the patient lose his hoofs entirely. 
4. However the tenderness of the feet may go off, in two or three days, the pain will be found to have affected the lungs, notwithstanding the usual precautions directed, as to symptomatic fever, may have been persevered in. See page 39-41. In this event, refer to Chap. III. and proceed as there directed, according to the symptoms. Keep the dunging in right trim; give cooling medicines, if any ; feed the patient much below his usual quantity, though he should crave for it. Do not permit him to rise, until the hoof has recovered its former hardness, and the drawn toe fills up; nor press the patient to go out too soon, nor then a great way at once: he will rather require a few weeks' run at grass, and much in-door care.

5. In the event of the case not going on thus favourably, and a thickening about the pastern and coronet is observable, clip and blister well these parts all round ; cover up, and put on a cradle. As before mentioned, when the hind feet thus undergo the inflammatory attack, the bowels are affected instead of the lungs, as in the former case, and require similar attention. See Chap. V. Should the fever not abate materially in a week, loss of the hoof is to be anticipated: at the coronet, the hoof will recede, leaving a small chasm, which no art or application can avert from extending, and the hoof will come off, leaving the sensible parts bare; and as the new hoof, which begins to form immediately, will never attain the full size, or become so hardy as before, the owner must now decide whether he will destroy the horse, or keep it and wait the event, for the lungs or the bowels, and sometimes both, will be continually ailing. If the latter alternative is resolved upon, wash the parts with a solution of burnt alum in water, once, which brings over the foot a thin film, and relieves the animal from much pain.

6. LAMENESS, that comes on slowly, and is utterly incurable, is produced by the same causes in a lower degree, which do not show their effects at once, but 
terminate either in contraction of the hoof gradually upon its contents, or in pomice foot. This latter consists in a severing of the firm connection that ought to subsist between the sole and the hoof, whereby the coffin bone and its bases press upon the sole, in such a manner as to change its form from a concave to convex ; whereupon the draught horse loses the power of making a purchase with the toe, but slips and slides about, whenever he would pull against the collar. Paring the sole of such heavy horses as we now contemplate, and applying the shoe hot, will have effected a good deal towards promoting pomice feet; whilst neglecting to pare the wall on shoeing, so as to give the shoe a firm bearing, which cannot be done when the shoe remains on above 3 to 4 weeks, are also among the causes of contraction ; and so is the want of moisture and the heat of litter. A stopping of cow-dung and clay commixed is a good preventive of both; or the artificial stopping made of felt cut to the shape of the sole, soaked in water, and secured by splinters of wood, as well as Mr. Cherry's pads, are found equally and more conveniently serviceable.

7. But a lameness comes on sometimes, without any contraction or other visible or ascertainable cause whatever; by some wrongly attributed to sprain in the superior part of the limb (shoulder or hip), and by others, to change of structure in the sensible part of the footrightly enough; age and pace having caused those dilapidations in the component parts of the internal foot, which is to be seen by comparison of the adhering navicular bone $(d)$ to the coffin bone $(c$,$) fig. 6$, with the same parts in healthy action, in fig. 5. See this interesting topic more fully handled in Chap. XIII. page $166, \& c$. and in the present, at page 185. As there is no cure, and scarcely any alleviation of this change of structure, when once fairly begun, we should be careful to avoid incurring so destructive a disorder, by not working our horses by sudden fits and starts, and then 
allowing long rests; for hereby, the very susceptible parts having been exerted excessively, become stiff and dry, and are unable to recover the proper tone and feeling, so as to undertake afresh the violent exercise to which they are again put. Fever is the consequence, though not violent, probably, yet requiring the milder treatment above prescribed : reduce the wall and quarters, if stiff, pare the sole, apply the linseed poultice, and blister the coronet in succession, but only so far as to lessen the fever. Nailing the shoe on one side only, allows the hoof to expand; on the benefits whereof so much reliance is deservedly placed. Chest-Founder is the term which has been applied of old to this state of the disorder, and not without reason, as before noticed. See section 2.

C It is no answer to what is here said of the effects of contraction, that some horses sport contracted heels without going lame; because much depends (indeed $a l l$ ) on the care that has been bestowed on such horses after very severe work, and the superior attention paid in those same stables to general health; so that such owners apprehend nothing from the influence of diseased lungs, or of the bowels, descending to the feet, though these should be a little feverish at any time. Notwithstanding this seeming security, such procrastinated, or chronic founder, gradually undermines and changes the natural organization of the hoof and sensible foot, and gives rise to various diseases.

8. NERVING-a surgical operation of modern invention, has been found to answer every good purpose which could be hoped for from so severe an ordeal, upon horses afflicted with 'chronic founder ;' i. e. such a lameness as never completely leaves the horse. This operation, however, though very simple to look upon, is the business only of a well-practised hand-always failing in those of any other, and should never be undertaken whilst great heat (i.e. fever) prevails, or the lameness is at its worst pitch. Neither are horses several years occasionally lame 
and subjected to hard road work, proper subjects to be operated upon; nor, indeed, old horses of any description, unless our new method turn out more favourable to them than the original mode of absolute excision.

9. Though we have consented to follow the old track in this, as in every other instance, of employing the ordinary or common term-Nerving, yet would Un-nerving better convey the idea of cutting away a part of the vessel which conveys the sense of feeling to the foot below. It consists in making a slight incision in the skin just above the fetlock joint; then, taking up the nerves which pass down superficially on each side the back sinew; and, when these are elevated sufficiently, by means of a needle introduced underneath, instead of dividing or cutting away any part (as hitherto practised) let a strong thread of horse hair be passed round each branch of nerve, making a tight ligature, and the horse will rise and go at once, without lameness. This method is strictly applicable to cases of recent lameness, and has been found effectual in one instance during eight months preceding the writing of this passage (March 21, 1832). The method hitherto practisednamely, excision of an inch of the nerve, experienced many disappointments; 1st. in the loss of the hoof, through cutting away injudiciously; 2nd. in the return of lameness, after a year or two of slow work, by the severity of the infliction; 3rd. in the absolute inefficacy of the operation: all which the improved method promiseth fair to obviate, by leaving every fibril in its original position, whilst surceasing only the communication of feeling, and consequently of pain, between the vertebral nerves and those of the feet.

9. Thrush or Frush, more frequently attacking the hind feet than the fore ones, we are justified in the belief that the filth and heat of the stables contribute greatly to produce the discharge of rotten matter from the cleft of the frog ( $\alpha$, fig. 4.), which constitutes this disease; but it is nevertheless only a symptom, or the 
effect of a change of structure within, arising from hard work and the ill-cured inflammation (i.e. founder), before noticed. In the fore feet, this is ever the simple cause; whilst, to slowness in the circulation behind, may fairly be attributed the copious flow of ichorous matter observable there. The remote cause has been stated, in the last page, to be contraction.

10. Although not lame at first, yet if neglected, the thrush, sooner or later, makes the horse unserviceable; the discharge becomes more offensive daily; the horn devolves into a mass of corruption, and peeling off exposes the sensible frog ( $q$, fig. 4$)$. The pain is very acute upon the touch, and canker at length pervades the whole foot, if efforts be not made to arrest its progress : delay in undertaking the cure, entails upon the horse incurably contracted heels to the end of his days. When young and vigorous, however, the discharge carries off any inflammatory symptoms which may have previously existed; and if it be stopped too abruptly, those symptoms return, but not so, if the measures be taken with judgment and decision.

11. Lower the system, by giving the laxative ball at page 93, until purgation commences. Give diuretics in either form; and if the patient be an old one, or the hinder feet be the seat of disease, repeat these, with the same view that we give diuretics in cases of grease. Relieve the compression of the hoof, by rasping the quarters; remove the rotten and detached horn, and wash away the filth. When the heat and inflammation have thus been lowered at the sole, apply any astringent whatever; and this, assisted by pressure, and tar at the frog, will render that part firm and solid, and the discharge will of course cease when the inflammation leaves the sensible frog and sole-the great importance of which parts may be learnt, if not already appreciated as they ought, by the Reader's turning to the plate, and taking a sight of these at $q, p$, fig. 4 . 


\section{Astringent ointment.}

Blue vitriol .........2 ounces.

White vitriol $\ldots \ldots \ldots . .1$ ounce.

Tar ................ 1 pound.

Hog's lard ......... Rub

down the vitriols (being previously powdered) in the lard, and add the tar. Cover a pledget of tow with the ointment, and at night introduce it to the bottom of the cleft, without force, taking it away in the morning; and as the sensible frog presents itself, lay another tow plaster over the former, the size of the exposed frog. Wrap up and bandage the whole, unless when the horse goes to work-an easy turn or two per day promoting the discharge and consequently the cure.

12. CANKER. - This disease frequently originates in thrush, and consists in a separation of the sensible and insensible sole and frog, beginning with the latter, and mostly attacks the hind feet of heavy working horses. As it generally proves very obstinate, and not unfrequently incurable, early vigorous measures become the more necessary; and even then the cure is a tedious and disagreeable affair to undertake, and one that is seldom repaid by the value of the animal.

13. Remove as much of the rotten horny bottom of the foot as may have separated from the sensible frog, bars, and sole (see fig. 4), with the knife; apply mild caustic to the fungus which will be found on the sensible surface, but not so where new horn may be forming: blue vitriol, powdered and laid on with care, is not excelled by any other application. Dress over this with the following-

\section{Mild liniment.}

Crystallised verdigris, powdered ... 1 ounce Honey $. . . . . \ldots \ldots \ldots . .2$ ounces Powdered bole and alum ...eeach $\frac{\mathrm{r}}{2} \mathrm{oz}$. mix in Vinegar.................. 3 ounces, over a very gentle fire. 


\section{Strong liniment.}

Oil of turpentine $\ldots .1$ ounce.

Sulphuric acid .. $\frac{1}{2}$ ounce, mix cautiously in Tar.............4 ounces.

Perhaps it would not be impertinent to add, that the strong liniment is to be employed only in the worst cases.

14. The disease being local, medicine is not always necessary, unless it lasts a long while; when the cure is nearly complete, one purgation, followed by diuretics, will be necessary to forefend the grease, which usually succeeds a protracted cure. Meantime, when the parts begin to look red and healthy, and the discharge loses that peculiar smell by which it is known, becoming whiter and of a thicker consistence, the cure may be considered as advancing. To this end, let the horse be worked as much in the dry as possible, in all cases avoiding moisture.

15. Corns. This is another of the diseases of contracted hoofs, and is of frequent occurrence, and mostly pertains to the fore feet. Resembling the corns in liuman feet, these are ascertained to exist by the touch, as consisting in little soft, reddish-looking spots, in the angle between the bars and the crust, at $d$, fig. 4 : when such symptoms appear, the cause of lameness is no longer doubtful. They are generally the consequence of bad shoeing, and are rendered incurable by the smith's paring out the corn (which gives partial relief) but leaving the heel of the shoe, or the crust at the heel, in the same state as when the pressure by one or the other inflicted the disease. Whereas, by cutting off the shoe heel, paring down and rasping the horny heel, and procuring expansion, permanent relief is soon obtained. One sided nailing contributes to this obvious means of relief most admirably - after the paring has been performed effectually; particularly when the corn is near the inner quarter (as is usual), and the said nailing is invariably on the outer quarter, the compression of the sensible sole (at $b$, fig. 4.) 
between the bars and the outer crust, which caused the corn, being thus relaxed and admitted to a healthy action; when absorption of the extravasated blood and matter which constitutes the disease takes place naturally, in recent cases it may be so eradicated.

16. But, it seldom happens that such precautions can be taken; so that, corns once contracted, a disposition thereto continues. It recurs upon every occasion of extra work upon old shoes, when they get embedded in the horn, and should be removed, the crust which grows down luxuriantly on the outside rasped away, as well as the angle inside the crust where corns are seated at $(d$, fig. 4.) In doing this, the workman must not be permitted to pare the bars: if he has sense, he will perceive how much their whole substance is now required, and he will see the necessity of adding to their relative prominency by always paring away the horn at the angle of the heels. If both heels have corns, let the bar shoe be affixed, provided the frog be solid and of sufficient substance for it to bear on; but if not, it must be chambered; or the heels may then be rasped and pared away, so as to receive no pressure whatever from the shoe, and frequent examinations may prevent bad cases of lameness, though no hopes of complete eradication can be wisely entertained.

17. Neglected awhile, the corn spreads underneath the horny sole, which should be laid open with the knife to its full extent, taking care not to touch the quick. Apply butter of antimony, and afterwards dress with tar (1 oz.) mixed with sulphuric acid, 1 ounce. If the heels are uncommon thick and unyielding, a poultice occasionally (not hot) relieves the stricture so occasioned; so, when the corn is of much extent, and the matter discharges in large quantities, a poultice to the whole foot will reduce the inflammation that remains from the operation and consequent discharge. Never apply the fire to corns, as some do. When the sore assumes a healthy appearance, dress with compound tincture of Benzoin, or digestive 
ointment, or tar alone. Allow a run at grass; and at every future removal of the shoes pare out the seat of corn a little, and apply to the spot a small portion of butter of antimony: leave the inner heel strong; rasp down the toes.

18. SaND Crack. Brittle hoof is the cause of the crack into which sand, or other substances may enter, that is so named, and is itself caused by the fever and contraction termed founder, before spoken of-page 188 . It mostly appears on the fore foot inner quarter, but when at the hinder feet, the crack usually occurs in front. When happening through some great exertion, it generally appears in its worst form at once, so deep as to expose the quick; but when of the mildest form, and scarcely deemed worthy of notice, because the horse does not go lame with it, may shortly become incurable through neglect. In this case, the firing iron, drawn across the fissure at its two extremities, will be sufficient to stop its progress in ordinary cases; but in none is the shoe allowed to bear on the part below, the crust being cut or thinned in that line repeatedly. Fill up the crack with wax, made warm enough for that purpose; such a slight pressure contributing to the healthy granulation of fresh horn, whilst preventing the access of dirt or sand, of wet, or cold atmospheric air. Give rest.

19. The cracks we have contemplated are of the milder sort. If the horse be worked, the crack extends, and becomes incurable. Cleanse out the dirt, thin down the edges of the crack, examine its base for the growth of "proud flesh" there; then apply a caustic, as copperas or butter of antimony, and wipe out the matter with pledgets of dry tow. Press into the chasm the warm wax as before; take it out, and examine to the bottom of the crack for evidence of fungous or proud flesh, and proceed as before directed. Keep the hoof moist; renewed stoppings, and finally the run of a meadow, or other damp ground, contribute to the cure. 


\section{CHAPTER XVI.}

Some Account of the Prescriptions, Remedies, and Applications, recommended in the course of the Work.

Alteratives. Medicines which act slowly are so called, as do many vegetables-by slight purgation, sweating, urinating, or otherwise. Some medicines, (tonics for example,) are always given in repeated small doses, as the alterative balls prescribed at page 47 ; another form at page 120, is diaphoretic, and so is the powder at the same page. The alterative worm balls at pages 73,74 , and the mercurial at page 142 , could not be given in any other manner.

Anodyne draught for disordered bowels, form of, 83 .

Antimony powders for mange, page 120.

Astringent ointment for the frush, p. 194; astringent lotions for grease, two forms of, at p. 141 ; and an ointment at p. 142.

Back-raking. The very serviceable " manual operation," so useful in many cases, and indispensable in obstinate costiveness, is yet most clumsily and too violently performed. We recommend it in a great variety of cases-see pp. 45, 81, 86, 100 ; and at pp. 88 and 97 , have shown how an examination of the straight gut conduces to direct us in the proper treatment of the knocked $u p$ horse-the long chase and ill usage that produces utter abasement of the animal's strength, sometimes affecting the lungs, at other times the bowels, and nearly as often the liver or spleen.

Balsam. An old name for the digestive ointment that is applied to old sores, wounds, \&c.: it is made by digesting sulphur in oil of turpentine in a sand heal. 
Balsam de Chili, or Chili Balsam, possesses no higher claim to our notice than the preceding; it is supposed to have been a succedaneum for petroleum, obtained by adding oil of aniseed to the spurious coal-tar petroleum.

Balsam, or balm, is also applied to any preparation, possessing the soothing or healing qualities, whether applied outwardly, or taken inwardly, thence termed balsam of life, or of this or that commixture. Thus we have the Balsam of Quinine, which derives its restorative powers from the due admixture of the extract of cinchona so named. In all cases of debility, proceeding from whatever cause, whether from fever, inflammation, or distemper, the Quinine balsam is given by us with complete success, and forms one item in the restorative means here recommended for adoption, after the removal of severe constitutional disorders : see p. 94.

Bandaging, the economy of, explained, 45, 81, 161 ; - the roller bandage, 148, 184.

Barbadoes Naphtha-the new name for Petroleum.

Bleeding. Is the very best or the very worst of the remedies employed by man, according as it may be performed judiciously or otherwise. See pages 38 and 50, where the economy or management is described at great length. We find the operation destructive in several cases of the epidemic distemper, p. 54 ; whenever the attack is accompanied by extraordinary debility; but when, on the contrary, the animal may be in full vigour previous to the attack, bleeding will not only relieve, but prevent the distemper assuming its more virulent symptoms; as was observed at pp. $45,53,125$. Bleeding is recommended at pages $26,32,34,40,48,57,75$, $81,96,101,118,151,187,188$. In some cases, bleeding should not be resorted to, as remarked at pp. 31,48 , 53 ; in others it would be disastrous; these occasions are pointed out at pp. 46, 54, 55, 70,82, 90.

Local bleeding - at the toe has been spoken of at page 161 , as admirably adapted to lower the heat and inflammation that always accompanies founder. The 
large vein will be opened by passing the knife from $(f)$ to $(e)$ fig. 4 on the plate. Bleeding in the mouth, is very desirable for all disorders of the head, and for loss of appetite arising from hard work.

Blistering, is performed on the horse by means of a liniment or ointment, with more or less of cantharides, according as greater effect may be required, as in the bone tumours we call ring bone, \&c. page 142. 'The form to be observed in making and applying blistering liniments and ointment will be found at pages 58 and 151, and this remedy is again recommended in several other cases_at pp. 49, 81, 152, 183.

Blue pill, one of the preparations of mercury, and recommended in liver obstructions, or distemper, p. 22.

Calomel, like the blue pill, is a preparation of mercury, and applies its quality to the liver. See pp.72, 88, 93 .

Cantharides is the main ingredient in blisters; but when oft repeated irritates the kidneys.

Caustics, the lunar, actual, \&c. class together, 29 ; an escharotic succedaneum for fire, 126.

Clysters, for management of these, see $34,45,68,81,86$.

Cold lotions, forms of, 107,132 ; economy of their application, 188 ; their use, 183,4 .

Colic drench, two forms of, 87 .

Cooling regimen recommended, 47, 66, 81 .

Coltsfoot decoction for catarrhal complaints, 57 .

Cordial balls are prescribed at page 30 ; though the draught or drench is highly preferable, as this acts at once upon the stomach, and the material is in every one's hands. Ale or beer made warm, or the malt mash, are equal to any thing we can recommend, and we are therefore chary in adding to the number of such prescriptions, which are already too many, and too frequently resorted to. The addition of ginger renders such a draught every thing that can be desired.

Cough ball, form of, 60 ; is also recommended, 57,62 . Cough drenches, two forms of, 60.

Detergent lotion, form of, at page 132 ; for ulcers, 28. 
Digestive ointment for sores, form of, at page 134.See above, Balsam. Digestive liniment, form of, 132 ; proper in poll-evil, 136; and for warbles, 137. Also prescribed at pp. 117, 137, 139, 153.

Diuretic balls, 119, 193. Diuretic powders, p. 35.

Distemper ball, form of, 54 ; highly proper, 22,56 .

Drench (the) preferable to balls, 36. See Cordial Tonic, Stomach-tube.

Embrocations, very proper in inflammations, 29; for bruises, 151, 162.

Eye remedies, forms of, wash, and poultices, 105 ; eye lotions, three forms of, 107.

Escharotic mixture (strong) for cauterizing farcy buds, page 126 .

Farcy Balls, two forms of, are given at pages 125, 6 .

Fever Powders, three forms of, at page 35 ; they are also recommended at page $16,31,46,104$; but in one case only are deemed undesirable, 99 .

Firing. Cases occur in which firing is indispensable; but is nevertheless resorted to too frequently, and performed too severely. Singeing the ears and the loose hairs of the coat, make a part of the same ferocious school of misintelligence. Throughout Chapter XV. we have frequently recommended the hot iron, in disorders of the legs; and for closing small punctured wounds, page 148 ; but the contrary advice is given at pages $154,162,183$. Anciently, for strain in the sinews and chronic lameness, an old practitioner of celebrity applied the fire upon the rind of bacon, and the operation came off much milder, but we do not find that it has been persevered in any where. For taking off the Farcy buds, we recommend the Escharotic mixture above referred to.

Hot mixture for fistula, page 133; another very strong, 136.

Irritating mixture for fistula, 133.

Laxative Balls, how operating, 91 ;-for the Yellows, 93,193 ; laxative drench, two forms of, 36,76 ; is re. 
commended in a variety of cases, see page $34,45,53$, $58,75,100,101,104$.

Liniment for canker, two forms, 194, 5 .

Linseed decoction, or cough drench, form of, 58 .

Lotions-see Astringent, Cold, Detersive, Saturnine. Mange applications,-three several, 121.

Mustard embrocation, form of, 83 ; for sore throat, 64 .

Nerving. Should be termed unnerving, as the operation consists in subtracting from the nerve which descends into the foot : see particular details at page 191,

Ointment-the stimulating, form of, 117 ; for sitfast. 138 ; astringent, for grease, 142.

Opiate - is advised at page 100 , in a case of suppressed urine. Opium 1 dram in solution is sufficient in ordinary cases, though a clyster with 2 drams of opium, will be found as efficacious in relieving the neck of the bladder, provided it can be retained a reasonable time. The Balsam of Quinine also acts as an Opiate upon debilitated animals.

Petroleum, or Barbadoes Tar, was once considered a sovereign remedy in obstinate coughs ; but an imposition being practised by the druggists which possessed no discutient property, Petroleum fell into disuse; until again brought forward (1830) by $B$. Hart, an amateur veterinarian of some repute, and recommended by him in a pamphlet. When obtained genuine, it is still entitled to consideration in all cases of scurfy eruptions, mange, and old ulcers. The agency for the disposal of the real article-under the term naphtha, is now confided to C. Clark, Veterinarian, of Stamford-street. See Balsam de Chili.

Physick-is the term generally applied to purgatives only, and for the Horse, Aloes of Barbadoes is the basis of all. A great number of prescriptions are given in the books, but are most of them deemed unnecessary to our present purpose-an increase or diminution of the aloes, constituting the chief change we are called upon to make. Two forms of purging balls are given at pages 46,73 , and 
under laxatives the enquirer will find as much information as he will need, as to emptying the bowels in the safest and best manner. See Drench, Stomach Pump.

Poisons-What are so? and counteracting agents, 67; Anti-poison ball, $i b$.; remedies, 68 ; farcy poison, 123.

Poultices-the economy of, 139, 140; and applicacation, $64,117,133,135,161,188$.

Rowels and setons advised, 28, 35, 45, 55, 104, 133, $182,3$.

Saturnine lotion proper, 27, 147, 151, 162 ; the form of, 132. See Colds. Saturnine poultice, form of, 149. Scouring Drench, two forms of, 82 ; the ball, 87.

Steaming the head in catarrh, method of, 118, 131. Stimulating draught, two forms of, 76.

Stomachic laxative, form of, 71.

Stomach tube. An invention for administering liquids to animals without spilling, and devoid of offence to the palate when bitter, in which way only tonics ought to be given to effect their purpose aright. In truth, all medicines that are intended to act upon the stomach, should be given in no other form than liquid. This instrument has been recommended to general use in administering drenches, at pages $30,36,99,101,104,117$; it is manufactured by John Read, of Regent's Circus, is without external seam, and is sufficiently long to reach the farthest stomach of horned cattle. When horses or other animals have been gorged or blown, Mr. Read has an accompanying apparatus-the Stomach-pump, by which the contents thereof may be diluted and drawn forth.

Tonics should always be given in the liquid form, otherwise they fail of their effect, totally. Four forms of tonics are given at pages 36 and 99 ; the arsenical is mentioned as dangerous at page 67.

Worm medicines, forms of, pages 73 ; balls most eligible for, 74 . 


\section{AUTHORITIES AND PERSONS}

\section{CITED IN THE COURSE OF THIS WORK.}

BRIDGES (JEREMIAH) an early explorer of the anatomy of the Horse's Foot, 162.

Cherry, (F.) his pads excellently adapted as a stopping for feet, 190 ; his remarks on broken knees, 153.

Clark (Bracy) eschews tonic remedies, 38; how mistaken, 70; his opinion of worms in the body, 69 .

ClaRK (JAMES), his thoughts on fevers erroneous, 32.

Coleman (EDWARD) his observations on the foot, 163; his fattyelastic substance exploded, 170; error concerning a circular foot, 173.

DudLEX's malleable shoes, still liable to objection, 175 .

DUPUY's (M.) doctrine of tuberculous affections, 116.

Freeman (Strickland) first dissected the Foot throughout, 162 ; was not surpassed by WhITE or CoLEMaN, 163.

Gibson (William) his treatise on the foot too learned, 13; did not examine the horse's hoof sufficiently, 162.

HINDS (JOHN) his section of the foot, the only one unimpaired by disease, as compared with others; his preparation delineated, 165 ; Veterinary Surgery, a proper study for all men, 13; his father on one-sided nailing, 178; his Groom's Oracle, 77.

Horse (the) Compilers of that work on broken knees, 153; they make free with Hinds's book, iv.

LaFosse (M.) neglected the dissection of the Foot, 162.

LAWRENCE (RICHARD) on Crib-biting, 111.

Monro (Dr.) inventor of the stomach pump, 38.

Osmer (WILIIAM) the most estimable of Veterinary writers, 33 ; his treatise on the Epidemic Distemper, 56, 70; it is identical with the Indian disorder, 25; and with the distemper of 1832; was the first who described navicular lameness, 162; and the coronary ring, 167 ; his seated shoe, improved, 174.

Pancras College-bleed exceedingly, 46.

READ (JoHN) his Stomach tube, 8c. 37.

SNAPE (ANDREW) first noticed disease of the (choler, or) liver, 89 ; omitted to explore the whole foot, 162.

WhipPy (the Messrs.) their knee-caps, very desirable, 154.

White (JAMES). The father of toric remedies, 38, 71; revised his opinions, viz. on fevers, 33 ; on stomach-staggers, 74 : as to the prevalence of worms, 68 ; practice on tumours, 134 ; practice confirmed, 118, 123, 4, 98, 135; indebted to W. Osmer, 56, and to Freeman, 163; his treatise on physiology too learned, 13; mistaken in lis practice-as to opium and camphor, 60 ; eyeglass, 105,106 ; scalding mixture, 136 ; cutting, 156 ; diseased section of the foot, 169; his practice improved upon, 84, 111, 173.

Y ARE (T. R.) his anti-crib-biter, principle of the invention, 113; obtains the medal, 114. 


\section{N D E X.}

Abscess-the critical, \&c. caused by bruises, 151.-See Tumours. Adhesion of parts, how occasioned, 30, 42, 92; of the liver and gut, 79, 91; remedy, 91, 92.

Air, wholesome, restores strength, $34,45,46,81$.

Anbury, how inflicted, 144, and cure, $i b$.

Anticor, caused by debility, 143 ; treatment, $i b$; epidemic, $i b$.

Apoplexy-Megrims, symptoms and treatment of, 74 .

Appetite (want of) denotes disorders, 16.

Arsenic, a tonic, 67 ; how detected in empoisonment, $i b$.

Back sinew, strains of,156,161,168; description of,6.-SeeTendons.

Bile, obstructions of, 92.-See Choler, Liver, Distemper.

Bladder, palsy of, 97, 98; diseases of, depend on kidneys, 98 ; neck of, inflamed, 100 ; concretions, $i b$.

Blind horses, change the coat at reverse seasons, 18 ; and why, $i b$. Blindness, heritable, 106.

Blood-redundancy of, disastrous, 26; its appearance in fevers, 45.-See Chapter XVI.

Blown animals, how carried off, 76.

Blows and kicks, effects of, and treatment, 151.

Botts ulcerate the stomach, 68; usually neglected, 69; the Bott controversy, 71.-See Worms.

Bowel complaint after hard work-a mistake for liver, 88 ; adhesion to the liver, 79, 91; affected by founder, 189.

Bowels, inflammation of, 31, 40 ; discrimination of from colic, 78 ; table of symptoms, $\mathbf{8 0}$.

Bowels, disease of, causes fever, 11 ; affects the coat, 17, and feet, $i b$. Breaking down, the principle of, 161 .

Broken knees, of several degrees, how incurred, 151 ; remedies for, 153 ; restoration of the hair, $i b$.

Broken wind originates in a cold, 42; symptom of the several kinds, 61 ; regimen for, 63.

Bruises, nature and treatment of, 150 ; at the coronet, 138 ; occasion poll evil, 135; of the hip and stifle, 160.

Burusatee, the Indian Epidemic, 122, 124.

Canker, how derived, 194; and treatment, $i b$. ; one cause of, 138. Cantharides, improper in some cases, 99, 100.

Carriage, the horse's, denotes his state of health, 20, 24 .

Catarrh incurable, 42,48 ; course of, 43 ; the cure of, is deceptive, 44 ; treatment, 45, 47-52; the Epidemic, 53 ; predisposition to, $i b . ;$ transferred to the liver, $\mathbf{6 6}, \mathbf{9 2}$.

Chest-founder, influences the feet, 24, 179, 186, 189, 191.

Choler-the bile so called of old, 89; how deranged, 17; when deranged, its effects, 90 ; certain cure for, 91. 
Clipping the heels, mischievous, 104.

Coat (the) proves the nature of disorders, 15-17; not always to be relied upon, 18 ; quick drying denotes health, 19 ; pen-feathered, $i b$; its colours, changes of, 19.-See Hidebound.

Coffin-joint lameness, one cause of, 138 ; another, 149 and 177; is of the back sinews, 161 ; in what it consists, $5,185-7$.

Coffin bone described, 5,166 ; changed in shape, 169.

Cold (a) its effects, 47, 115; how affecting the coat, 15, 17; neglected, ruinous, 48 ; a check on the perspirable vessels, 121 ; causes glanders, 128

Colic pains, what, 34, 79; term given to all internal disorders, 78. Colic, the right spasmodic kind, symptoms of, 80 ; errors concerning, 85 ; discrimination needful, 86 ; treatment, 87.

Colour-alteration in, by illness, 19.

Contagiousness - the opinion well supported, 20.

Corn, gorging, too much, its evil effects, 16.

Corns, a disease of contraction, 195 ; recent cases soon eradicated, 196 ; treatment, $i b$.

Coronary ring described, 5, 169. So termed by Osiner, 167 .

Costiveness, the sole cause of some disorders, 34, 45, 77, 81 .

Cough, on taking up, 39; depends on inflammation, 42, 44, 48; treatment of, 57-60; attends broken wind, 61 ; and inflammation of the stomach, 70; and worms, 72; and adhesion of the midriff, 92 ; none with glanders, 130 .

Crib-biting taught, 109; acquired, 110; is an unsoundness, 111; remedies for, $112-114$.

Curb, how incurred, 183 ; remedy, $i b$.

Cutting of several degrees, 155; how ascertained, 156.

Death indicated, $20,26,29,30,66$; endangered, 38 .

Debility, or low fever, evinced; 38,40 ; is indicated by the nostrils, 24; it remains after fever, 11 ; and accompanies the distemper, 21 ; unfavourable symptoms, $43,46,47,53$; affects the feet, 187 ; occasions grease, 140 ; remedy, 141 ; and dropsy, 143.

Digestion, organs of, symptoms of diseased, 25 ; recovery of lost, 70 ; depraved, cause of disordered eyes, 110 , and of tumours, $115,118$.

Diabetes, how brought on, 96 ; symptoms and treatment, 99 .

Diseases, several that have one common origin, 115; the cause of many, 11, 15-when wrongly named, dangerous, 14,15 ; a predisposition to, 115 ; carried off by treatment, 127 .

Distemper, first symptoms of, 21 ; the five species described, with treatment of, 52-55; transferred to the liver, 66,92 ; connected with tuberculous affections, 116 ; that of 1832 described, 20 ; how attacking, 21 ; treatment, 22 ; symptoms of, variable, 22.

Dry gripes, what? $30,42,79,87$.

Dunging-its indications of disorder, $17,20,45$; scanty, in Distemper, 21, 22.

Effusion, what? 26 ; on extr bleeding, 51 ; in Catarrh, 43. 
Entanglement of the bowels, what, 79.

Epidemic fever-discrimination necessary, 38; of several kinds 52 ; treatment, 53 ; fatal termination, 66 ; lungs and liver sympathize, 70, 92; assumes a farcy appearance, 125 ; disease of 1832 , 20 ; the Indian, 122, 124.-See Distemper.

Excretions, low depraved, 115 ; causes tumours, $i b$.

Exercise-too strong occasions broken wind, 61 ; and other diseases, 11 ; subjects young horses to distemper, 22.

Eyes, denote inflammation, 44 ; diseases of, 102 ; causes and treatment, 103-107; lotions for, $i b$; eruptions on, 108; influenced by stomach disorders, 16 ; the intelligencers of pain and of pleasure, 22 ; colour of the lids in distemper, 21, 22.

Farcy, \&c.-true doctrine regarding, 115; cause and appearance, 122-4: treatment, 125 ; buds, how reduced, 126.

Farriery, the art improved, 8, 12, 162.

Feeding, the economy of, 61,2 ; generous, necessary in some diseases, 126, 130; excess of, harmful, 115; the usual mode of, too stimulating, 13; too much, 15 ; of refusing food, 16 ; arises from bad mouth, $i b$.

Fever, how produced, 11, 32 ; symptom of recession, 24 ; the pu. trid, symptoms of, $24:$ of the feet, 170, 186 ; it accompanies every disease, 32 ; simple fever, what? 33 ; cure for, 34 ; symptomatic fever indicated, 34 ; cause and treatment, $38-41$; indicates inflammation, 79; and obstructed bile, 92.

Fistula in the Withers, easily removed 131 ; treatment, 132 ; operation for, 133; scalding, not required, 134.

Foot-Sections of healthy and diseased feet, how differing, 5, 169, 173 ; fast work, spoils the best, 172 ; unsound feet require attention, 176 ; disorders of the foot, 185 ; fever of the, 186 ; contraction and inflammation, $i b$; bleeding at the, $6,51,188$; fever of, how caused, 138, 191 ; wounds of, 149 ; pointing wrong, remedy for, 156 ; study of its economy neglected, 164,198 ; worthy of note, 165 ; its arcana laid open, 5, 6, 168.-See Shoeing.

Founder, remedied, 177; the common cause of all foot diseases, 188 ; treatment, $i b$.; how detected, 24 ; of the chest, 24,186 ; affects the lungs, 189-191.

Frog pressure, how manifested, 170 ; admits not of dispute, 175; anatomical dissection of, 6,169 .

Glanders, a tuberculous disorder, 115 ; connected with the lungs, 116, 123: the subject a perplexed one, 127; salt a preventive, $i b$. and a remedy, 131; pretended cures, 128,131 ; what is the true sort, 128 ; test for ascertaining, 130 ; infectious, or not ?129; copperas, cantharides, and mercury-delusions, 130-1 ; signs of the slight touch, 24 ; and of the confirmed, $i b . ;$ affect the lungs, 41 ; come of ill-cured strangles, 118.

Grease-origin of tuberculous diseases ; 115 ; causes of, 139 ; treatment, 144 ; it succeeds ill-cured canker, 195.

Gripes, the dry, 30 ; mistaken term, 79 ; on physick taking, 83.- 
Guts, twisting of the, 30. See Entanglement.

Haw of the eye, not to be cut out, 103 ; treatment of, 107.

Head, the, is indicative of state of health, 20 ; turn of, denotes the several affections of the body, 24; blows on, 152 .

Heat necessary to the cure of wounds, 154; when excessive, the groundwork of disease, 11-14, 15 .

Heart, congestion at the, in distemper, 21.

Hidebound-not an original disorder, 17 ; it denotes internal disorder, $44,70$.

Hoof-brittle and soft, horses liable to, 186 ; loss of hoof, how arriving, 189 ; contraction of.-See Foot Founder, Thrush, \&c.

Jaundice, symptom of, and remedies, 92.-See Yellows.

Inflammation the cause of all constitutional disorders, 11 ; how ascertained, 24 ; what it is, 25 ; treatment, $26-31$; what not genuine, 33, 85 ; intestinal, how transferred, 70 ; table for distin-* guishing true, 80 ; treatment, 81 ; of wounds, 149.

Interfering, mostly incurred by thorough breds, 155 .

Kidneys, inflammation of, several kinds, 95 ; treatment, 96 ; examination of bladder, $\mathbf{9 7}$.

Kicks and bruises acquired, 152 : treatment, $i b$.

Kuees (Broken) various kinds of, 153 ; test of the worst, $i b$; precautions and remedies, $i b$; Cherry's recommendation, 154 .

Knock up, symptoms and true seat of, 18 ; treatment, $i b .93$.

Lameness, occasioned by ill-cured fevers, 11 ; from wounds, 149 ; from strains-the shoulder, 158 ; tests for ascertaining its seat, $i b$. ; from bone-tumours, 158,160 ; of the feet 185 ; various, $i b$; occasional, 186; from disordered lungs, $i b$.; of legs and feet, how differing, 179; the kinds of, how denoted, 180 ; signs of, $i b$. ; coming up from grass, cause of, 181 ; coming on, very slow, 189 ; how promoted, 190; the seat of, mistaken, $i b$. ; not always attending coutraction, 191.

Locked jaw terminates inflammation, 44; appearance of eyes in, 22.

Low bred cattle afflicted with bone tumours, 160 .

Litter-eating, cause and remedy, 114.

Liver, signs of its being the seat of disease, 17, 24; is the seat of distemper, 20 ; symptoms of diseased, 25, 31, 41 ; influenced by bad lungs, $47,66,92$; liable to inflammation, 89 ; fatal, 90 ; adherent to gut, 91 ; affected by hard work, 88 .

Lungs, symptoms of diseased, 25, 27, 31, 33; inflammation of, $42-47$; very liable to disorder, 41 ; affected in glanders, $i b$. ; ill cured, the cause of glanders, 128 ; bad, occasions lameness, 186 ; and is affected by founder, 188 ; when diseased, cause fever, 11 ; and staring coat, 17 ; the first symptom of distemper, 21 ; cause of stinking breatl, 23.

Mallenders, what, 184; treatment, 185.

Mange, low incurred, 118 ; treatment for, 120 ; obstinate cases, remedies, 121.

Manner of behaviour, cliange of, 15; shows inward illness, 19, 20. 
Medicines often employed injudiciously, 11, 14.

Molten grease of two kinds, treatment, 84 .

Moon-blindness, 102 ; treatment of, 105.

Mouth, signs of disordered, and cure, 16 ; colour in distemper, 21, 23; hot, denotes fever, 23.

Murrain, what so termed, 124. See Distemper.

Nailing, one-sided, allows of expansion, 177, 191 ; in the quarters and toes, 175 ; for corns, 195.

Navicular lameness, how occasioned, $5,161,168$; well founded, $181,185,187$; the bone described, 6 .

Neglect, the besetting sin of horsemen, 146, 149.

Nerving, i. e. un-nerving, requires skill, 191 ; precautions, $i b$. ; how performed, 192 ; its failure, $i b$.

Nostrils, colour of lining, denotes the state of health, 23, 24; a discharge in fever, $\mathbf{5 5}$.

Organs of life, how affected by inflammation, 11 ; and affecting each other, 16.

Operations : bleeding, 50 ; for tumour, 28, 56, 117, 124; for fistula, \&c. 133 ; for sitfast, 137 ; for wens, 144 ; for founder, 191.

Over-reaching, treatment of, 149, 200.

Pace, when uncertain, denotes illness, 17, 20; is destructive of the feet, 165; and of feet and lungs, 187.

Perspiration, checked by drinking, 18 ; profuse, a sign of disorders, $i b . ;$ and of anxiety, $i b$.

Physicking overmuch, its effects, 12.

Physicking, mode improved, 37, 73, 74; recommended, 54 ; goes off by urine, 66 ; effect of over-dosing, 82 .

Physiology, how acquired, 13; a difficult science to acquire, $i b .165$.

Piping, how occasioned, 63; and remedy.

Poisons, the vegetable, taken by cattle, 67 ; symptoms and remedies, 68.

Poll-evil, causes of, 134 ; scalding mixture, $i b$; operation, 133, 136.

Pomice-footed, how incurred, 186, 190.

Principles of doctoring, how to be acquired, 12, 19.

Quittor, causes of, 138, 197 ; remedy for, 139.

Receipts, dangerous nature of quackish, 15.

Rest, indispensable to a cure, 152, 187, 197.

Restorative means of reinstating health, 34, 45, 81 ; great danger of neglecting, $44,47,54,56,92$; tonics, 38,70 ; after scouring, 83; under mercurial treatment, 127.

Ring-bone, what, 183 ; treatment, $i b$.

Roaring, how alleviated, 62 ; is of several degrees, 63 ; concealed, how detected, 24 .

Saddle galls, cause of, and treatment, 136.

Sallenders, seat of, and treatment, 184.

Sandcrack, described, 197; treatment of, $i b$.

Scouring of the bowels, remedies, 82 ; in flatulent colic, 87 ; in s 3 
jaundice, 83 , 93; in molten grease, 84 ; the result of diseased liver, 17.

Secretions and excretions, depraved, 115 ; promoted, conduce to the cure, 127; of imperfect excretions, 19, 134, 140.

Shivering, an unfavourable symptom, 33 ; when not, 26,39 .

Shoeing, bad, the cause of most disorders, 172 ; smiths to notice the bearing, 170, 173; of preparing the loof, 173-4,177; and the shoe, $i h . ;$ it requires a periodical remove, 174 ; nailing, 177 ; pointing the toe, 178 .

Shoulder, setting on, its effects on the tread, 156 ; strain of the, seldom occurring, 157; bone tumour on it, an obscure cause of lameness, $158,160$.

Sickness, of every sort, signs by which to ascertain, 15.-See Cout, Stomach, Eyes, Mouth, \&c.

Signs of diseases impending, 15 ; prompt attention averts a fatal termination, 22 ; of disease existing, 80, 96; of lameness, 180, 183.

Sitfasts, what, 137 ; and treatment, $i b$.

Skin, the, sure indications of health and disease, 19.

Spasmodic colic, cause and treatment, 87.

Spavin, bone, what, 181 ; treatment, 182 ; blood spavin, 185.

Spleen, enlargement of, upon hard work, 88.

Splents described, 182; treatment, 183.

Stables, filthy, occasion blear eyes, 102 ; how to reform, 104.

Stable management, averts disorders, 14 ; effects of overaction, 15

Staggers or vertigo, induced by remains of fever, 11 ; how denoted, 25 ; symptom of, 40 ; stomach staggers, 74 ; mad staggers, 75 ; treatment, $\mathbf{7 6}$; prevention, 77.

Stomach, always influenced by disease of other organs, 16 ; and affects the eyes, 23,102 ; signs of inflamed, $i b$. ; decided inflammation, 66 ; transferred to the liver, $i b$. ; how affected by poisons, 67 ; botts afflict it, 68 ; recovers its tone slowly, 70 ; stomach staggers, 75.

Stomach tube, improved mode of giving drenches, 37 .

Strains, a necessary study with sportsmen, 156 ; of the shoulder, not often, $i b$.; how occasioned, and cure, 158; of the stifle, hock, and hip-joint, 159; of the back, seldom, 160; of the back sinews, 161, 168.

Strangles, distinguishing signs of, 24 ; treatment of, 116 ; of illcured, 118; becomes glanders, $i b$.

Sun's rays influence the horse's well-being, 18.

Suppuration, what, 26, 27 ; usually preferable, 28 ; of the lungs, 44 .

Surfeits, how occasioned, 15,18 ; surfeit and mange, how connected, 118; the term applied to all tuberculous appearances, 119 ; symptoms, and treatment, $i b$.

Sweating, profusely, how brought on, 11; how checked, 18; a sign of disorder, $i b$.

Symprathy of the orgaus of life, 16 ; the stomach and lungs, 40 , $13,46,68,70$; of lungs and bowels, 81,5 ; lumgs and liver, 42. 
Sympathetic fever, 138.

Symptoms of various diseases, 2, 39, 41; of deceitful, 43, 45. Symptoms of disorder, how to be met, 12; the knowledge of, 15 ; of the corresponding symptoms, 16; variable nature of, 20, 22 .

Tendons, liable to be pricked, 150 ; treatment, $i b$. ; strain of, 161 ; how produced, 122.

Thrush described, 192 ; treatment, 193.

Toe, pointing of, affected by setting on of the shoulder, 155, 178, 182 ; bleeding at the, how done, 161 .

Tonics, ill appreciated, 38; ball or drench, which preferable, 36 ; proper, 97,99 ; in grease, 140.

Training, severe, incurs distemper, 22, and lameness, 180.

Tuberculous affections, many, 116; termed surfeit by the stable people, 119 ; tubercles on lungs in farcy and glanders, 123 ; partial appearance of, $125,142$.

Tumours of several kinds, doctrine respecting, 115 ; from wounds, 148 ; and bruises, 151; of bone, a cause of lameness, 158; are symptomatic of fever, 26 ; the operation on, $28,56,117,124$, 133, 137; an extensive class of diseases, 115 ; how characterised and distinguished, $116-139$; doctrine of tuberculous disorders, 142 ; indolent, treatment of, $143,4$.

Veterinary knowledge, how acquired, 8, 12, 162.

Vices of horses, how inculcated, 109 ; remedies, 111.

Vives consequent upon ill-cured strangles, 118.

Urine, how affected by various substances, 66 ; bloody urine, 95 ; suppression of, 99 ; mistaken treatment, 96 ; re-absorbed, 98 ; excess of, 99 ; bloody, $i b$. ; incontinence of, 100 ; is al. ways defective in distemper, 21.

Warbles, treatment of, 135.

Warts on the eye-lids, treatment, 107; on the body, 144.

Water, cold, occasions coingh, 59.

Water farcy, what: and remedy, 142.

Weaving, a solitary vice, 114 ; remedy, $i b$.

Wens, nature and treatment of, $143-4$.

Wheezing, cause of, 65 ; situation and remedy, $i b$.

Wind, thick or broken, how affected, 61 .

Windgalls, mistaken practice, 184 ; treatment, $i b$.

Wind-sucking, how acquired, 110 ; remedies, 111; mistaken practice, 112 .

Worms, of three kinds 71 ; botts, 68 ; ravage the stomach, 69; remedies, 72; and varied treatment, 73.

Wounds, occasion fever, 39, 40; in the sole, 139 ; incurred from violence, 146; first applications, 147 ; contused, and punctured, treatment, 148; of the foot, 149 ; of tendons, 150.

Yellows, a symptom, 75, 83; denotes disordered liver, 89 ; in extra purgation, 91 ; influence of the lungs, 92.-See Jaundice. 
Lately published, by the same Booksellers.

\section{HINDS'S WORKS ON FARRIERY,}

\section{ON \\ BREEDING, REARING, MOUNTING, AND TRAINING HORSES INTO CONDITION;}

Illustrated with numerous Copper-plates and Engravings on Wood,

3 vols. price $1 l$. $10 s$. 6d. in red, or separately, as follows :-

1 st. Hinds's Veterinary Surgery, 2d Edit. (Vol. I.) 12 d.

2nd. The Grooms' Oracle, $2 \mathrm{~d}$ Edition, (2d Vol.) .... 7 0

3rd. Osmer's Celebrated Treatise on the Horse, 5th

Edition, modernized by $\mathrm{Mr}$. Hinds ......... 8

4th. Rules for Bad Horsemen, by Thompson and

Hinds, new Edition, with Additions $\ldots \ldots \ldots .63$

** The last two pieces together, form the Third Volume.

Volume the First is a full Treatise on Diseases-and is entitled, VETERINARY SURGERY AND PRACTICE OF MEDICINE;

OR,

FARRIERY TAUGHT ON A NEW PLAN:

Being a familiar Treatise on all the Diseases and Accidents to which the Horse is liable; the Causes and Symptoms of each, and the most approved Remedies employed for the Cure in every Case ; with Instructions to the Shoeing-Smith, Farrier, and Groom, how to acquire Knowledge in the Art of Farriery, and the Prevention of Diseases. Preceded by a popular Description of the Organs of Life, and Animal Functions in Health, and showing the Principles on which these are to be restored when disordered.

\section{Opinions delivered concerning this Work.}

"It is to the physiology and diseases of the Horse that Mr. Hinds pays most attention, and for this very reason we are disposed to pay attention to his book. He leaves the old beaten track of writers on Farriery, and in a style much more familiar and interesting than hitherto-(which in similar works is daily becoming more fashionable)-he brings his reader on from cause to effect, from symptom to cure, in a truly edifying and instructive manner. The truth is, Mr. Hinds is no visionary,-for there are quacks in the Veterinary profession as well as in every other,-but a practical Veterinary Surgeon, who has had much experience among horses, and who, at the same time, has made their diseases the subject of his habitual study. Although, according to the old aphorism, we 
here find that 'doctors differ,' we have reason to believe, from our own knowledge in Farriery, that wherein they may differ, our author would be able to maintain his ground against all those who have published on the same subject before him." - Scots Agricultural Magazine, No. 3.

"At length we may congratulate ourselves and the public-that is to say, the sporting and equestrian part of it, that something substantial and equal to its importance is likely to be achieved for the Practice of Horse Medicine. Next to the forthcoming broods of practitioners in this art or mystery being capable of answering satisfactorily their EXAMINERs' technical questions, they would do well to study the principles upon which the mitigation of disorders is to be undertaken; a study they will be enabled to enter upon with delight, by assiduously comprehending the plain and accurate demonstrations set fortl in admirable style, in the first book of Mr. Hinds's Veterinary Surgery. Finally, until this volume of Veterinary Surgery and Practice of Medicine came forth, no book had been published for twenty-five years which was half so well calculated to place the study and practice of Farriery on their proper bases ; and we augured truly, on the appearance of the first edition, that the public approbation must attend a work in which so much hard labour, keen research, accurate deduction, and sound practical knowledge were evident in every chapter." Weekly Dispatch, Aug. 10, 1829.

Nimrod, a literary signature of much renown, well known to every gentleman of eminence in the sporting world, quotes repeatedly, and with becoming deference, from the pages of $M r$. Hinds's Work, (Vet. Surg.) and founds a long series of valuable papers on information derived from this volume, concerning lameness, shoeing, the tread, \&c. See Sporting Mag. Aug. 1828, pages 473 to 491 ; also Nov. and Dec. and again in 1829, frequently.

Volume the Second of MR. HINDS'S WORKS consists of CONVERSATIONS ON CONDITIONING, ENTITLED,
THE GROOMS' ORACLE,
AND POCKET STABLE-DIRECTORY:

In which the Management of Horses generally, as to Health, Dieting, and Exercise, are considered, in a Series of familiar Dialogues, between two Grooms engaged in Training Horses to their Work. With Notes, and an Appendix, including Extracts from the Receipt-Book of Jorn Hin DS, V.S. 2nd Edition, price $7 s$.

The Sporting Magazine for May, 1829, expresses its surprise that " hitherto no Stable Guide, addressed to the capacity of servants, should have issued from the press. All the old books of Farriery, 


\section{Lately published, by the same Booksellers.}

from their stiffness, failed to instruct as they ought ; but in this volume the matters treated of, independent of the manner in which it is executed, is much to be commended. We no where discern a wish on the part of the Authors to display fine learning; but, on the contrary, they render topics of the most difficult nature perfectly intelligible to the meanestcapacities. As to the points upon which they converse, we discover none omitted that could be desirable to the practical horse-keeper or owner,- the most commonplace that may be known to every trainer of eminence, in part or in the whole, being brought forth in a pleasing and truly instructive manner, for the benefit of the less-expert and junior persons. But we must quit T'le Oracle by recommending it to the notice of those for whom it was especially compiled."

“ Mr. J. Hinds's Grooms' Oracle not only comprehends every kind of information relating to the diseases of a horse, but gives ample and admirable directions how that noble animal should be treated, so as to obviate disease in every variety of service in which it may be employed." Vide Taunton Courier, April 8, 1829.

"The matter taught, we are fain to believe, is of the utmost importance to the well-being of horses of every description, and of the higher bred cattle in particular; the object of the speakers being to talk of training horses into fit condition for getting through their work in style- whether that be of the Turf, the Chase, or the Road. As usual in works of this nature, amidst much that is quite new information, there is a good deal of intelligence that is known to all Training-Grooms, as, 1st. The mode of keeping down flesh whilst keeping up the stamina; 2d. Of putting pace into the horse ; $3 \mathrm{~d}$. Of improving his stretch and form of going, as well as sustaining his lasting qualities." Vide Age, March 22, 1829.

The Weekly Dispatch, sporting newspaper, goes on with its observations on the state of the Veterinary Art,-thus, "the immense advantages of post mortem examinations is evident to all but the meanest capacity, and was strenuously insisted upon in the Author's former volume, as it is again in this Grooms' Oracle, in more familiar terms. If the practice of Veterinary Medicine and Surgery is thus in a fair way of being disclosed to vulgar eyes, and laid open to the comprehension of ordinary minds, no less so is the Art of Training horses into condition for every species of work here placed in a more just and rational light than we have hitherto been in the habit of hearing and seeing the subject treated. Mar. 15, 1829.

ALso, with fine Engravings of the various Breeds of Horses, Price $8 s$.

A TREATISE ON THE HORSE,

ITS DISEASES, LAMENESS, AND IMPROVEMENT;

In which is laid down the proper Method of Shoeing the different Kinds of Feet. Also, some new Observations on the Art and Practice of Farriery; and on the Nature and Difference in the se- 
veral Breeds of Speedy Horses; showing on what Principles their Perfection depends, and by what Methods the Breeding of Speedy Animals may be greatly improved and amended. By WILLIAM Osmer, Veterinary Surgeon, and many Years Shoeing-Smith in Blenheim-Street, Bond-street. Fifth Edition, newly re-written, with considerable Additions, by JoHn Hinds, V. S.

A contemporary Critic observes-" Mr. Hinds, the Author of 'Veterinary Surgery,' the 'Grooms' Oracle,' and other publications of considerable merit, has just brought out a fifth edition of Osmer's Treatise, witl valuable additions. As one proof of the intrinsic merit of the original, we observe, that most of our celebrated Veterinarians have made free with his doctrines, and his terms, copying even his very words, in many instances, and adopting his ideas, his opinions, and general deductions.-Osmer's Treatise, though rich in materials, and long time a source of valuable instruction to the ardent professional inquirer, was not systematically arranged, and, consequently, much of its interest was overlooked by the general Reader. To remedy this apparent defect, $M r$. Hinds has classified the whole into parts, and these again into sections ; and, to parry the charge of plagiarism, which is cast with no unsparing harid on several celebrated professors, Mr. Hinds has included his additions between brackets. After stating his inducements for issuing this improved edition, the Editor concludes thus:- " For these liberties I offer no apology: if they be not judicious, I ask not applause; if not requisite, I deserve blame; if impertinent, pity." No apology, however, is necessary: the arrangement is judicious and absolutely requisite; and, so far from deserving either blame or pity at our hands, Mr. Hinds is entitled to the thanks of every lover of that beautiful quadruped, the Horse, for having thus separated the tares from the wheat, and gathered into luxuriant sheaves a rich harvest for the proper treatment and benefit of our favorite animal."-Sporting Magazine for May, 1830.

Another says-" Osmer's Treatise on the Horse, by J. Hinds, is among the most valuable of our recent publications. Mr. Hinds's ' Grooms' Oracle,' and ' Veterinary Surgery,' ought to be in the liands of every Gentleman, who either has in possession, or has a chance of possessing, the noble animal to whose proper treatment the Author has directed his enlightened researches. If to these publications the present excellent treatise be added, it may be safely averred, that every useful or important point of instruction relating to the welfare of the Horse, and the interests of its owner, will have been scientifically, profitably, and satisfactorily developed."-Taunion Courier, March 3, 1830.

"Here is another of those books on the Horse, which he who runs may read, and all who read can understand," is very aptly observed at the commencement; and in truth no other kind of 
writing on subjects that are purely practical, will be received at the present day, when 'the school-master is abroad' in every art and every science, and the public mind may be pronounced athirst after knowledge. In this very desirable quality, plainness of language, and teachableness of manner, Mr. Hinds is already known by some considerable works on Farriery, to which the present volume is a necessary and important addition ; and moreover does honour to the candid and manly avowals of its editor, as to certain revisions to which his own practice has submitted since lie became acquainted with the works of Osmer. How this author should have remained solong neglected by the public, seeing the sterling merit of every page, is easily accounted for in the neglect of that lucid order which characterises all our modern books of instruction, and none more so than the former volume of Mr. Hinds on the treatment of horses in health and disease. We can find no room for extracts ; but that part of the volume which treats of the breeding speedy cattle, is well worth all the attention that can be bestowed upon it by every horse-breeder, as being replete with good sound maxims, practical remarks, and points to be observed in bringing the parents together, in the treatment of mare and foal, before, at, and after the time of gestation, and for avoiding those numerous errors in rearing, which forms the just opprobrium of many of our best studs. To say that we recommend the volume to notice on this account, is not enough-it is indispensable; for we really never yet met with any that pretended to treat on such subjects, certainly none which has left an impression on the memory equal to the volume of Old Osmer. His treatment of Epidemic Distemper also is incomparably clear and discriminative, under its different symptoms." - Weekly Dispatch, March 14, 1830.

Just published, Price 3s. 6d. with fine Plates, viz.-1. Mounting ;

2. The True Seat on Horseback.

\section{RULES FOR BAD HORSEMEN;}

\section{Hints to Inexpert Travellers;}

And Maxims worth Remembering by the most experienced Equestrians. By Charles Thompson, Esq.

New Edition, with modern Additions, by JoHn Hinds.

Gilbert \& Rivington, Printers, St. John's Square, London. 



, 


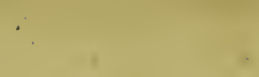

s

\section{$+$}





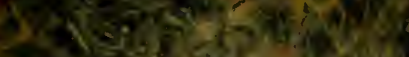

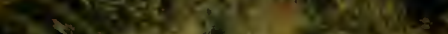

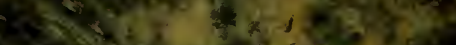

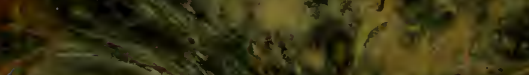

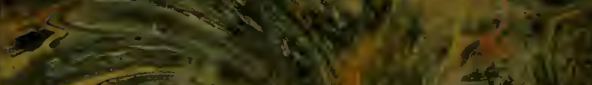

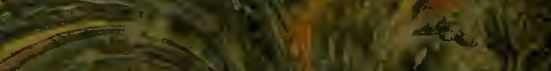

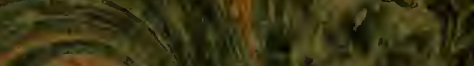

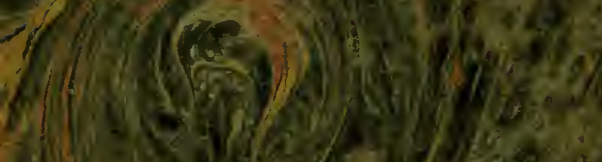

(5)

4.

113.

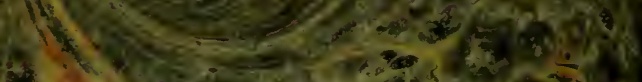

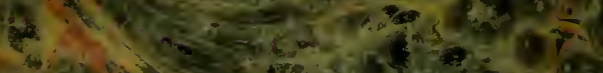

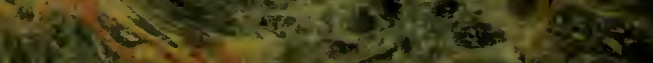

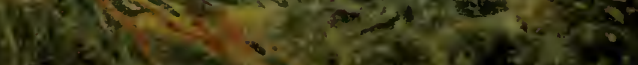

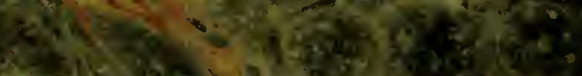

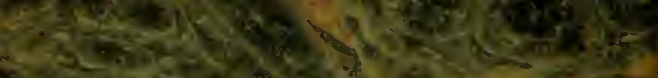

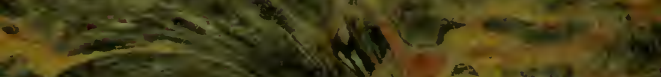

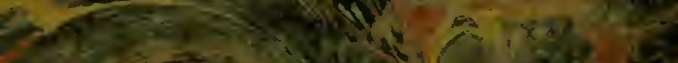

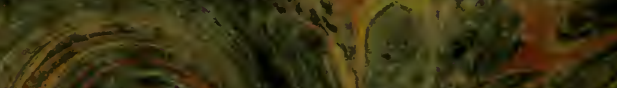

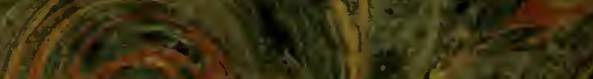

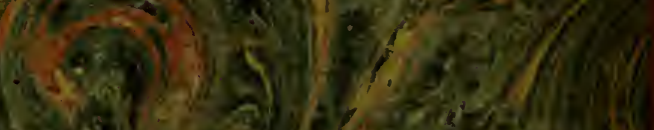

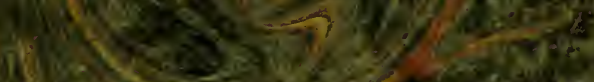

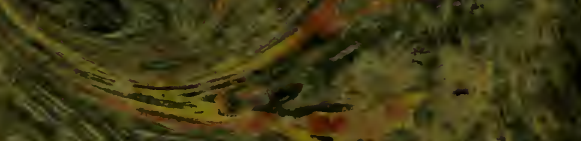

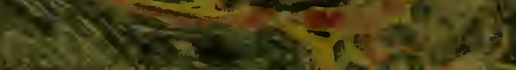

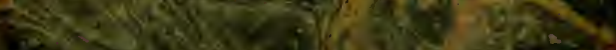

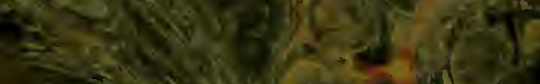

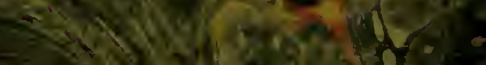

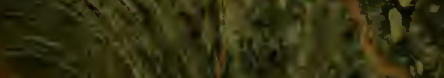

